University of Windsor

Scholarship at UWindsor

$10-5-2017$

\title{
Factors Associated with Distress in Caregivers of People with Personality Disorders
}

Paige Brianne Lamborn
University of Windsor

Follow this and additional works at: https://scholar.uwindsor.ca/etd

\section{Recommended Citation}

Lamborn, Paige Brianne, "Factors Associated with Distress in Caregivers of People with Personality Disorders" (2017). Electronic Theses and Dissertations. 7272.

https://scholar.uwindsor.ca/etd/7272

This online database contains the full-text of PhD dissertations and Masters' theses of University of Windsor students from 1954 forward. These documents are made available for personal study and research purposes only, in accordance with the Canadian Copyright Act and the Creative Commons license-CC BY-NC-ND (Attribution, Non-Commercial, No Derivative Works). Under this license, works must always be attributed to the copyright holder (original author), cannot be used for any commercial purposes, and may not be altered. Any other use would require the permission of the copyright holder. Students may inquire about withdrawing their dissertation and/or thesis from this database. For additional inquiries, please contact the repository administrator via email (scholarship@uwindsor.ca) or by telephone at 519-253-3000ext. 3208. 
Factors Associated with Distress in Caregivers of People with Personality Disorders

By

Paige B. Lamborn

\begin{abstract}
A Thesis
Submitted to the Faculty of Graduate Studies through the Department of Psychology in Partial Fulfillment of the Requirements for the Degree of Master of Arts at the University of Windsor
\end{abstract}

Windsor, Ontario, Canada

2017

(C) 2017 Paige Lamborn 
Factors Associated with Distress in Caregivers of People with Personality Disorders

by

Paige B. Lamborn

APPROVED BY:

\begin{tabular}{c} 
D. Kane, \\
Faculty of Nursing \\
\hline C. Thomas, \\
Department of Psychology \\
K. Cramer, Advisor \\
Department of Psychology
\end{tabular}

September 6, 2017 


\section{DECLARATION OF ORIGINALITY}

I hereby certify that I am the sole author of this thesis and that no part of this thesis has been published or submitted for publication.

I certify that, to the best of my knowledge, my thesis does not infringe upon anyone's copyright nor violate any proprietary rights and that any ideas, techniques, quotations, or any other material from the work of other people included in my thesis, published or otherwise, are fully acknowledged in accordance with the standard referencing practices. Furthermore, to the extent that I have included copyrighted material that surpasses the bounds of fair dealing within the meaning of the Canada Copyright Act, I certify that I have obtained a written permission from the copyright owner(s) to include such material(s) in my thesis and have included copies of such copyright clearances to my appendix.

I declare that this is a true copy of my thesis, including any final revisions, as approved by my thesis committee and the Graduate Studies office, and that this thesis has not been submitted for a higher degree to any other University or Institution. 


\begin{abstract}
The present study investigated a variety of stressors experienced by caregivers of people with personality disorders, how these stressors relate to each other and psychological distress, and caregivers' intentions to seek help, using the Stress Process Model (Pearlin, Mullan, Semple, \& Skaff, 1990). Caregivers ( $N=106)$ completed an online survey; 85\% of the sample supported a loved one with borderline personality disorder and over $90 \%$ of the care-receivers had additional acute psychopathology. Partial Least Squares Path Modelling revealed that caregivers who were male, younger, or residing with their loved one were more likely to experience stressors. Salient primary stressors, or those arising from the needs of the care-receiver, included the caregivers' worry and care-receivers' level of instrumental demands and interpersonal problems. Important secondary stressors, or impacted areas of the caregivers' lives outside the caregiving relationship, included strains in the caregivers' schedules, family relationships, and health, as well as reduced mastery and caregiving esteem. The model supported a trajectory through which demographic characteristics and experiences of stigma and problems with services increase the likelihood of experiencing primary stressors, which, in turn, are predictive of higher secondary stressors. Higher levels of stressors increase the risk of experiencing psychological distress. Additional preliminary analyses revealed that caregivers reported higher intentions to seek emotional and informational support, rather than instrumental, as well as a preference for formal, rather than informal, informational support. The present study has implications for understanding the broader impact of personality disorders, developing strategies to better support caregivers, and clarifying the way caregiving stressors give rise to outcomes such as psychological distress.
\end{abstract}




\section{ACKNOWLEDGEMENTS}

I would like to thank my friends and family for the support they've given me throughout this project and my broader educational pursuits. In particular, I'd like to thank my mother, Kelly Lamborn. She has always been my most influential role model and biggest supporter. None of my achievements would have been possible without her.

I'd also like to thank my committee members, Drs. Cheryl Thomas and Debbie Kane for their comments and suggestions, which have deepened and bettered this project. I also thank my supervisor, Dr. Ken Cramer, for his informational, emotional, and instrumental support throughout this project.

I must acknowledge the organizations and agencies that supported recruitment for this study. This project would not have been possible without the enthusiastic and generous support of those working directly to support caregivers of people with personality disorders. I thank my contacts at such agencies for their willingness to support this research by helping me reach out to potential participants. Finally, thank you to the caregivers who participated in this research. I am honoured to have been entrusted with your stories. 


\section{TABLE OF CONTENTS}

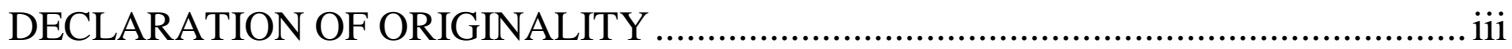

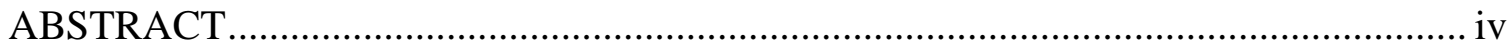

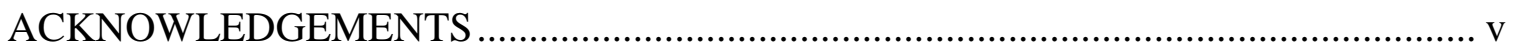

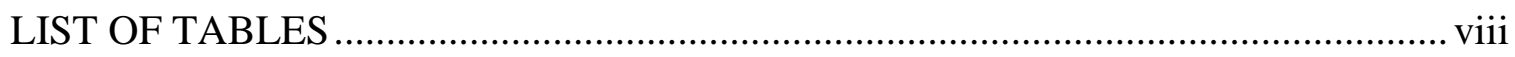

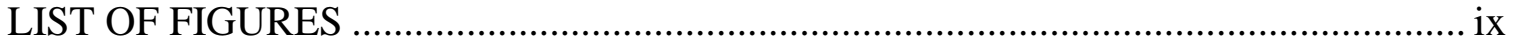

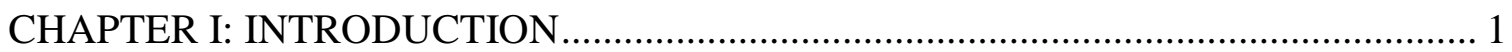

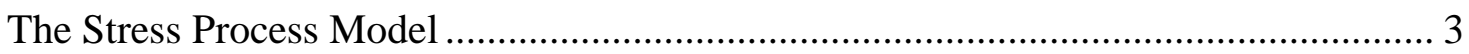

Applications of the Stress Process Model................................................................... 4

Caregivers of People with Personality Disorders .......................................................... 6

Caregivers of People with Personality Disorders and the Stress Process Model ........... 9

The Stress Process Model and Help-Seeking …………................................................ 20

Help-Seeking of Personality Disorder Caregivers ....................................................... 25

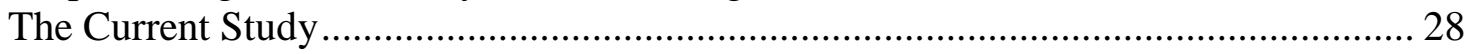

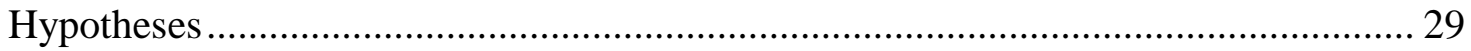

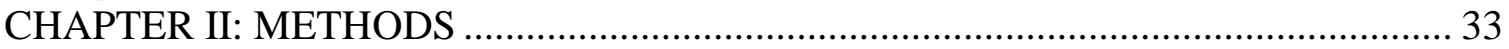

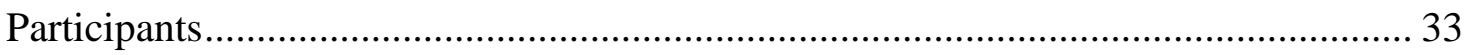

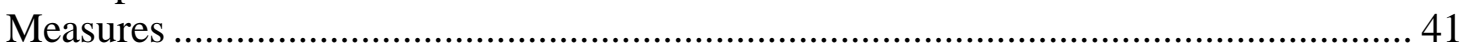

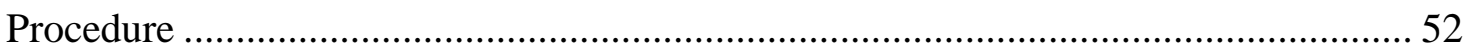

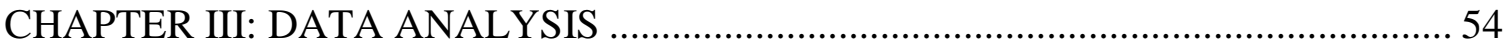

Hypothesis 1 - Partial Least Squares Path Modelling ................................................ 54

Hypothesis 2 - Repeated Measures Analysis of Variance.............................................. 59

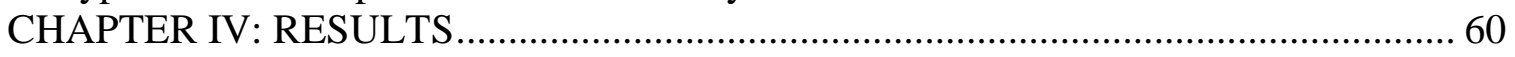

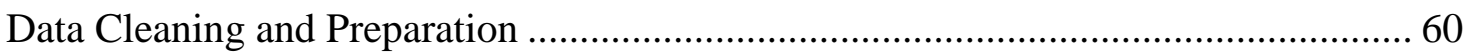

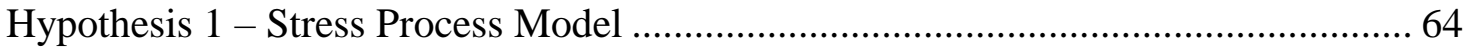

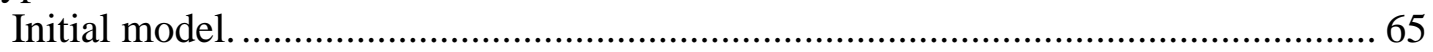

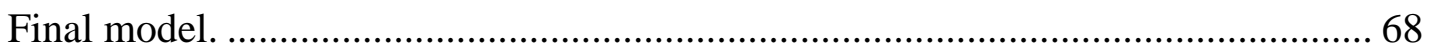

Hypothesis 2 - Help-Seeking Intentions................................................................... 76

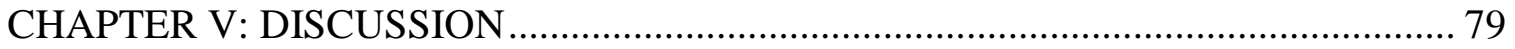

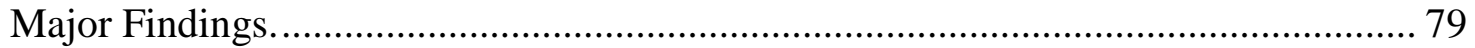

Characteristics of Caregivers of People with Personality Disorders ............................ 85

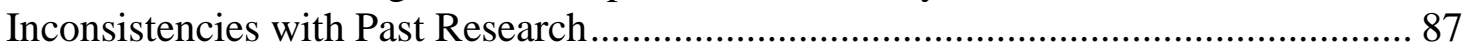

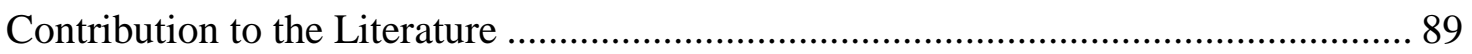

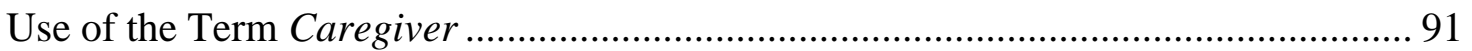

Caregivers of People with BPD versus Other Subtypes ............................................... 94

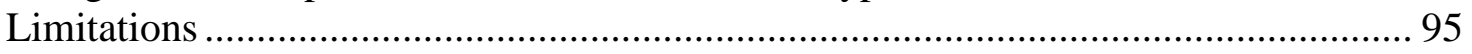

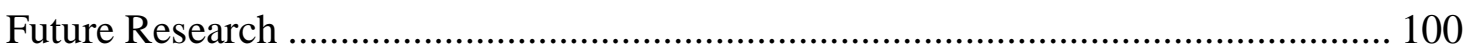

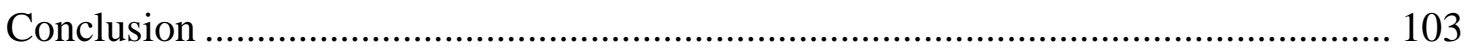

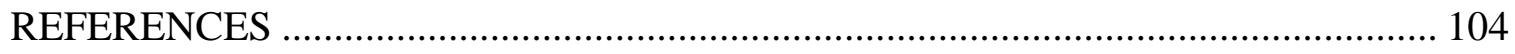

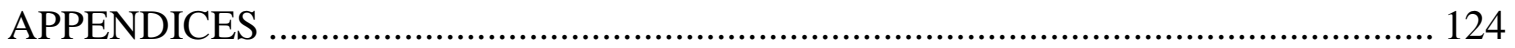

Appendix A: Recruitment Flyer............................................................................ 124

Appendix B: Demographic Questionnaire ............................................................ 125

Appendix C: Caregiving Relationship Questionnaire............................................... 128

Appendix D: Experience of Caregiving Inventory ………….................................... 132

Appendix E: IIP Personality Disorder Scales (Informant-Report) ............................. 137 


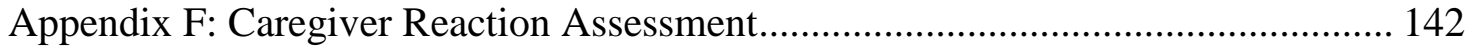

Appendix G: Mastery Scale ............................................................................ 145

Appendix H: Perceived Caregiver Burden Scale: Sense of Entrapment Subscale ..... 146

Appendix I: General Help-Seeking Questionnaire ................................................. 147

Appendix J: Kessler Psychological Distress Scale .............................................. 150

Appendix K: Research Ethics Board Clearance Certificate .................................... 151

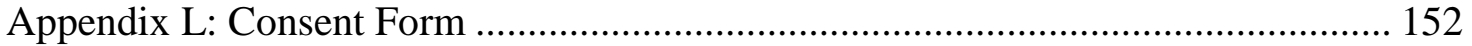

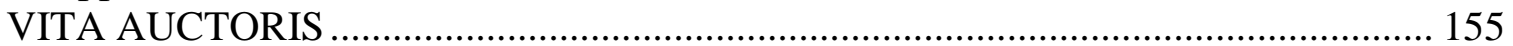




\section{LIST OF TABLES}

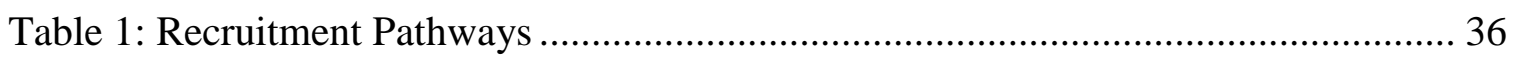

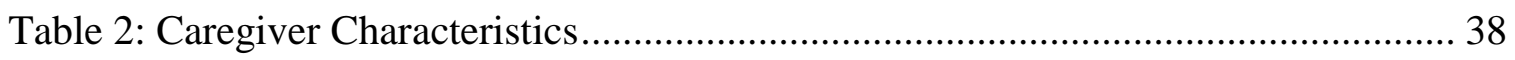

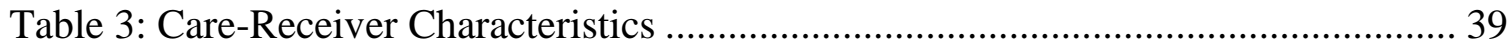

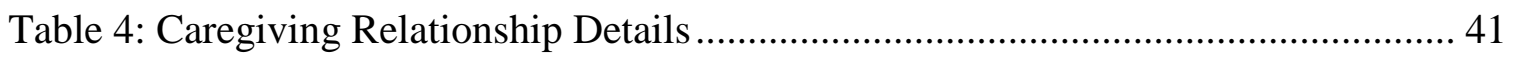

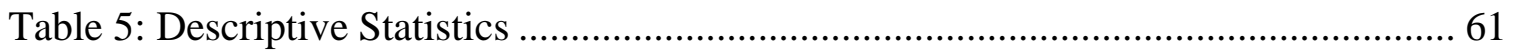

Table 6: Effect Sizes for Change in Determination Coefficients ................................ 74

Table 7: Parameter and Bootstrap Estimates ............................................................. 75 


\section{LIST OF FIGURES}

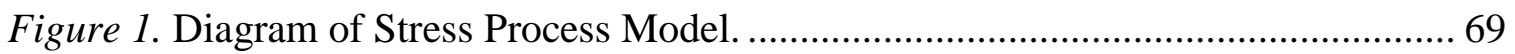

Figure 2. Interaction of intentions to seek help, by help source and help type............... 78 


\section{CHAPTER I}

\section{INTRODUCTION}

Personality disorders are a form of mental illness characterized by pervasive and inflexible patterns of maladaptive behaviour (American Psychiatric Association; APA, 2013). Although personality disorders are associated with high levels of interpersonal strife (e.g., Few et al., 2010; Miller et al., 2010), those diagnosed may not be distressed by their condition or view themselves as disordered (APA, 2013). As such, the loved ones who provide care and support to people with personality disorders may bear much of the distress associated with the condition. Though relatively little is known about caregivers of people with personality disorders, there is a large base of literature regarding the experiences of other caregiving groups. Generally, caregiving appears to be a stressful endeavour. For instance, family caregivers of people with psychiatric conditions report mean levels of psychological distress that are significantly higher than the general population, with $61 \%$ meeting criteria for severe distress (Provencher, Perreault, St. Onge, \& Rousseau, 2003). However, caregivers of people with personality disorders endorse levels of disempowerment and burden that are significantly higher than those of other caregiving groups (Bailey \& Grenyer, 2014), suggesting that supporting someone with a personality disorder is especially taxing.

Caregivers of people with personality disorders are defined by their active involvement in the recovery and wellbeing of a loved one with a personality disorder. Past research has operationalized their role as providing regular care or support to a loved one with a personality disorder (Bailey \& Grenyer, 2013), and promoting their wellbeing and recovery in a supportive relationship (Bailey \& Grenyer, 2014). Other studies have 
defined caregivers of people with personality disorders more broadly, as supportive, unpaid family members and friends (Dunne \& Rogers, 2013), those who self-identify as caregivers and have frequent contact with their loved one (Scheirs \& Bok, 2007), or those whom the person with the personality disorder perceives as their closest care-providing contact (Bauer, Döring, Schmidt, \& Spieß1, 2012). It is important to note that, although the term caregiving is often used in reference to instrumental tasks (Pearlin, Mullan, Semple, \& Skaff, 1990), caregiving can also take the form of emotional support (Dunne \& Rogers, 2013). Caring for a loved one with a serious mental illness can involve managing disruptive symptoms, coordinating care, and assisting with medication, among other functions (Bradford \& Palmer, 2016; Ohaeri, 2003). Thus, caregivers of people with mental illness may provide assistance with instrumental tasks, as well as emotional and spiritual support (AlMakhamreh, 2017). Informal caregivers have been recognized as primary supporters of mental health care after the deinstitutionalization movement of the nineteenth century, despite indications that many caregivers are highly burdened (Reinhard, 1994).

The current study uses the Stress Process Model (Pearlin et al., 1990) to identify which stressors in the lives of caregivers of people with personality disorders are predictive of psychological distress. The Stress Process Model divides the caregiving experience into four levels: (a) background variables, including demographic information and details about the caregiving relationship; (b) primary stressors, which arise from the needs of the care-receiver; (c) secondary stressors, or impacted areas of the caregiver's life outside the caregiving relationship; and (d) coping and social support, represented in this study by caregivers' help-seeking intentions. By examining the salient factors at 
each level, as well as how the levels interact, the current study elucidates the experiences and struggles of caregivers of people with personality disorders, highlighting the areas in which they need and may be willing to seek support. This provides a deeper understanding of both the circumstances and nature of their distress, and may allow clinicians to better meet caregivers' unique needs.

\section{The Stress Process Model}

There are many aspects of caregiving that could be linked to distress. Indeed, everything from caregiver gender (Hill, Shepherd, \& Hardy, 1998; Provencher et al., 2003 ) to their cognitive appraisals of the situation (Lazarus \& Folkman, 1984; Szmukler et al., 1996) has been implicated in the study of caregiving outcomes. One framework for organizing the multitude of variables associated with caregiving is the Stress Process Model (Pearlin et al., 1990). The Stress Process Model divides the caregiving experience into three levels of stressors, which, along with social support and coping, contribute to caregiving outcomes. The first level includes background variables, such as demographic details and information about the caregiving relationship. These are considered to set the stage for how caregivers deal with caregiving demands. Next, primary stressors arise directly from the needs of the care-receiver, including their problematic behaviour and dependency, as well as the caregiver's sense of overload. Pearlin and colleagues (1990) posit that primary stressors are long lasting and increase in intensity over time. The third level is the secondary stressors. These include areas of the caregiver's life outside the caregiving relationship, which are nonetheless impacted by the caregiving role. These include external strains, such as with job, financial, or family responsibilities, as well as internal conflicts, including role captivity or a reduced sense of mastery. In addition to 
negative internal strains, Pearlin and colleagues (1990) suggest that caregivers may experience positive internal changes, such as an increased sense of competence or personal enrichment. Secondary stressors ultimately reflect the way caregivers' lives become organized around the caregiving role. As they are viewed to arise from the primary stressors, secondary stressors may be particularly influential when caregiving stress is chronic (Pearlin et al., 1990). The Stress Process Model posits that background variables and the two levels of stressors usually contribute to negative outcomes, such as physical strain and psychological distress.

The Stress Process Model outlines coping and social support as potential buffers of the relations between stressors and outcomes. Coping is defined as skills used to manage three aspects of caregiving: the situation itself, the meaning of the situation, and the stress arising from the situation (Pearlin et al., 1990). Two forms of social support are also identified: instrumental support, which refers to practical assistance in the provision of daily care, and expressive support, which is provided by caring, trustworthy confidants. Together, coping and social support are thought to account for some of the individual differences in how caregivers respond to stressors. Pearlin and colleagues (1990) posit that details about caregivers' background, stressors, coping skills, and social support can be used to understand the caregiving process and the way stressors give rise to outcomes, such as psychological distress.

\section{Applications of the Stress Process Model}

Although the Stress Process Model was originally based on the experiences of those caring for loved ones with Alzheimer's Disease (Pearlin et al., 1990), it has been used with other caregiving populations. One study of caregivers of psychiatric patients 
(mostly psychotic disorders; only 3\% cared for people with personality disorders) found the primary and secondary stressors were positively associated with caregiver distress, whereas support from family members was related to lower distress (Provencher et al., 2003). In a regression model, many secondary stressors, along with age and employment status, significantly predicted psychological distress. The direct effects of social support were also tested, and surprisingly, caregivers who had more support from friends and more frequent contact with the care-receivers' service providers had higher levels of distress. Although none of the primary stressors were significant predictors in the final model, the variables accounted for a large proportion of variance in psychological distress. The authors suggested that secondary stressors might mediate the relation between primary stressors and distress, with the more widespread impact accounting for the effects of problematic behaviours and caregiving activities (Provencher et al., 2003).

These findings are consistent with an application of the Stress Process Model to those caring for terminally ill loved ones, which found that, as a group, the primary stressors accounted for a large amount of the variance in caregiver outcomes, but few significantly predicted depression or life satisfaction in the final models (Haley, LaMonde, Han, Burton, \& Schonwetter, 2003). The direct effects of social support were also tested, with social activities predictive of caregiver life satisfaction, but more visits from loved ones and smaller social networks indicating higher depression (Haley et al., 2003). Although the finding that more social visits predict higher levels of caregiver depression may seem counterintuitive, it has been suggested that caregivers who receive more social support may have more difficult loved ones to support (e.g. Bauer et al., 2012), which could lead to higher rates of caregiver distress. Both applications of the 
Stress Process Model accounted for substantial proportions of explained variance in caregiving outcomes, from $42 \%$ (Haley et al., 2003) to 61\% (Provencher et al., 2003). These findings suggest that the Stress Process Model can be used successfully to organize and link caregiving stressors and outcomes.

\section{Caregivers of People with Personality Disorders}

Personality disorders. Personality disorders are characterized by long-standing and pervasive patterns of culturally deviant inner experiences and behaviour (APA, 2013). The Diagnostic and Statistical Manual of Mental Disorders (DSM-5) recognizes ten personality disorder subtypes, which are categorized into clusters (APA, 2013). Those with Cluster A personality disorders are considered to be odd or eccentric; this includes schizoid personality disorder, marked by a lack of interest in social activities and general isolation; schizotypal personality disorder, featuring odd thinking, beliefs, or perceptual experiences; and paranoid personality disorder, characterized by suspicion and distrust of others. Cluster B denotes disorders that are dramatic, emotional, or erratic. Cluster B includes narcissistic personality disorder (NPD), which is characterized by a pattern of grandiosity, entitlement, and lack of empathy for others; antisocial personality disorder, which features a pattern of violation of and disregard for the rights of others; borderline personality disorder (BPD), marked by unstable interpersonal relationships and difficulties with emotional regulation; and histrionic personality disorder, characterized by theatricality and attention-seeking. Finally, Cluster C is considered to represent fearful or anxious traits. Avoidant personality disorder is characterized by social inhibition, hypersensitivity, and feelings of inadequacy; dependent personality disorder features a marked need to be taken care of and fear of separation; and obsessive- 
compulsive personality disorder (OCPD) is characterized by scrupulous behaviour related to work, finances, and interpersonal relationships. Other possible diagnoses include other specified and unspecified personality disorder, wherein the individual has characteristics of a personality disorder, but does not meet the full criteria for any of the subtypes detailed above (APA, 2013). A nationally representative survey of DSM-IV personality disorders in the United States suggested prevalence estimates of 5.7\% for Cluster A, $1.5 \%$ for Cluster B, $6.0 \%$ for Cluster C, and $9.1 \%$ for any personality disorder (Lenzenweger, Lane, Loranger, \& Kessler, 2007).

Characteristics of caregivers. Until recently, caregivers of people with personality disorders had received little attention in the empirical literature. A systematic review of six studies found that such caregivers had a mean age of 51, almost $90 \%$ were the care-receivers' parents, and more than half of those were mothers (Bailey \& Grenyer, 2013). A more recent study on caregiving relatives of people with BPD is largely consistent, although the sample was more evenly split between parents and significant others (Bailey \& Grenyer, 2015). More than half of relatives surveyed reported that they were their loved ones' primary caregiver and just over half resided with their loved one (Bailey \& Grenyer, 2015). The study of caregivers of people with personality disorders has largely focused on those caring for people with BPD (Bailey \& Grenyer, 2013). This may be due in part to the symptoms of BPD, such as feelings of emptiness, impulsivity, and unstable interpersonal relationships (APA, 2013). These may lead those with BPD to experience more distress than those with other personality disorders, necessitating support from others. For instance, one study found that out of all personality disorder subtypes, BPD was the most strongly associated with overall impairment (Miller et al, 
2010). Yet, Bailey and Grenyer (2014) found no differences between the self-reported burden of those caring for someone with BPD and those supporting loved ones with the other personality subtypes. Alternatively, there are many online resources (Bailey \& Grenyer, 2014; Goodman Patil, Triebwasser, Hoffman, \& Weinstein, 2011) and several support groups (e.g., Gunderson, Berkowitz, \& Ruiz-Sancho, 1997; Hoffman et al., 2005; Pearce et al., 2017) designed specifically for loved ones of people with BPD, which may make them easier to recruit for research studies than caregivers of people with other personality disorders. Still, past studies suggest that caregivers of people with personality disorders are often close family members, directly involved in their loved ones' lives.

Outcomes for personality disorder caregivers. Caring for someone with a personality disorder is associated with high levels of psychological distress. One study found that caregivers of people with BPD scored higher than the general Dutch population on psychological symptoms such as anxiety, depression, somatization, distrust, hostility, and sleeping problems (Scheirs \& Bok, 2007). Moreover, the level of distress experienced by many personality disorder caregivers is consistent with that of psychiatric populations. Caregivers of people with BPD have endorsed emotional dysregulation consistent with post-traumatic stress disorder patients and almost 65\% have profiles indicative of major affective or anxiety disorders (Bailey \& Grenyer, 2014; 2015). Caregivers of people with personality disorders appear to be under greater strain than other caregiving groups; BPD carers have endorsed more grief and levels of burden more than one standard deviation higher than published accounts of caregivers of other psychiatric illnesses (Bailey \& Grenyer, 2014; 2015). However, despite consistent 
findings that caregivers of people with personality disorders experience high levels of distress, little is known about how specific stressors in their lives relate to that distress. Caregivers of People with Personality Disorders and the Stress Process Model

\section{Background variables.}

Demographics. Although the Stress Process Model has not yet been used to understand the lives of caregivers of people with personality disorders, past research can inform its application with this population. For instance, previous research has linked background variables to caregivers' outcomes. Females, who make up the majority of personality disorder caregivers, have been found to experience more distress than men, even after targeted interventions (Bauer et al., 2012; Hoffman, Fruzzetti, \& Buteau, 2007; Scheirs \& Bok, 2007). Older caregiver age has also been shown to predict higher depression scores (Scheirs \& Bok, 2007). However, a study of mothers caring for their adult children with psychosis found that demographic details accounted for only a small amount of variance in the caregivers' overall psychological distress (St. Onge \& Lavoie, 1997). A more powerful predictor may be kinship, as biologically unrelated caregivers endorse higher levels of hostility (Scheirs \& Bok, 2007). More recent reports also show more extensive burden if the caregiver is not biologically related (Bailey \& Grenyer, 2015), or is a spouse or partner (Bauer et al., 2012). There is evidence that many personality disorder subtypes carry a strong hereditary component (Torgersen et al., 2000), but these findings may also relate to whether the caregiver resides with their carereceiver. Features of the care-receiver, such as their gender (being male), or age (being older), have been linked to caregiver hostility and sleeping problems, respectively (Scheirs \& Bok, 2007). 
Chronicity. A unique background characteristic facing personality disorder caregivers is the chronic and pervasive course of personality disorders. Explicit in the criteria for a personality disorder diagnosis is a long duration, with widespread impact on multiple life domains (APA, 2013). The course of caring for someone with a personality disorder appears to be long; one study found a mean length of caregiving of almost 13 years, with a maximum of 61 years (Bailey \& Grenyer, 2014). There is also evidence that problem behaviours starting in adolescence are associated with later parental distress stemming from BPD morbidity (Goodman et al., 2011). In their systematic review, Bailey and Grenyer (2013) showed that by a mean care-receiver age of 27, caregiving had already taken place for more than 10 years, further highlighting the adolescent onset and long course of the disorder. However, it is interesting to note that one study found that the length of the caregiving relationship was not related to the caregiver's level of psychological distress or burden (Bailey \& Grenyer, 2015). This, combined with findings that non-biologically related and spousal caregivers experience more distress than biologically related carers (Bailey \& Grenyer, 2015; Bauer et al., 2012; Scheirs \& Bok, 2007), suggests that a non-biological relationship, or living with the care-receiver, may be better predictive of caregiver distress than the relationship length.

Stigma. Another background variable that may be related to personality disorder caregivers' distress is their heightened potential to experience stigma, particularly in their interactions with the mental health care field. Past theory on the aetiology of personality disorders often blamed parents for causing their children's disorder and this concept permeated early literature (e.g., Herman, Perry, \& van der Kolk, 1989; Weaver \& Clum, 1993). Although the view that parents can cause their children to develop a personality 
disorder has largely fallen out of favour, many caregivers still identify stigma and prejudice as major sources of burden (Bauer et al., 2012). Similarly, family members have reported feeling blamed by mental health practitioners, who questioned the quality of the client's early upbringing (Buteau, Dawkins \& Hoffman, 2008), or stigmatized and dismissed by mental health care staff (Dunne \& Rogers, 2013). Some authors argue there is a unique and additional stigma associated with having BPD, above and beyond other mental illnesses, such that families experience surplus stigma when a member has BPD (Krawitz, Reeve, Hoffman, \& Fruzzetti, 2016). Thus, it appears that stigma weighs heavily upon personality disorder caregivers.

\section{Problems with services.}

Clinicians ' perceptions. Those caring for people with personality disorders have largely indicated dissatisfaction with their loved ones' clinicians and treatment (Bauer et al., 2012; Buteau et al., 2008; Dunne \& Rogers, 2013; Goodman et al., 2011). There are a number of factors that may give rise to this frustration, including clinicians' negative perceptions of those with personality disorders. One study showed that $80 \%$ of clinicians reported viewing clients with BPD as difficult, with $84 \%$ indicating that BPD clients were more difficult than those with other forms of psychopathology (Cleary, Siegfried, \& Walter, 2002). Moreover, clinicians have been found to perceive personality disorder clients as more difficult than those with other forms of psychopathology, even if their demands are the same, simply by virtue of knowing their personality disorder diagnosis (Crawford, Adedji, Price, \& Rutter, 2010). It has been suggested that nurses may be less likely to view personality disorder clients as ill, leading them to interpret their maladaptive behaviour as simply 'bad' or defiant, rather than 'mad' or influenced by 
underlying psychopathology (Bland \& Rossen, 2005). These perceptions may be influenced by the nature and prognoses associated with personality disorders; the chronic and recurrent course may cause frustration through clients' failure to improve (Koekkoek, van Meijel, \& Hutschemaekers, 2006). Such treatment outcomes may also be affected by poor commitment to therapy; many people with personality disorders simply do not want treatment (Bateman \& Tyrer, 2004).

In addition to these perceptions, there are specific traits represented in personality disorder samples that are associated with clinician frustration. BPD has been identified as particularly stressful for mental health care workers, due in large part to the distressing self-destructive behaviours, including self-harm or suicidal gestures, that are common among those with BPD (Perseius, Kåver, Ekdahl, Åsberg, \& Samuelsson, 2007). Moreover, traits associated with BPD have been linked to treatment dropout, including impulsivity and poor commitment to change (Barnicot, Katsakou, Marougka, \& Priebe, 2011). Although BPD appears to present a unique challenge, a study of so-called 'difficult patients' found that all personality disorder subtypes fell into this category. The four dimensions of difficult patient behaviour identified (viz. being distant, demanding, aggressive, and attention seeking or manipulative) were all associated with personality disorder diagnoses, and the three personality disorder clusters were represented within the three subtypes of difficult patients identified ("unwilling care avoider," "ambivalent care seeker," and "demanding care claimer"; Koekkoek et al., 2006, p. 796). As such, traits found in personality disorder clients are linked to difficult therapeutic relationships.

Treatment structure. Contributing to clients' failures to make treatment gains, and possibly stemming from clinicians' apparent distaste for clients with personality 
disorders, is the lack of structure with which many personality disordered individuals interact with the mental health care system. Difficult patients have been found less likely to have treatment plans (Koekkoek et al., 2006), and those with personality disorders appear to be no different. Some authors posit that many people with personality disorders are treated primarily through emergency room visits, brief hospitalizations, and overburdened community facilities (Bateman \& Tyrer, 2004). However, compared to those with depression, people with personality disorders were found more likely to receive outpatient psychotherapy (a surprising $96 \%$ of those with personality disorders surveyed), inpatient treatment, and psychotropic medication (Bender et al., 2001). These findings suggest that, although they are likely to receive treatment aside from acute care, those with personality disorders are still frequent customers of psychological services in varied forms. Successful treatment of clients with personality disorders is facilitated by an atmosphere of teamwork with strong leadership (Crawford et al., 2010). Additionally, effective communication, specialist involvement, and treatment stability have been identified as important elements in treating personality disorders (Bateman \& Tyrer, 2004). It is possible that such structure and unity may be weakened by the varied approaches through which those with personality disorders access services. Similarly, caregivers of people with BPD have noted poor communication with their loved ones' mental health services as a major stressor (Dunne \& Rogers, 2013). This is consistent with a recent study of personality disorder treatment services in England, which revealed low levels of carer involvement in activities such as service development and care planning (Dale et al., 2017). Whether due to clinicians' perceptions, treatment structure, 
or other factors, problems with the services accessed on their loved ones' behalf appear to be a major burden for caregivers of people with personality disorders.

Summary of background variables. Demographic variables, such as caregiver gender and age, have been shown to account for small amounts of variance in the psychological distress experienced by caregivers. Additionally, caregivers of people with personality disorders are likely to be subjected to a long course of caregiving, although this may be less distressful than being biologically unrelated to, or residing with, the carereceiver. Unique factors associated with caring for someone with a personality disorder, such as experiencing stigma and problems with services, may also be related to distress.

Primary stressors. The Stress Process Model suggests that primary stressors may include the care-receiver's problematic behaviours and the extent of their day-to-day dependence on the caregiver (Pearlin et al., 1990). In line with this, a qualitative report found that many caregivers had concerns related to their loved ones' symptoms and condition progression, including worrying about the care-receiver's future, self-harm or suicidal gestures, and excessive demands (Bauer et al., 2012). Problematic symptoms such as mood swings, personality changes, lack of trust, and irresponsible or aggressive behaviour were also burdensome (Bauer et al., 2012).

Interpersonal problems. Perhaps even more salient than the above-mentioned symptoms, a pervasive form of problematic behaviour that is associated with personality morbidity is interpersonal difficulty. The DSM-5 general criteria for personality disorders state, "the characteristics that define a personality disorder may not be considered problematic by the individual" (APA, 2013, p. 647). As such, the caregivers of people with personality disorders, who are often close family members or significant others, may 
bear the brunt of the interpersonal dysfunction. Some of the personality disorder subtypes feature traits that are not inherently distressful. For instance, those with narcissistic or antisocial personality disorder often display strong entitlement, either as deserved by their perceived special status or license to do as they please without regard to others (APA, 2013). When people with personality disorders do experience distress, it appears to be largely ego-syntonic, stemming from an inability to express the symptoms or characteristics of their disorder. For example, histrionic personality disorder features marked distress when the individual is not the center of attention, along with drastic attempts to refocus attention on them (APA, 2013). Finally, other subtypes manifest distress in ways that may place burden on the people around them. Paranoid and schizotypal personality disorders are characterized by problems in interpersonal relationships due to suspiciousness or discomfort in social situations, and those with dependent personality disorder rely on others extensively (APA, 2013). As such, the DSM-5 criteria suggest that the impact of a personality disorder, if not felt by the person diagnosed, is likely to be borne by those around them.

There is also empirical evidence to suggest that much of the distress associated with personality disorders manifests as interpersonal difficulties. Miller and colleagues (2010) found that out of multiple indices of functional impairment, antisocial, borderline, histrionic, narcissistic, and obsessive-compulsive personality disorders were most strongly related to causing distress to others; the remaining personality disorder subtypes were most strongly associated with impaired social functioning. Causing distress to others and impairment in social situations have also been linked to extreme levels of neuroticism, agreeableness, conscientiousness, and extroversion; traits that have, in turn, 
been associated with the majority of DSM-5 personality disorder categories (Few et al., 2010). These findings suggest that both formal personality disorders and their underlying traits are related to impaired social functioning, with up to half of personality disorder subtypes placing the burden of this dysfunction on other people. Other research has shown people with personality disorders to have greater impairment in social situations compared to those diagnosed with depression (Skodol et al., 2002), and other domains of functioning (Trull, Jahng, Tomko, Wood, \& Sher, 2010). Those with personality disorders also have more problems in work, romantic, and social settings than those without, leading to the perception that personality disorders "manifest themselves in such a way as to disrupt relationships" (Trull et al., 2010, p. 7).

Despite evidence that a large proportion of the impairment associated with personality disorders is related to interpersonal functioning, there is some support for more diffuse impairment. Extreme levels of the traits associated with both personality disorders and social maladjustment (conscientiousness, neuroticism, extraversion, and agreeableness) have also been associated with indices of overall impairment, beyond just social domains (Few et al., 2010). Moreover, formal personality disorder diagnoses are associated with global dysfunction (Miller et al., 2010) and poorer quality of life (Cramer, Torgersen, \& Kringlen, 2006). Despite these findings, other research suggests that difficulty in wider domains may be accounted for by interpersonal strife. Miller, Campbell, and Pilkonis (2007) found that the level of social impairment experienced by people with NPD mediated the relation between personality disorder symptoms and both depression and global functioning scores. These results suggest that broader impairment may be accounted for by the well-established interpersonal difficulties associated with 
personality disorders. As such, interpersonal struggles may directly affect people with personality disorders' relationships and indirectly account for other areas of impairment. These findings, combined with the notion that personality disorders may not always result in the experience of distress (APA, 2013; Montgomery, Lloyd, \& Holmes, 2000), suggest that the bulk of the burden associated with personality disorders may be placed on others, including their caregivers.

Instrumental needs. Pearlin and colleagues (1990) suggest that caregivers' involvement in their loved ones' daily activities may be a salient primary stressor. Personality disorder caregivers endorse burden across multiple life domains, including physical strain and impact to relationships (Goodman et al, 2011). As such, caregivers may be burdened by supporting their loved one in aspects of day-to-day life, such as managing money. However, in contrast to the toll of their loved ones' interpersonal difficulties, carers of people with personality disorders may be less burdened by their loved ones' instrumental dependence. For instance, almost half of BPD caregivers do not reside with the loved one they care for (Bailey \& Grenyer, 2015). Another study found no differences in the abilities of people with personality disorders and those with major depression to carry out household duties, with both groups showing fair to good functioning, on average (Skodol et al., 2002). As such, the care-receivers' needs for instrumental support may be less salient to caregivers than other primary stressors.

Worry. In contrast to the potential lack of instrumental dependency, caregivers of people with BPD endorse patterns of anxious concern, overprotectiveness, and emotional closeness (Bailey \& Grenyer, 2015). Caregivers of people with personality disorders have also reported burden arising from helplessness and the fear of being subjected to 
excessive demands by their loved ones (Bauer et al., 2012). These features of excessive worry and involvement map well onto the subjective overload posited by Pearlin and colleagues (1990), including the fatigue associated with providing unrelenting and demanding care. Indeed, high emotional involvement has been related to carer burden and psychological distress (Bailey \& Grenyer, 2015); the cost of such high emotional concern appears to be taxing on caregivers. Based on past research, caregivers' worry and their loved ones' interpersonal problems are likely to contribute to caregivers' distress, although instrumental dependency may be relatively less distressful.

Secondary stressors. Research has identified a number of secondary stressors, indicating that many areas of personality disorder caregivers' lives are affected by their loved one's illness. Strain arising from juggling multiple roles appears to be a major source of stress. More than half of those caring for their children with BPD reported that caregiving had impacted their marriage or social life, $36 \%$ indicated changes to their career trajectory, and $44 \%$ reported an impact to their standard of living (Goodman et al., 2011). The biggest strain endorsed by one sample of caregivers was on their family relationships (Bailey \& Grenyer, 2014), and another study found that $70 \%$ of personality disorder carers worried about the burden the illness placed on other members of the family (Bauer et al., 2012). Other areas of impact include physical health, with more than half of BPD caregivers reporting physical health strain (Goodman et al., 2011), and financial burden (Buteau et al., 2008; Dunne \& Rogers, 2013). One study found that more than half of personality disorder carers experienced financial strain (Bauer et al., 2012), and another that the out-of-pocket costs of a BPD diagnosis was more than $\$ 14,000$ per year, which increased further if the care-receiver was a victim of rape or had 
comorbid conduct disorder (Goodman et al., 2011). Clearly, caring for someone with a personality disorder is costly, both financially and in other areas of life.

Caring for someone with a personality disorder may also impact caregivers' selfperceptions. For instance, personality disorder caregivers show levels of empowerment that are five standard deviations lower than published levels endorsed by caregivers of disabled children (Bailey \& Grenyer, 2013). This disempowerment maps onto Pearlin and colleagues' (1990) suggestion that caregivers may have a reduced sense of mastery, or the feeling that one has control over the situations they encounter. Given the long course of personality disorders and problems with services facing personality disorder caregivers, it is consistent that they may feel a lack of control. Moreover, caregivers' low levels of empowerment may lead them to feel that they have no way out of caregiving and are thus trapped within the role. Role captivity has been endorsed by those caring for loved ones with schizophrenia (Ferriter \& Huband, 2003) and dementia (Smyth \& Milidonis, 1999). Given the long course, interpersonal difficulties, and disempowerment associated with caring for someone with a personality disorder, role captivity and reduced mastery may be salient internal secondary stressors.

The Stress Process Model also posits a role for positive changes associated with caregiving under the category of secondary stressors. Specifically, increases in caregiving competence and broader personal enrichment are suggested as areas in which a caregiver may feel they have benefitted from caregiving (Pearlin et al., 1990). To date, no studies have examined whether caregivers of people with personality disorders experience such gains from caregiving. However, the caregivers are often mothers or 
significant others of the care-receivers (Bailey \& Grenyer, 2014). As such, they may have positive feelings towards being able to support their loved one's recovery.

Summary. There is support for the application of the Stress Process Model to the experiences of caregivers of people with personality disorders. Along with demographic characteristics, features associated with the caregiving history, such as facing stigma or problems with services, have been associated with distress. Caregivers' primary stressors likely include the care-receivers' interpersonal impairment and their own worry, whereas the care-receivers' instrumental demands may be less salient. Secondary stressors likely include family, schedule, health, and financial strains, along with role captivity and reduced mastery. Gains from caregiving have not yet been examined, but as previous research has focused on the negative aspects of supporting someone with a personality disorder, these may help provide a more well-rounded picture of caregivers' experiences.

\section{The Stress Process Model and Help-Seeking}

Social support. In addition to background variables, primary stressors, and secondary stressors, the Stress Process Model outlines social support and coping skills as ways in which distress might be buffered (Pearlin et al., 1990). However, a puzzling mix of results has emerged from studying the relation between social support and caregiving outcomes. Some studies have found results in the expected direction; one review found that perceiving professional support and advice as sufficient was associated with decreased burden (Baronet, 1999). However, other findings have been counterintuitive. One study did not find a significant relation between psychological distress and support from friends or close confidants, with a significant link only for family support (St. Onge \& Lavoie, 1997). Others have found no association between family support and burden 
(Baronet, 2003); or that other predictors, such as socio-economic status and marital adjustment were better predictors of burden than social support (Robinson, 1990). Importantly, findings from applications of the Stress Process Model have also been mixed; one found that caregivers with more social activities had higher life satisfaction (Haley et al., 2003), but another found that more support from friends and more frequent contact with the care-receiver's service providers was linked with higher levels of distress (Provencher et al., 2003). One reason for these mixed results may be that many studies do not fully differentiate between the types and sources of support sought.

Types of social support. There are at least three types of social support that caregivers may require: instrumental, emotional, and informational (Kutner et al., 2009; MacLeod, Skinner, \& Low, 2012; Wittenberg-Lyles, Washington, Demiris, Oliver, \& Shaunfield, 2014). Pearlin and colleagues (1990) outline two of these within the Stress Process Model. Instrumental support takes the form of direct assistance with caregiving duties, such as through respite care or help with household chores. Expressive, or emotional, support is that provided by caring, trustworthy, uplifting confidants who assist caregivers in managing the emotional load of their role. However, caregivers of people with personality disorders may also need informational support, as they have been found to have little knowledge about personality disorders (Hoffman, Buteau, Hooley, Fruzzetti, \& Bruce, 2003), and often have difficulty finding up-to-date information and relevant treatment options for their loved one (Buteau et al., 2008; Dunne \& Rogers, 2013). Clarification of the type and function of social support may produce more interpretable findings regarding the role of social support in caregiving outcomes. For instance, one 
study found that instrumental and emotional support were differentially influential, depending on the type of burden examined (Baronet, 1999).

Sources of social support. The source from which caregivers seek help is another equivocal matter in the literature, involving a division commonly drawn between formal (i.e., paid) and informal (i.e., unpaid) support. The separation often reveals a useful perspective on the differential views caregivers have towards seeking help. There is some indication that caregivers may be reluctant to ask informal sources, such as friends and family, for instrumental assistance with caregiving (Wittenberg-Lyles et al., 2014). Specifically, caregivers may view doing so as a violation of relationship boundaries, by asking too much of acquaintances, or acknowledging that family members had previously failed to provide support. However, other studies have found that carers of people with dementia used informal help more often than formal (Jarrott, Zarit, Stephens, Townsend, \& Greene, 2005; Smyth \& Milidonis, 1999). Still other research has found a mix of preferences for support sources, with parents of adult children with schizophrenia more likely to seek help from family, general practitioners, friends, psychiatrists, or neighbours than self-help groups, psychologists, or clergy (Ferriter \& Huband, 2003). In terms of outcomes, formal support has been found to predict decreased depression, anger, overload, and worry for caregivers of people with Alzheimer's Disease, whereas informal support had no relation to caregiving outcomes (Jarrott et al., 2005). However, formal and informal help have both been associated with increases in caregiving gains for families of people with schizophrenia (Chen \& Greenberg, 2004).

Coping. Pearlin and colleagues (1990) posit three major functions that coping can serve in response to stressors. The first is to manage the situation giving rise to stress. 
This may involve dealing directly with the care-receiver's behaviour, attending to highpriority stressors while letting others go, and gathering information about the illness. Managing the meaning of the situation includes doing things that reduce the threat of the situation, such as accepting the illness, staying positive, and trying to see a larger picture. Finally, caregivers can cope by managing the stress symptoms that result from the situation. These behaviours include spending time alone, exercising, reading, and other self-care behaviours that caregivers perform for themselves. These coping functions are represented in the empirical literature. For instance, Hill, Shepard, and Hardy (1998) found that those caring for people with bipolar disorder reported seeking advice in managing their role as a carer (reflecting management of the situation), as well as help for their own symptoms of stress, anxiety, and depression (managing meaning and stress).

Coping through social support. One way that coping functions may be fulfilled is through seeking the aforementioned types of social support: emotional, instrumental, and informational. Previous research has operationalized attempts to manage meaning as seeking counselling, and managing the situation as the use of respite services, which are forms of emotional and instrumental help, respectively (Del Santo et al., 2008). Yet, there is evidence that multiple coping functions can be attained from each form of social support. For example, instrumental support can help caregivers manage the situation directly by reducing amount of care required in acute episodes (Baronet, 2003). However, the provision of instrumental support has also been associated with better management of meaning, through decreases in depression and anger in carers of Alzheimer's patients (Jarrott et al., 2005), and management of stress symptoms, through increased self-care behaviour (Brown, Chen, Mitchell, \& Province, 2007). Emotional 
support can assist caregivers in managing meaning; support groups emphasizing mutual trust and emotional disclosure have been associated with decreased family burden and improved functioning (Chien, Thompson, \& Norman, 2008). Yet, such support groups have also been found to help manage the situation and stress, through promoting feelings of competence in caregiving and the need for self-care (O’Connor, 2003). Informationbased interventions can change the way caregivers approach the situation by reducing criticism and overprotection, while facilitating understanding and awareness (MacDonald et al., 2014). Additionally, such psycho-educational support groups have also been associated with meaning-making, such as accepting the diagnosis and its implications, redefining the relationship, and working through grief for caregivers of Alzheimer's patients (Cummings, 1997).

Seeking support can provide a wide range of coping functions for caregivers. Thus, although the Stress Process Model does not make explicit the role of help-seeking, it can be used to address the buffer variables included in the model: social support and coping. Help-seeking intentions, or the likelihood an individual will seek help for a particular problem from a certain source, can provide useful information. First, helpseeking intentions have been closely linked to actually seeking help for a variety of problems (Wilson, Deane, Ciarrochi, \& Rickwood, 2005), and can thus serve as an estimate of future help-seeking behaviours. Second, ratings of the helpfulness of past service use are robust predictors of future help-seeking intentions (Cusack, Deane, Wilson, \& Ciarrochi, 2004). Thus, help-seeking intentions can indicate the impact of past help-seeking attempts and the likelihood of future help-seeking behaviours. 


\section{Help-Seeking of Personality Disorder Caregivers}

There is evidence to suggest that caregivers of people with personality disorders require all three forms of support, but may have difficulty securing such help. Caregivers of people with personality disorders may require support for the day-to-day tasks of caregiving. Personality disorder caregivers endorse high levels of burden (Bailey \& Grenyer, 2014), and are distressed by the symptoms of their loved ones' illnesses (Bauer et al., 2012). Caregivers who attempt to manage the impact of their loved ones' symptoms by being involved in their care may reach barriers; almost half report being excluded from treatment decisions, and many endorse poor cooperation with the clinical centers and institutions involved in their loved ones' treatment (Bauer et al., 2012; Lawn \& McMahon, 2015). Similarly, in crisis situations, almost 30\% of BPD caregivers sought help from emergency services, suggesting few perceived options for help with acute care (Lawn \& McMahon, 2015). Based on these findings, personality disorder caregivers may be unlikely to seek formal instrumental support, and may instead rely on informal sources such as family and friends if they need assistance with caregiving tasks. Yet, as caregivers of people with personality disorders may receive fewer instrumental demands than other caregiving groups (Bailey \& Grenyer, 2015; Skodol et al., 2002), instrumental support may be less salient to them than other forms of help. For instance, an Australian study found that $82 \%$ and $70 \%$ of BPD carers did not access occupational therapists or social workers, respectively, for support (Lawn \& McMahon, 2015).

There is evidence for a lack of knowledge about personality disorders among caregivers. Between $40 \%$ and $62 \%$ of BPD caregivers did not have the disorder explained to them by a mental health professional, and only a third had it described in a 
way they understood (Bailey \& Grenyer, 2014; Lawn \& McMahon, 2015). Hoffman and colleagues (2003) showed that more than a third of family members of people with BPD could not accurately describe their loved one's symptoms. Finally, family members have reported difficulty finding current information, with little assistance from clinicians (Buteau et al., 2008; Dunne \& Rogers, 2013). However, the impact of increasing caregivers' knowledge is unclear. Thirty-eight percent of BPD carers indicated that accessing educational information about BPD was helpful to them (Lawn \& McMahon, 2015), whereas Hoffman and colleagues (2003) found that family members who knew more about BPD had significantly higher levels of burden and depression. Focus groups have revealed that many personality disorder specialists believe that increasing education and training for loved ones would improve the outcomes of personality disorder services (Fanaian, Lewis, \& Grenyer, 2013). Yet, given caregivers' frustration with the services accessed to help their loved ones, they may be more likely to seek information related to caregiving through informal means, such as internet forums or peer-led support groups.

The emotional toll of caring for someone with a personality disorder is evident throughout the literature. In one study, almost $90 \%$ of parents of daughters with BPD endorsed emotional burden stemming from caregiving (Goodman et al., 2011). Another found that almost all personality disorder caregivers interviewed named at least one emotional burden (Bauer et al., 2012). Moreover, caregivers of people with personality disorders are known to have elevated levels of grief, emotional dysregulation, and clinical levels of mood and anxiety symptoms (Bailey \& Grenyer, 2014). In seeking emotional support, family members caring for someone with BPD have reported difficulties maintaining informal support networks of friends and family members (Buteau et al., 
2008). Compared to instrumental and informational help, formal emotional support may be the most accessible of the three, with $36 \%$ of BPD carers reporting that seeking counselling for themselves was helpful or very helpful (Lawn \& McMahon, 2015). Similarly, caregiver psychoeducational groups have been identified as important sources of emotional support and social connection (Weegmann \& Head, 2016).

Despite evidence for frustration stemming from formal services, empirical trials indicate that there is a high demand for support interventions developed specifically for personality disorder caregivers. Hoffman and colleagues (2005) created a psychoeducational, coping-focused intervention, called Family Connections, to meet the needs of family members of people with BPD. Two trials of the intervention have been conducted, and both had participation waitlists, high attendance, low attrition, and high follow-up questionnaire return rates, all indicating a high need for and interest in the intervention (Hoffman et al., 2005; Hoffman, Fruzzetti, et al., 2007). These results are consistent with Sanders and Pearce (2010), who were unable to keep up with demand for an intervention they ran for family members of people with personality disorders, and Pearce and colleagues (2017), who had a high retention rate for their psychoeducational program for family members of youth with BPD. Still, caregiver opinions about formal support appear to be split; almost 30\% of Australian BPD caregivers found that support from mental health professionals was helpful to them, whereas just over $20 \%$ rated the same services as very unhelpful (Lawn \& McMahon, 2015). As such, the literature is unclear; caregivers of people with personality disorders seem to desire targeted formal interventions, but may be unhappy with what they are able to find when seeking such services. 
Overall, there appear to be barriers between caregivers and formal support. Bailey and Grenyer (2015) found almost all relatives of people with BPD surveyed had sought support, but nearly $40 \%$ were unsatisfied with what they had found. Another study showed that $62 \%$ of BPD carers had wanted to access support, but noted not being taken seriously, lack of support availability, and financial difficulties as major barriers (Lawn \& McMahon, 2015). In the United Kingdom, caregivers have reported that they would appreciate more support, but were not aware of how to get it (Dunne \& Rogers, 2013). Some caregivers may not seek formal support at all. One study found that very few of the caregivers surveyed were part of a self-help group or caregiving organization (Bauer et al., 2012), and Lawn and McMahon (2015) reported that almost 30\% of BPD caregivers had never sought support for themselves. The literature suggests that caregivers of people with personality disorders desire targeted programs. However, formal support, such as that for instrumental and informational needs, may be unavailable or disappointing to caregivers. Caregivers endorse barriers to getting formal support and past research suggests that they may be unsatisfied with the services they are able to find.

\section{The Current Study}

The current study is an exploratory application of the Stress Process Model to the experiences of caregivers of people with personality disorders. The primary objective was to identify which aspects of caregiving are most predictive of psychological distress. The study also examined caregivers' intentions to seek help for their own needs. An online survey examining stressors from each level of the Stress Process Model was administered, and statistical modelling was used to examine the interplay of the stressors and their collective effects on caregivers' psychological distress. Past research shows 
that caregivers of people with personality disorders experience high levels of distress, but not which areas of their lives are most distressful. The current study fills that gap, by examining many facets of caregivers' lives and relating these to their level of distress.

\section{Hypotheses}

Hypothesis 1 - Stress Process Model. Hypothesis 1 concerns the relations among the levels of the Stress Process Model and is divided into seven parts. First, biologically unrelated caregivers endorse higher levels of hostility (Scheirs \& Bok, 2007), and more extensive burden (Bailey \& Grenyer, 2015; Bauer et al., 2012) than carers who are unrelated. Additionally, carer age and gender have both been associated with distress (Bauer et al., 2012; Hoffman, Fruzzetti, et al., 2007; Scheirs \& Bok, 2007). As such, it is hypothesized that: (1a) caregivers who are older, female, reside with their care-receiver, and are biologically unrelated to them have higher levels of the primary stressors (i.e., care-receiver interpersonal problems, caregiver worry, and care-receiver instrumental needs). According to the Stress Process Model, primary stressors give rise to secondary stressors (Pearlin et al., 1990). Thus, it is hypothesized that: (1b) having more worry, care-receiver interpersonal problems, and care-receiver instrumental needs leads to higher secondary stressors (i.e., more health, financial, schedule, and family strains, as well as lower mastery and higher role captivity). The Stress Process Model also posits that secondary stressors are positively related to caregiving outcomes, such as psychological distress (Pearlin et al., 1990). Moreover, applications of the Stress Process Model have indicated that secondary stressors may mediate the relation between primary stressors and distress (Provencher et al., 2003). Accordingly, it is hypothesized that: (1c) 
secondary stressors mediate the relation between primary stressors and distress, and higher levels of the secondary stressors predict higher psychological distress.

Evidence suggests that negative experiences with past help-seeking ventures and experiencing stigma are salient aspects of caregiving for someone with a personality disorder (Bauer et al., 2012; Buteau et al., 2008; Goodman et al., 2011), and are also related to the likelihood of seeking help. Ratings of the helpfulness and perceived quality of past service use have been shown to be robust predictors of future help-seeking intentions (Cusack et al., 2004; Wilson et al., 2005). Additionally, a systematic review identified stigma as a major barrier to seeking help for mental health needs (Clement et al., 2015). Additionally, stigma that was internalized or related to seeking treatment had small but consistent negative associations with help-seeking (Clement et al., 2015). Thus, it is hypothesized that: (1d) experiencing more stigma and more problems with services leads to lower help-seeking intentions.

Studies of caregiving groups have suggested that those who experience more burden or stress will be more likely to seek help. For instance, compared to those who did not seek help, African-American caregivers of the elderly who accessed support had higher levels of stressors arising from the needs of the care-receiver (Pickard, Inoue, Chadiha, \& Johnson, 2011). Additionally, burden from the behavioural problems of dementia patients has been found to predict increased caregiver service use (Roelands, van Oost, \& Depoorter, 2008). Bauer and colleagues (2012) have also suggested that caregivers of people with personality disorders who receive social support may be more burdened than those who receive less help. Thus, it is hypothesized that: (1e) higher levels of primary stressors (interpersonal problems, instrumental needs, and caregiver 
worry) lead to a higher likelihood of seeking help. Similarly, a wider impact on caregivers' lives has also been shown to be predictive of help-seeking behaviours. Specifically, higher levels of perceived stress, or the sense that life was uncontrollable, unpredictable, and overbearing, were predictive of increased help-seeking, and caregivers who sought help were found to have worse perceived health than those who did not access services (Pickard et al., 2011). Consistent with these findings, it is hypothesized that: (1f) higher levels of the secondary stressors lead to higher help-seeking intentions. Finally, larger social networks have been linked to decreased psychological distress under the Stress Process Model (Haley et al., 2003), and caregivers have reported seeking education about BPD and formal counselling as helpful (Lawn \& McMahon, 2015). Moreover, the Stress Process Model outlines social support and coping, measured in this study by caregivers' help-seeking intentions, as ways the negative effects of caregiving stressors may be buffered (Pearlin et al., 1990). Thus, it is hypothesized that: (1g) higher help-seeking intentions lead to lower distress.

Hypothesis 2 - help-seeking intentions. Previous literature suggests caregivers' interactions with formal mental health services are largely negative, with the possible exception of seeking emotional support (Bauer et al., 2012; Goodman et al., 2011; Lawn \& McMahon, 2015). As such, it is hypothesized that: (2a) caregivers have lower intentions to seek help from formal than informal sources for instrumental and informational support, but not emotional support. Secondly, as caregivers report emotional burden (Bauer et al., 2012; Goodman et al., 2011) and a lack of information regarding caregiving (Bailey \& Grenyer, 2014; Buteau et al., 2008; Hoffman et al., 2003; Lawn \& McMahon, 2015), but potentially fewer instrumental demands, it is hypothesized 
that: (2b) caregivers have higher intentions to seek emotional and informational support, compared to instrumental support, regardless of the help source. 


\section{CHAPTER II}

\section{METHODS}

\section{Participants}

Recruitment. The eligibility requirements to participate in the study were as follows: (1) caring for a loved one who had been diagnosed with a personality disorder by a mental health care professional, (2) being actively involved in the loved one's recovery and wellbeing, (3) having contact with the loved one at least once a week, and (4) having been a caregiver for at least one year. The recruitment materials clearly expressed these inclusion criteria. Conversely, the recruitment flyer (Appendix A) also informed potential participants that we were not looking for responses from (1) those diagnosed with personality disorders, (2) those caring for people with mental illnesses other than personality disorders, (3) those caring for people with undiagnosed or selfdiagnosed personality disorders, (4) those in contact with their loved one less than once a week, or (5) those caregiving for less than one year. Caregiving was defined as being actively involved in and supportive of the care-receiver's wellbeing and recovery, including through providing emotional or instrumental support.

Recruitment was carried out through a variety of means. When possible, recruitment pathways were chosen to attempt to reach caregivers of people from across the personality disorder subtypes, rather than only those caring for people with BPD. The first recruitment strategy was posting advertisements for the study on online forums, which host communication boards where site members can discuss their experiences. The text of the study flyer was posted onto the forums, from accounts made specifically for the study on each site. Once posted, site members were able to view the study 
information as they browsed the forum. Some of the sites accessed for recruitment were devoted specifically to personality disorders, such as BPDFamily (https://bpdfamily.com) and an online OCPD Support Group (http://ocpd.freeforums.org). Others focused more broadly on mental health or caregiving, such as Carers Space (https://space.carers.org) and PsychForums (http://www.psychforums.com).

Social media and forum websites with broader focuses were also accessed for recruitment. Facebook (https://www.facebook.com) allows members to create 'groups' centered on virtually any topic, allowing people in similar situations to connect. Groups referencing personality disorders in their titles were contacted and, when permitted by the group administrators, the researcher posted the study flyer within the group, from a Facebook account made for the study. Additionally, the Personality Disorder Awareness Network posted the study flyer on their organization Facebook pages several times. Reddit (https://www.reddit.com) is a general forum website on which members can create new sub-forums (called "subreddits" and denoted by ' $r$ ' ' before the subreddit title) related to whatever topic they choose. The survey flyer was posted on several subreddits, including r/schizoid, r/BPDlovedones, r/OCPD, and r/caregiving. Finally, Meetup (https://www.meetup.com) allows individuals to join groups based on organizing inperson 'meet-ups' for like-minded people in the same geographical area. The groups can be formed around any theme. Groups related to supporting a loved one with a personality disorder were contacted; one group distributed the study flyer to its members.

Several formal organizations also assisted with recruitment, by passing the study flyer and information onto potential participants. Most of the organizations that assisted with the study provided services for loved ones of people with BPD, often by delivering 
the previously described Family Connections program. Organizations that were involved in this study include the Ottawa Network for BPD, the Sashbear Foundation (in Toronto), the New England Personality Disorder Association, Friends for Mental Health (Quebec), Family Association for Mental Health Everyday (Ontario), and the National Education Alliance for Borderline Personality Disorder (United States). Many of the organizations made the study flyer available to potential participants at support group meetings or on their websites, whereas others distributed the study flyer through email newsletters.

The final recruitment strategy involved snowball sampling. Those who completed the survey were encouraged to give the link to others they thought might be interested in and eligible for the study. A message appeared at the end of the survey, thanking caregivers for their time and input and requesting that they share the study information. A .pdf copy of the study flyer was provided on the page to facilitate caregivers' ability to share information about the study. See Table 1 for a complete list of the recruitment pathways.

In most cases, the study flyer was provided to potential participants without the direct link to the survey. Rather, those interested in participating were required to contact the researcher in order to request the link. This procedure was chosen in discussion with the Research Ethics Board (REB) at the University of Windsor, due to the sensitive nature of the study items and their focus on the caregivers' perspective, without the opportunity for the care-receiver to also contribute. Moreover, as several of the recruitment pathways involved communities that included people with personality disorders, the procedure was used to prevent those with personality disorders from accessing the survey, which may have caused them undue distress. There were a few 
Table 1

Recruitment Pathways

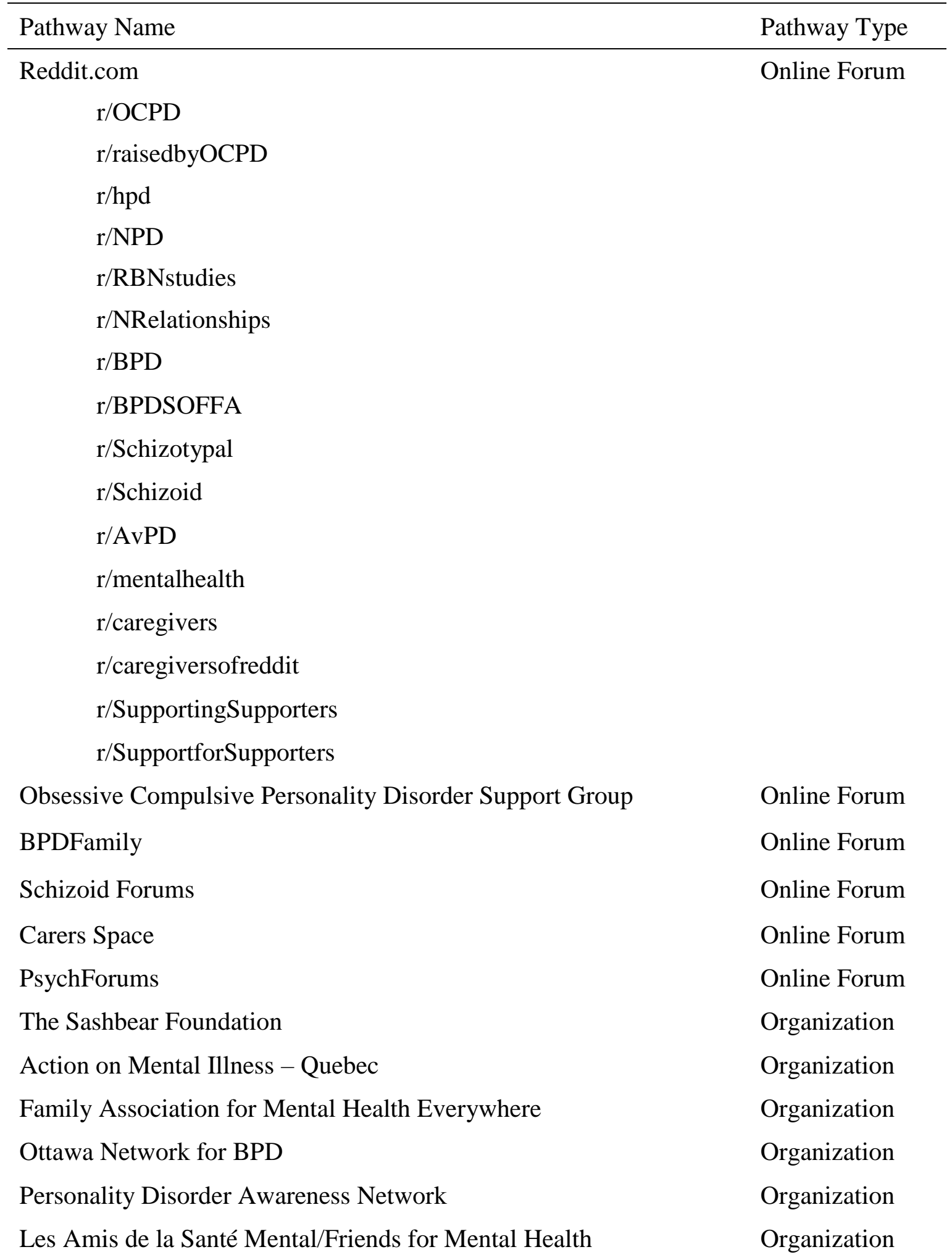


Mental Health Association of Southeastern Pennsylvania

Organization

New England Personality Disorder Association

Organization

Florida Borderline Personality Disorder Association

Organization

Inner Solutions

Organization

National Education Alliance for Borderline Personality Disorder

Organization

Sanctuary Carer Support Group - Borderline Personality Disorder

Organization

Facebook.com groups*

Social Media

Meetup.com groups*

Social Media

Snowball sampling or word-of-mouth

Other

* To preserve group members' anonymity, the specific groups are not named.

exceptions in which the direct link was shared with potential participants. BPDFamily caters specifically to family members of people with BPD and the site administrators required that the direct link be provided to their members. Three organizations with emailing lists sent the direct link and study flyer to their caregiving members through email. These exceptions were deemed appropriate, as the link was provided directly and only to caregivers, minimizing the risk of an adverse event.

Participants. A total of 162 people accessed the online survey. Of these, 106 caregivers (77 female) met the eligibility requirements and completed the survey. In terms of recruitment, $59 \%$ found the study through online forums, $24 \%$ were recruited through caregiving support organizations, and 17\% accessed the survey through other methods. The mean caregiver age was $46.84(S D=10.93)$. The majority of the respondents (85\%) supported someone with BPD; $46 \%$ and $44 \%$ were parents and partners, respectively. For more information about the characteristics of the caregivers and care-receivers, please refer to Tables 2 and 3, respectively. Details about the caregiving relationship can be found in Table 4. 
Table 2

Caregiver Characteristics

\begin{tabular}{|c|c|}
\hline Characteristic & $n(\%)$ or $M(S D)$ \\
\hline Age & $46.84(10.93)$ \\
\hline \multicolumn{2}{|l|}{ Sex } \\
\hline Male & $28(26.4)$ \\
\hline Female & 77 (72.6) \\
\hline Other & $1(0.9)$ \\
\hline \multicolumn{2}{|l|}{ Ethnicity } \\
\hline Aboriginal/First Nations & $1(0.9)$ \\
\hline Caucasian & $93(87.7)$ \\
\hline Hispanic/Latino & $3(2.8)$ \\
\hline Indian/South Asian & $1(0.9)$ \\
\hline Other & $5(4.7)$ \\
\hline Prefer not to answer & $3(2.8)$ \\
\hline \multicolumn{2}{|l|}{ Education } \\
\hline Did not finish high school & $1(0.9)$ \\
\hline High School & $12(11.3)$ \\
\hline College or trade school & $25(23.6)$ \\
\hline Undergraduate university degree & $40(37.7)$ \\
\hline Master's degree & $19(17.9)$ \\
\hline Doctoral degree & $9(8.5)$ \\
\hline \multicolumn{2}{|l|}{ Employment Status } \\
\hline Employed full-time & $61(57.5)$ \\
\hline Employed part-time & $15(14.2)$ \\
\hline Unemployed & $7(6.6)$ \\
\hline Other & $23(21.7)$ \\
\hline \multicolumn{2}{|l|}{ Lifetime diagnosis of: } \\
\hline Major Depression & $23(21.7)$ \\
\hline Bipolar Disorder & $3(2.8)$ \\
\hline Anxiety Disorder & $24(22.6)$ \\
\hline Post-Traumatic Stress Disorder & $9(8.5)$ \\
\hline Obsessive Compulsive Disorder & $5(4.7)$ \\
\hline Eating Disorder & $2(1.9)$ \\
\hline Attention-Deficit/Hyperactivity Disorder & $5(4.7)$ \\
\hline Substance Use & $1(0.9)$ \\
\hline Personality Disorder & $1(0.9)$ \\
\hline Other & $5(4.7)$ \\
\hline No Diagnoses & $61(57.5)$ \\
\hline
\end{tabular}


Table 3

\section{Care-Receiver Characteristics}

\begin{tabular}{|c|c|}
\hline Characteristic & $n(\%)$ or $M(S D)$ \\
\hline Age & $32.12(12.89)$ \\
\hline \multicolumn{2}{|l|}{ Sex } \\
\hline Male & $38(35.8)$ \\
\hline Female & $65(61.3)$ \\
\hline Other & $3(2.8)$ \\
\hline \multicolumn{2}{|l|}{ Ethnicity } \\
\hline Aboriginal/First Nations & $2(1.9)$ \\
\hline Arabic/Middle Eastern & $1(0.9)$ \\
\hline Asian & $1(0.9)$ \\
\hline Black/African & $0(0)$ \\
\hline Caucasian & $91(85.8)$ \\
\hline Hispanic/Latino & $1(0.9)$ \\
\hline Indian/South Asian & $1(0.9)$ \\
\hline Other & $7(6.6)$ \\
\hline Prefer not to answer & $1(0.9)$ \\
\hline \multicolumn{2}{|l|}{ Education } \\
\hline Did not finish high school & $19(17.9)$ \\
\hline High School & $34(32.1)$ \\
\hline College or trade school & $30(28.3)$ \\
\hline Undergraduate university degree & $15(14.2)$ \\
\hline Master's degree & $5(4.7)$ \\
\hline Doctoral degree & $3(2.8)$ \\
\hline \multicolumn{2}{|l|}{ Employment Status } \\
\hline Employed full-time & $23(21.7)$ \\
\hline Employed part-time & $12(11.3)$ \\
\hline Unemployed & $51(48.1)$ \\
\hline Other & $19(17.9)$ \\
\hline Prefer not to answer & $1(0.9)$ \\
\hline \multicolumn{2}{|l|}{ Personality Disorder Diagnoses } \\
\hline Schizoid & $4(3.7)$ \\
\hline Schizotypal & $5(4.7)$ \\
\hline Paranoid & $5(4.7)$ \\
\hline Borderline & $90(84.9)$ \\
\hline Narcissistic & $9(8.5)$ \\
\hline Histrionic & $2(1.9)$ \\
\hline Antisocial & $2(1.9)$ \\
\hline Avoidant & $2(1.9)$ \\
\hline Dependent & $7(6.6)$ \\
\hline Obsessive-Compulsive & $13(12.3)$ \\
\hline Not Otherwise Specified & $8(7.5)$ \\
\hline Other & $2(1.9)$ \\
\hline
\end{tabular}




\begin{tabular}{lc}
\hline Diagnosed with More Than One Personality Disorder? & $27(25.5)$ \\
Yes & $79(74.5)$ \\
No & \\
Additional Diagnoses & $47(44.3)$ \\
Major Depressive Disorder & $21(19.8)$ \\
Bipolar Disorder & $56(52.8)$ \\
Anxiety Disorder & $5(4.7)$ \\
Schizophrenia Spectrum Disorder & $32(30.2)$ \\
Post-Traumatic Stress Disorder & $12(11.3)$ \\
Obsessive Compulsive Disorder & $17(16.0)$ \\
Eating Disorder & $19(17.9)$ \\
Attention-Deficit/Hyperactivity Disorder & $3(2.8)$ \\
Oppositional Defiant Disorder & $1(0.9)$ \\
Conduct Disorder & $26(24.5)$ \\
Substance Use & $5(4.7)$ \\
Other & $8(7.5)$ \\
No other diagnoses &
\end{tabular}


Table 4

Caregiving Relationship Details

\begin{tabular}{lc}
\hline Aspect & $n(\%)$ or $M(S D)$ \\
\hline Length of caregiving relationship (in years) & $13.02(8.92)$ \\
Years since first personality disorder diagnosis & $5.16(5.56)$ \\
Hospitalizations in past 12 months & $1.33(2.03)$ \\
Relationship to care-receiver & \\
Biological parent & $46(43.4)$ \\
Adoptive parent & $3(2.8)$ \\
Child & $4(3.8)$ \\
Sibling & $2(1.9)$ \\
Friend & $1(0.9)$ \\
Spouse & $32(30.2)$ \\
Unmarried Partner & $15(14.2)$ \\
Other & $2(1.9)$ \\
Yes & $93(87.7)$ \\
No & $12(11.3)$ \\
Yes & \\
No & $36(34.0)$ \\
Receive assistance with caregiving? & $70(66.0)$ \\
\hline
\end{tabular}

\section{Measures}

\section{Background variables}

Demographics. Demographic details were gathered through self-report items about the caregivers' age, gender, ethnicity, education level, and employment status. Respondents were also asked to provide similar information about the care-receiver (see Appendix B).

Caregiving relationship. Participants were asked a series of self-report questions about their caregiving relationship. These included the duration of caregiving, their relationship to the care-receiver, whether they reside with the care-receiver, and whether 
they identify as the care-receiver's primary caregiver. Participants were also asked to provide information about their loved ones' diagnosis, including comorbidities, when the care-receiver was diagnosed, and the number of hospitalizations in the past year. This information is consistent with past studies examining the experiences of personality disorder caregivers (Bailey \& Grenyer, 2014; Goodman et al., 2011; see Appendix C).

Problems with services. Caregivers' perceptions of past problems with services were measured by the Problems with Services subscale of the Experience of Caregiving Inventory (ECI; Szmukler et al., 1996; see Appendix D). The ECI is a 66-item self-report measure of caregivers' appraisals of their experiences with a variety of caregiving stressors. The measure has 10 subscales, aimed at both positive and negative aspects of caregiving. However, not all of the subscales were administered, for brevity's sake. The measure asks caregivers how often they have thought about a specific stressor in the past month, which is rated on a 5-point Likert scale from 0 (never) to 4 (nearly always). The ECI has shown construct validity under a stress-coping model; ratings on the negative ECI scales significantly predicted psychological distress in both community carers and those caring for recently discharged people with schizophrenia (Szmukler et al., 1996). These findings were replicated in another study, which also showed that more than a third of the variance in negative ECI ratings could be accounted for by caregivers' stressors, social support, and service use (Joyce, Leese, \& Szmukler, 2000). Although the scale was originally based on the experiences of those caring for patients with schizophrenia and has not yet been used with caregivers of people with personality disorders, the ECI has performed similarly with caregivers of people with other psychological conditions, including anorexia nervosa (Treasure et al., 2001). The wording of the items was altered 
slightly; the original items refer to the care-receiver by male pronouns (e.g., "his illness"; Szmukler et al., 1996, p. 141). Where relevant, this was changed to "your loved one" (e.g. "your loved one's illness") to make the items more widely applicable.

The ECI-Problems with Services subscale contains eight items (see Appendix D). An example item is, "How often in the past month have you thought about how mental health professionals do not take you seriously?" The ECI-Problems with Services subscale has shown high internal consistency, with a Cronbach's $\alpha$ of .90 (Szmukler et al., 1996). This is consistent with the current investigation, in which the ECI-Problems with Services subscale had a Cronbach's $\alpha$ of .92 . Past research has supported the use of the ECI-Problems with Services subscale independently of the other subscales (Harvey et al., 2002).

Stigma. The ECI-Stigma subscale (Szmukler et al., 1996; see Appendix D) was used to examine participants' appraisals of experiencing stigma. The ECI-Stigma subscale has five items; an example is, "How often in the past month have you thought about feeling unable to tell anyone about your loved one's illness?” The ECI-Stigma subscale has shown good internal consistency; the original developers found a Cronbach's $\alpha$ of .82 (Szmukler et al., 1996). Similarly, the ECI-Stigma subscale had a Cronbach's $\alpha$ of .82 in the current study. Past research has supported the validity of the ECI-Stigma subscale when used apart from the other subscales (Muralidharan, Lucksted, Medoff, Fang, \& Dixon, 2014).

\section{Primary stressors.}

Interpersonal problems. The extent of the care-receiver's interpersonal problems was measured using the Inventory of Interpersonal Problems - Personality Disorder 
Scales (IIP-PD; Pilkonis, Kim, Proietti, \& Barkham, 1996; see Appendix E). The IIP-PD was based on the original Inventory of Interpersonal Problems (IIP; Horowitz, Rosenberg, Baer, Ureño, \& Villaseñor, 1988). The IIP was developed to identify sources of interpersonal distress for therapy clients. Other versions have been constructed from the original pool of items, including the IIP-PD. The IIP-PD was developed to identify interpersonal problems that distinguish between those with and without personality disorders, as well as between those with Cluster B and C personality disorders (Pilkonis et al., 1996). Although the latter objective was largely unsuccessful due to the substantial overlap between the clusters and their associated interpersonal problems, the authors indicated that the IIP-PD is able to "explicate the interpersonal dilemmas associated with personality disorders" (Pilkonis et al., 1996, p. 365).

The IIP-PD is a self-report measure, composed of 47 items and five subscales: interpersonal sensitivity (11 items; example: "I am too sensitive to rejection"), interpersonal ambivalence (10 items; "It is hard for me to take instructions from people who have authority over me"), aggression (7 items; "I argue with other people too much"), need for social approval (9 items; "I worry too much about disappointing other people") and lack of sociability (10 items; "It is hard for me to socialize with other people"). Participants are asked to rate how distressful the problem is on a 5-point Likert scale from 0 (not at all) to 4 (extremely). The IIP-PD subscales have generally shown good internal consistency, with Cronbach's $\alpha$ ranging from .83 (interpersonal sensitivity and interpersonal ambivalence) to .90 (aggression and need for social approval; Pilkonis et al., 1996). The scale developers demonstrated validity by distinguishing those rated by clinicians to have personality disorders from those without; these results were also cross- 
validated in several samples, including in people with depression and with BPD (Pilkonis et al., 1996). Moreover, the construct validity of the measure was supported through a confirmatory factor analysis and findings that those who met personality disorder criteria had elevations on the IIP-PD subscales (Stern, Kim, Trull, Scarpa, \& Pilkonis, 2000).

The IIP-PD was modified for the purposes of the study; the measure is originally in a self-report format (e.g. "It is hard for me to ignore criticism from other people"), but was made into an informant-report instrument (e.g. "It is hard for your loved one to ignore criticism from other people"). This allowed caregivers to rate their loved ones' behaviour on items designed specifically to measure the types of interpersonal problems associated with personality disorders. There is support in the literature for the validity of informant-report versions of IIP measures. Hill, Zrull, and McIntire (1998) had participants complete self- and peer-report versions of the IIP-64, another version created from the original pool of IIP items. They found moderate correlations between the selfand peer-reports, and that participants were more likely to underreport externalizing problems, but had greater awareness of internalizing problems, compared to peer-reports. Another study found a high correspondence between peer-rated personality disorder traits and peer-ratings on the IIP (Clifton, Turkheimer, \& Oltmanns, 2005). Finally, Pagan, Eaton, Turkheimer, and Oltmanns (2006) provided support for the validity of peer-ratings on the IIP, such that peers who were rated as less self-sacrificing, needy, or assertive were less likely to participate in research studies. As such, the IIP-PD items were rewritten to allow caregivers to rate their loved ones' interpersonal problems. In the current study, the informant-report IIP-PD subscales had Cronbach's $\alpha$ ranging between .85 (Interpersonal Sensitivity) and .93 (Aggression and Lack of Sociability). 
Difficult behaviour. As a validity check of the informant-report version of IIPPD, the ECI-Difficult Behaviours subscale (see Appendix D) was administered to measure the caregivers' appraisals of their loved ones' difficult behaviours beyond the interpersonal domain. The ECI-Difficult Behaviours subscale has 8 items, which inquire about behaviour such as irritability, recklessness, and suspicion; for example, "How often in the past four weeks have you thought about your loved one being moody?" It was expected that participants' ratings of their loved ones' interpersonal problems and difficult behaviour would be positively correlated. In past research, elevations on the IIP have been associated with negative affectivity (Tracey, Rounds, \& Gurtman, 1996), as well as impulsivity, mistrust, and aggression (Vittengl, Clark, \& Jarrett, 2003). In the past, the scale has shown strong internal consistency ( $\alpha=.91$; Szmukler et al., 1996), and in the current study the scale had a Cronbach's $\alpha$ of .88. Thus, to check the informantreport version of the IIP-PD and reduce redundancy, scores on this measure were not entered into the final analyses, but rather served as an external validity check of the informant-report version of the IIP-PD. The results of these analyses are presented in the Results section.

Instrumental needs. Caregivers' appraisals of the extent to which the carereceiver depends on them for day-to-day matters were measured with the ECI-Need To Back Up subscale (see Appendix D). The subscale consists of 6 items; an example is, "How often in the past month have you thought about backing up your loved one when they run out of money?" Past investigations of the scale have shown moderate internal consistency ( $\alpha=.76$; Szmukler et al., 1996). This is similar to the current study, in which the subscale had a Cronbach's $\alpha$ of .75. 
Worry. The extent that caregivers worry about their loved one's dependency was measured with the ECI-Dependency subscale (see Appendix D). It has 5 items aimed at caregivers' appraisals of the impact of the care-receiver's dependence. An example item is, "How often in the past month have you thought about how your loved one is always at the back of your mind?" In the past, the subscale has shown strong internal consistency $(\alpha=.87$; Szmukler et al., 1996). However, the current investigation found a somewhat lower Cronbach's $\alpha$ of .72.

\section{Secondary stressors.}

External strains. The impact of caregiving on respondents' family relationships, finances, physical health, and social life were measured using the Caregiver Reaction Assessment scale (CRA; Given et al., 1992; see Appendix F). The CRA is a 24 item selfreport measure with five subscales: Disrupted Schedule (5 items; example: "I have to stop in the middle of my work or activities to provide care"), Financial Problems (3 items; "Caring for my loved one puts a financial strain on me"), Lack of Family Support (5 items; "It is very difficult to get help from my family in taking care of my loved one"), Health Problems (4 items; "It takes all my physical strength to care for my loved one"), and Esteem (7 items, discussed later). Participants rated their agreement with each statement on a 5-point Likert scale from 1 (strongly disagree) to 5 (strongly agree). The CRA has demonstrated construct validity in Dutch caregivers of cancer patients, through correlations with other related constructs, such as changes to social life and overall burden (Nijboer, Triemstra, Tempelaar, Sanderman, \& van der Bos, 1999). Reviews of measures related to caregiving have supported use of the CRA over similar measures (Gelkopf \& Roe, 2014), as well as its strong internal consistency ( $\alpha$ between 
.80 and .90) and validity (Whalen \& Buchholz, 2009). Moreover, the CRA has shown lower inter-scale correlations than similar measures (e.g., Perceived Caregiver Burden scale; Stommel, Given, \& Given, 1990), suggesting that the subscales measure discrete concepts. The question wording was altered slightly; the original items refer to the caregivers" "partner," which was replaced with "loved one," to reflect the fact that caregivers of people with personality disorders may be parents, children, or significant others. The subscales had Cronbach's $\alpha$ ranging from .82 (Financial Problems, Health Problems, and Lack of Family Support) to .83 (Disrupted Schedule).

Mastery. Pearlin and Schooler's (1978) 7-item measure of mastery was used to measure the extent to which caregivers feel they have control over circumstances in their lives (see Appendix G). An example item is, "I have little control over the things that happen to me." Participants rated the items on a 4-point Likert from 1 (strongly disagree) to 4 (strongly agree). However, the items were then reverse-coded, such that higher scores on the measure indicated higher levels of mastery. Past studies have shown the scale to have adequate internal consistency, ranging from $\alpha$ of .77 to .94 (Cairney $\&$ Krause, 2008). In the current study, the scale had a Cronbach's $\alpha$ of .83 .

Role captivity. The Sense of Entrapment subscale from the Perceived Caregiver Burden scale (PCB; Stommel et al., 1990; see Appendix H) was used to measure caregivers' feelings of being trapped in their role as a caregiver. The subscale is part of the larger PCB, which largely overlaps in content with the CRA. As such, only the unique subscale was administered. The subscale has 9 statements, with which caregivers rated their agreement on a Likert scale from 1 (strongly disagree) to 5 (strongly agree). An example item is, "I feel I was forced into caring for my loved one." The original 
developers tested the scale in three samples of caregivers, and found the internal consistency to be strong, with $\alpha$ between .86 and .87 (Stommel et al., 1990). The scale had a Cronbach's $\alpha$ of .92 in the current sample.

Esteem. The CRA Esteem subscale (see Appendix F) was used to measure caregivers' self-esteem related to caregiving. In contrast with the other CRA subscales, the Esteem scale reflects positive experiences, with higher scores indicating a favourable impact of caregiving. An example item is, "I feel privileged to care for my loved one." The subscale has been found to have adequate internal consistency, with a Cronbach's $\alpha$ of .73 (Nijboer et al., 1999). This is consistent with the current study, which found $\alpha=$ .75 .

Gains. The ECI-Positive Personal Experiences subscale (see Appendix D) measured the extent to which caregivers felt they had gained from caregiving. Whereas the CRA Esteem subscale focuses on the gains related specifically to caregiving, the ECIPositive Personal Experiences subscale has a broader focus, including caregivers' sense of inner strength and feelings of competence. The subscale has 8 items; for example, "I have become more confident dealing with others." The original developers of the scale found strong internal consistency, with a Cronbach's $\alpha$ of .86 (Szmukler et al., 1996). The ECI-Positive Personal Experiences had a Cronbach's $\alpha$ of .85 in the current study.

Help-seeking intentions. Participants' intentions to seek help from formal and informal sources for emotional, instrumental, and informational support were measured using the General Help-Seeking Questionnaire (GHSQ; Deane, Wilson, \& Ciarrochi, 2001; see Appendix I). The GHSQ is a matrix-style measure of help-seeking intentions that can be modified to fit the sources of help and types of problems being studied. The 
GHSQ has shown construct and predictive validity. For instance, help-seeking intentions measured by the GHSQ were positively correlated with actually seeking help from the specified source within three weeks, in an adolescent sample (Wilson et al., 2005). GHSQ intentions have also been related past to help-seeking behaviour, such that having previously sought professional help was positively associated with intentions to seek professional help again, and negatively associated with intentions to seek help from family (Ciarrochi \& Deane, 2001). Moreover, positive ratings of past treatment have been associated with higher help-seeking intentions (Cusack et al., 2004). The GHSQ has demonstrated reliability, with adequate internal consistency for intentions to seek help for concerns such as suicidal thoughts and personal emotional problems (Cronbach's $\alpha$ ranging from .70 to .83 ), as well as test-retest reliability ranging from .86 to .88 (Wilson et al., 2005). Although the GHSQ has not yet been used with caregivers, it has been used with diverse groups, including male therapy clients (Cusack et al., 2004) and adolescents (Wilson et al., 2005).

In its general form, the measure asks participants, "If you were having [problemtype], how likely is it that you would seek help from the following people?" and lists potential sources of help (Wilson et al., 2005, p. 19). In the current study, three "problem-types" were specified: (1) "problems dealing with your emotions related to caregiving," (2) "problems dealing with the day-to-day tasks related to caregiving," and (3) "problems finding information related to caregiving." These questions correspond to emotional, instrumental, and informational help, respectively. The following seven formal help sources were supplied for each problem-type: psychologist, psychiatrist, social worker, family doctor, nurse, professional-led support group, and emergency 
services/hospital. The following seven informal help sources were also supplied: family, friend, co-worker, neighbour, church member, peer-led support group, and online source. Participants also had the option to indicate that they would not seek help from anyone. The sources were selected based on past research about caregivers' preferences for and uses of a variety of help sources (Bailey \& Grenyer, 2015; Ferriter \& Huband, 2003; Hill, Shepherd, \& Hardy, 1998; Lawn \& McMahon, 2015). Participants were asked to rate the likelihood that they would seek help for each problem type from each source on a Likert scale from 1 (extremely unlikely) to 7 (extremely likely). When the help types were divided into formal and informal sources, the scales showed internal consistency ranging between $\alpha=.70$ (informal informational support) and .83 (formal instrumental support). However, when endorsements of the help types were averaged with formal and informal sources combined, the scales showed higher reliability, with $\alpha$ between .83 and .84 .

Psychological distress. The 10-item form of the Kessler Psychological Distress scale (K10; Kessler et al., 2002; see Appendix J) was used to measure psychological distress. The K10 was developed as a screening tool to identify depression and anxiety symptoms in the general population (Kessler et al., 2002). An example item is, "During the last 30 days, about how often did you feel depressed?" Participants rated each item on a 5-point Likert scale from 1 (none of the time) to 5 (all of the time). The scale has been found to accurately discriminate DSM-IV affective and anxiety disorders, with incremental validity over measures such as the General Health Questionnaire and Short Form Health Survey (Andrews \& Slade, 2001). The K10 has been used in populationlevel studies in Australia and the United States (Kessler et al., 2002). The K10 was also administered in a nationally representative Canadian survey, and found to accurately 
identify current depression and agree closely with Composite International Diagnostic Interview for depression (Cairney, Veldhuizen, Wade, Kurdyak, \& Streiner, 2007). It has previously been used with caregivers of young people with first episode psychosis, wherein psychological distress was significantly related to coping style (Cotton et al., 2013). A previous investigation found that the scale had excellent internal consistency ( $\alpha$ $=.93$; Kessler et al., 2002). Similarly, the current study found a Cronbach's $\alpha$ of .92 .

\section{Procedure}

The study procedure and all recruitment pathways were reviewed and cleared by the University of Windsor REB prior to being implemented (see Appendix K for the ethics clearance certificate). After contacting the researcher and obtaining the direct link, or using the direct link if it was provided with the study flyer, participants accessed the survey online, where it was hosted by FluidSurveys. Participants could access the study when and wherever it was convenient for them. The first page of the survey provided general information and encouraged the participants to complete the survey in one sitting, in a quiet, private location where they would not be distracted or interrupted. The next page showed the consent form (see Appendix L), which outlined the study's purpose and participants' rights, including that to withdraw from the survey at any time. At the bottom of the page, participants indicated their consent by clicking a button reading, "I consent to participate," which launched the survey. If participants did not consent, they were taken to a closing page, which thanked them for their time, but did not provide additional information about the study or compensation.

The questionnaires each appeared on their own page of the survey, to ensure continuity of the measures' instructions and rating scales. The ECI and IIP-PD items 
were each split across two pages, to keep the item anchors in view and the number of questions on each page approximately equal. The survey was constructed such that the demographic questionnaire and caregiving history questions always appeared first, in that order, but the remaining measures appeared in a randomized order, to avoid any priming or order effects. Both pages of the ECI and IIP-PD appeared consecutively. The study was pilot tested by approximately 20 people from the University of Windsor Psychology Department and the community, which revealed that the study required approximately 30 minutes to complete. This information was provided on the study flyer, information page, and consent form, so that participants could plan to have enough time to complete the survey in one sitting.

At the end of the survey, participants were shown a closing information page, with additional details about the purpose of the study, instructions for entering the compensation draw, and a request that they share the study information with other potential participants. The researcher's contact information and a list of community resources were also provided on the final page of the survey. To enter the compensation draw, participants were asked to send an email to an address created specifically for the study, requesting that their name be added to the draw. This procedure kept participants' email addresses separate from their responses, to ensure that there was no way to connect individual responses with participants' identities. 


\section{CHAPTER III}

\section{DATA ANALYSIS}

\section{Hypothesis 1 - Partial Least Squares Path Modelling}

Hypotheses 1a through 1g were tested using Partial Least Squares Path Modelling

(PLS-PM). PLS-PM is a statistical modelling technique that allows researchers to represent and examine the interplay of hypothetical constructs, called latent variables. In PLS-PM, latent variables are represented as weighted sums of observed or measured variables, often called indicators (McIntosh, Edwards, \& Antonakis, 2014). Once calculated, hypotheses about the relations between latent variables can be tested. In the current study, the levels of stressors outlined in the Stress Process Model, including background variables, primary stressors, and secondary stressors, were treated as latent variables. The stressors that fall under each level (such as family, health, schedule, and financial strain in the case of secondary stressors) were modelled as indicators of their respective latent variables. PLS-PM allows researchers to simultaneously specify on the one hand a measurement model, which represents the correspondence between a block of indicators and the latent variable they are hypothesized to represent, and on the other hand a structural model, which models the hypothesized relations among the latent variables (Chin, 1998; Haenlein \& Kaplan, 2004). PLS-PM analyses also provide weight relations that can be used to estimate case values, or individual scores, on the latent variables (Haenlein \& Kaplan, 2004).

PLS-PM is an alternative to Structural Equation Modelling (SEM), with different statistical assumptions and goals that make it an appropriate analysis for this study. Whereas SEM analyses are based on covariance matrices, PLS-PM is variance-based 
(Haenlein \& Kaplan, 2004). Similarly, the goal of SEM is to replicate the sample covariance matrix as best as possible with a hypothesized model; in PLS-PM, the focus shifts to maximizing the amount of variance in the dependent variables that is explained by the model (Chin, 1998). Furthermore, SEM and PLS-PM differ in the way the relations within the measurement model (those between the indicators and their latent variables) and within the structural model (those between latent variables) are estimated. SEM analyses typically use a Maximum Likelihood (ML) algorithm to compare the observed and model-implied covariance matrices, which introduces strict assumptions. Namely, to interpret the significance tests associated with ML, multivariate normality must be satisfied and a sample size of upwards of 200 is required (Kline, 2016). In comparison, PLS-PM uses Ordinary Least Squares (OLS), which is akin to more common regression analyses (Chin, 1998). A final difference between PLS-PM and SEM techniques is the way in which latent variables are estimated mathematically. In SEM, latent variables are specified as the cause of indicator variables and error is modelled to be associated with the indicators (Kline, 2016). In contrast, PLS-PM models are specified such that the indicators cause the latent variables and error is not explicitly modelled (McIntosh et al., 2014).

As mentioned, latent variables are represented in PLS-PM as weighted sums, or linear composites, of the indicators (Chin, 1998). The weights are assigned so as to maximize two criteria: the amount of variance accounted for in the indicators, and the amount of variance explained in the dependent latent variables (i.e., those affected by other latent variables in the model). To achieve this, the indicators are first all given equal weights. Then, an iterative approach adjusts the weights in relation to both the 
measurement model (i.e., the relative weighting of the indicators within a given block) and the structural model (i.e., the relations among the latent variables in the model; Chin, 1998; Haenlein \& Kaplan, 2004). This procedure is repeated until a convergence criterion is satisfied, at which point the weights provide an optimal combination of the indicators in making up each latent variable.

In representing latent variables, researchers must determine whether to specify reflective or formative indicators. Reflective indicators, called Mode A in PLS-PM analyses, suggest the indicator variables within a block are all caused by the same underlying construct, such that changes in the latent variable should result in similar changes across all of the indicators (Chin, 1998). The latent variable is thus viewed as giving rise to the scores on the observed variables and the objective of the analysis is often to explain or predict the observed variables. In contrast, formative indicators are conceptualized as a group of variables that combine to form the latent variable, such that changes in the latent variable may not result in similar changes across each of the indicators (Chin, 1998; Haenlein \& Kaplan, 2004; McIntosh et al., 2014). In this approach, referred to as Mode B in PLS-PM analyses, indicators within a block may correlate with each other, but are not required to do so (Haenlein \& Kaplan, 2004). Haenlein and Kaplan (2004) offer a concept of 'life stress' as an example of a latent variable that could be comprised of job loss, divorce, and being involved in an accident all modelled as formative indicators. Changes in any one of the indicator variables could affect one's level of life stress and changes in one indicator need not affect the others. Whereas reflective indicators all represent the same latent construct, formative indicators 
can combine to represent looser categories or constructs, such as (and certainly relevant to the present study) levels of caregiving stress.

PLS-PM is not without its disadvantages (Chin, 1998; Haenlein \& Kaplan, 2004). A major advantage of SEM is the ability to explicitly model error as affecting the indicators, which allows the latent variables to be pure representations of the underlying construct (unbiased by measurement error). In contrast, error is not explicitly modelled in PLS-PM, and the latent variables are simply weighted composites of the observed variables, so the latent variables in PLS-PM are biased by measurement error (Chin, 1998). Because of this, PLS-PM models are thought to provide truly consistent estimates only as the number of indicators and sample size increase infinitely, a problem referred to as "consistency at large" (Haenlein \& Kaplan, 2004, p. 292). However, using composites to model latent variables can adjust somewhat for unreliability, by giving more weight to more reliable indicators (McIntosh et al., 2014). A second drawback to using PLS-PM is that the technique generally lags behind SEM in terms of model evaluation (McIntosh et al., 2014). To evaluate the PLS-PM model in this study, the $\mathrm{R}^{2}$ values for dependent latent variables were examined, to determine the model's predictive ability (Chin, 1998). Additionally, the relative weights the indicators received in making up the latent variables were considered, as well as the strength and directions of the paths between latent variables. Bootstrapping - an empirical resampling technique - was also used to examine the stability of the model estimates, which relates to the external validity of the model (Chin, 1998).

PLS-PM was chosen to analyze the first set of hypotheses in the current study for several reasons. It places relatively few demands on the measurement scale of the data, 
sample size, and distributional assumptions, relative to other techniques (Chin, 1998;

Haenlein \& Kaplan, 2004). For instance, because the iterative procedure used to estimate parameters analyzes parts of the model separately, an adequate sample size is required only in relation to the largest single computation, such as the block with the largest number of formative indicators, rather than the whole model (Chin, 1998). Some authors have argued that the utility of PLS-PM in very small samples has been overstated and that more simulation studies are needed (McIntosh et al., 2014). Yet, SEM is regarded as a large-sample technique, often requiring sample sizes upward of 200 to return reliable estimates (Kline, 2016), making it inappropriate for use with the current sample. Additionally, PLS-PM does not make assumptions about the distributions of variables, nor the statistical independence of cases, as correlations among cases are not taken into account (Chin, 1998). To interpret significance tests associated with SEM analyses, strict (and often untenable) assumptions must be satisfied (Kline, 2016).

PLS-PM also allows formative indicators to be modelled, which is the appropriate choice for these analyses, given that the Stress Process Model levels of background variables, primary stressors, and secondary stressors are best modelled as being formed by the variables that fall under those categories (rather than as giving rise to the individual stressors). PLS-PM is appropriate for the current model because it provides information about the weight each indicator gets in making up its latent variable (Chin, 1998), which indicates the relative importance of each stressor in making up its level of the Stress Process Model. Additionally, PLS-PM analyzes the strength and directions of the relations between the latent variables, which corresponds to hypotheses 1a through 1g. Finally, the amount of variance accounted for in the dependent latent variables, 
including psychological distress in the current model, is calculated in PLS-PM analyses (Chin, 1998).

\section{Hypothesis 2 - Repeated Measures Analysis of Variance}

As participants rated their likelihood of seeking help for each problem-type and source of help, a 2 (Source: formal vs. informal) by 3 (Type: emotional vs. informational vs. instrumental) factorial repeated measures analysis of variance (RANOVA) was used to examine differences in help-seeking intentions. Planned contrasts were used to test the specific hypotheses. Hypothesis 2a was tested by comparing endorsements of formal versus informal support when looking individually at emotional, informational, and instrumental types of support. As it was hypothesized that caregivers would prefer informal, rather than formal, support for informational and instrumental support, significant mean differences in favour of informal support were expected for those support types. Similarly, as it was hypothesized that caregivers would indicate no preference for formal versus informal emotional support, a significant difference for this comparison was not expected. It was also hypothesized that, overall, caregivers would have higher intentions to seek emotional and informational support, compared to instrumental support (hypothesis $2 \mathrm{~b}$ ). This was examined by contrasting intentions to seek emotional versus instrumental support, and informational versus instrumental support, with formal and informal sources combined. Significant differences were expected between emotional and instrumental support, and between informational and instrumental support, with lower intentions to seek instrumental support in both comparisons. 


\section{CHAPTER IV}

\section{RESULTS}

\section{Data Cleaning and Preparation}

The dataset was cleaned using SPSS version 20, so that all included responses met the eligibility criteria, completed the survey within a reasonable amount of time, and did not appear to be outliers on the model variables. In terms of the eligibility criteria, 42 cases were removed, with 38 of those failing to endorse that their loved one had been diagnosed with a personality disorder. The mean survey completion time for the overall dataset was 35.84 minutes $(S D=76.92)$. Survey duration times were converted into standardized ( $z$ ) scores and a cut-off of \pm 2.5 was used to identify outliers. Through this method, 2 cases were removed for taking an abnormally long time. An additional 7 cases were removed that had durations of less than 10 minutes, which corresponded to less than 3 seconds per question. After this procedure, the new mean completion time was 27.40 minutes $(S D=17.91)$. After removing cases as outlined above, a remaining 5 cases had more than $15 \%$ missing data, so they were removed. The remaining missing data were handled using Expectation Maximization imputation on the item-level data. Little's MCAR test was not significant, $\chi^{2}(6726)=5.82, p=1.00$, indicating that the missing data could be classified as missing completely at random. Potential outliers on the scale scores were identified using Mahalonobis distance (cut off value of 55.47, corresponding to 27 degrees of freedom and $\alpha=.001$ ) and Cook's distance (cut-off value of 1; Cohen, Cohen, West, \& Aiken, 2003). One potential outlier was identified, but after inspection it was not deemed problematic and was left in the dataset. The final sample size was 106. See Table 5 for descriptive statistics. 
Table 5

Descriptive Statistics

\begin{tabular}{|c|c|c|c|c|}
\hline Variable & $n(\%)$ or $M(S D)$ & Possible Range & $\alpha$ & Tolerance \\
\hline \multicolumn{5}{|l|}{ Caregiver Gender } \\
\hline Male & $28(26.4)$ & - & - & - \\
\hline Female & $77(72.6)$ & - & - & - \\
\hline Other & $1(0.9)$ & & & \\
\hline \multicolumn{5}{|l|}{ Residence Status } \\
\hline With Care-Receiver & $71(67.0)$ & - & - & - \\
\hline Not with Care-Receiver & $35(33.0)$ & - & - & - \\
\hline \multicolumn{5}{|l|}{ Kinship } \\
\hline Biologically Related & $52(49.1)$ & - & - & - \\
\hline Not Biologically Related & $54(51.9)$ & - & - & - \\
\hline Caregiver Age & $46.84(10.93)$ & - & - & - \\
\hline Problems with Services a & $13.94(8.85)$ & $0-32$ & .92 & .78 \\
\hline Stigma $_{a}$ & $9.45(5.01)$ & $0-20$ & .82 & .87 \\
\hline Interpersonal Sensitivity & $2.86(0.74)$ & $0-4$ & .85 & .36 \\
\hline Interpersonal Ambivalence ${ }_{b}$ & $2.46(1.07)$ & $0-4$ & .92 & .40 \\
\hline Aggression $_{b}$ & $2.38(1.21)$ & $0-4$ & .93 & .36 \\
\hline Need for Social Approval $_{b}$ & $2.17(1.00)$ & $0-4$ & .88 & .73 \\
\hline Lack of Sociability & $2.24(1.15)$ & $0-4$ & .93 & .73 \\
\hline Worryb & $13.01(3.83)$ & $0-20$ & .72 & .50 \\
\hline Instrumental Needs $b$ & $13.84(5.29)$ & $0-24$ & .75 & .57 \\
\hline Health Strains $s_{c}$ & $3.21(0.95)$ & $1-5$ & .82 & .35 \\
\hline Family Strains $_{\mathrm{c}}$ & $2.93(0.97)$ & $1-5$ & .82 & .72 \\
\hline Financial Strains $_{c}$ & $3.42(1.11)$ & $1-5$ & .82 & .71 \\
\hline Schedule Strains $_{c}$ & $3.71(0.90)$ & $1-5$ & .83 & .43 \\
\hline Mastery $_{c}$ & $18.95(3.82)$ & $7-28$ & .83 & .78 \\
\hline Role Captivity $_{c}$ & $3.34(0.97)$ & $1-5$ & .92 & .22 \\
\hline Esteem $_{c}$ & $3.19(0.72)$ & $1-5$ & .75 & .29 \\
\hline Gains $_{c}$ & $16.22(6.51)$ & $0-32$ & .85 & .90 \\
\hline \multicolumn{5}{|l|}{ Help-Seeking: Emotional } \\
\hline Overall $_{d}$ & $3.53(1.13)$ & $1-7$ & .83 & .30 \\
\hline Informal $_{e}$ & $3.50(1.16)$ & $1-7$ & .70 & .31 \\
\hline Formale & $3.56(1.43)$ & $1-7$ & .78 & .37 \\
\hline \multicolumn{5}{|l|}{ Help-Seeking: Instrumental } \\
\hline Overall ${ }_{d}$ & $3.34(1.22)$ & $1-7$ & .84 & .39 \\
\hline Informal $_{e}$ & $3.25(1.22)$ & $1-7$ & .72 & .34 \\
\hline Formale & $3.44(1.59)$ & $1-7$ & .83 & .42 \\
\hline \multicolumn{5}{|l|}{ Help-Seeking: Informational } \\
\hline Overall $_{d}$ & $3.64(1.13)$ & $1-7$ & .83 & .38 \\
\hline Informal $_{\mathrm{e}}$ & $3.26(1.10)$ & $1-7$ & .70 & .32 \\
\hline Formal $_{\mathrm{e}}$ & $4.02(1.45)$ & $1-7$ & .78 & .34 \\
\hline Psychological Distress & $26.36(8.79)$ & $10-50$ & .92 & - \\
\hline
\end{tabular}


Note. Variables with the same subscript were tested for tolerance together.

IIP-PD check. As a validity check of the rewritten IIP-PD scales, bivariate correlations were computed between the IIP-PD informant-report subscales and the ECIDifficult Behaviours subscale. The correlations ranged from $r=.11$ (Need for Social Approval) to $r=.68$ (Interpersonal Sensitivity), indicating that the informant-report IIPPD subscales were positively correlated with the ECI-Difficult Behaviours, as expected. These results support the use of the IIP-PD subscales in an informant-report format.

\section{Assumptions - PLS-PM.}

Predictor specification. Although PLS-PM does not make assumptions about the distribution of the variables or independence of the observations, one of its foremost assumptions is predictor specification - the assumption that residuals (or error terms) are not correlated across different parts of the model (Wold, 1985). Within the structural model, it is assumed that the latent variables have uncorrelated residuals with each other and the residuals of dependent latent variables are uncorrelated with the predictor latent variables (Sellin, 1995). Similarly, it is assumed that, in the measurement model, indicator residuals are uncorrelated with both the latent variables and their residuals (Sellin, 1995). Although there is no formal test for predictor specification, Haenlein and Kaplan (2004, p. 292) suggest that the assumption "can be considered as fulfilled in most cases."

Absence of multicollinearity. Chin (1998) indicates that it is important to check for multicollinearity when modelling formative indicators, given that the latent variables are formed through multiple regression analyses. As such, tolerance was examined within each block of indicator variables. A cut-off of tolerance values not less than .10 is 
commonly used (Cohen et al., 2003). The tolerance values are presented in Table 5. Notably, none fell below the cut-off of .10, indicating that the assumption of absence of multicollinearity was satisfied. However, two indicators from the block of secondary stressors had relatively low tolerance levels, namely .22 for role captivity and .29 for esteem. Moreover, these variables had a bivariate correlation of -.83 , suggesting they measured nearly opposite concepts.

Sample size. An adequate sample size in PLS-PM is calculated in reference to the largest single computation, such as the block with the largest number of indicators. In the model, the largest block (the secondary stressors) had eight indicators. Chin (1998) provides a heuristic of 10 cases per predictor, which indicates that the current sample size is appropriate for the analyses. A power analysis with the program $\mathrm{G}^{*}$ Power, specifying a medium effect size $\left(f^{2}=.15\right), \alpha=.05$, and power $=.80$, revealed an ideal sample size of 109, indicating the current sample size is likely sufficient.

\section{Assumptions - RANOVA.}

Sphericity. RANOVA assumes that the variances of the difference scores for each pair of conditions are equal in the population (Pituch \& Stevens, 2016), an assumption referred to as sphericity. This was inspected using Mauchly's W, which tests the null hypothesis that the variances are not equal; when significant, the assumption is not tenable. As there were only two conditions for help source (i.e. formal versus informal), sphericity was not tested for that effect. For the effect of help type, the assumption of sphericity was supported $W(2)=.949, p=.07$. Sphericity was also supported for the interaction term between help source and type, $W(2)=.972, p=.23$. Thus, the statistics reported below reflect that sphericity was assumed and no corrections were applied. 
Normality. Another assumption of RANOVA is that the scores in each cell being compared (in this case, each help type by source combination) are normally distributed. The skewness and kurtosis values for all cells fell between \pm 2 and \pm 3 , respectively, indicating normality. The Shapiro-Wilk test of normality was used as a formal test, following indications that it is more powerful than other tests of normality, across both distribution styles and sample sizes (Razali \& Wah, 2011). The Shapiro-Wilk test was not statistically significant for any of the cells, with the exception of formal instrumental support $(p=.006)$. These results generally support the assumption of normality. Finally, inspection of the scale histograms revealed that the scales each approximated a normal distribution. As such, it was determined that the assumption of normality was satisfied.

\section{Hypothesis 1 - Stress Process Model}

Model specification. The PLS-PM analyses were conducted using the plspm package in R Studio, version 1.0.136. The categorical variables were dummy coded as follows: gender (male $=0$, female $=1$ ), kinship (biologically related $=0$, biologically unrelated $=1$ ), and residence status (does not reside with care-receiver $=0$, resides with care-receiver $=1$ ). The plspm program automatically standardizes all continuous variables, such that they have a mean of 0 and a variance of 1 . In defining the measurement model, the background variables outlined by the Stress Process Model were split into two blocks, to better reflect the hypotheses. The latent variable herein referred to as the Background Variables was represented by caregiver age, caregiver gender, kinship, and residence status, whereas the latent variable named Caregiving History was composed of problems with services and stigma. The Primary Stressors latent variable was comprised of five care-receiver interpersonal problems (sensitivity, ambivalence, 
aggression, need for social approval, and lack of sociability), as well as their level of instrumental needs and the caregiver's worry about their loved one. The Secondary Stressors latent variable was formed by health, family, schedule, and financial strains, as well as esteem, gains, mastery, and role captivity. Help-Seeking Intentions was formed by emotional, instrumental, and informational help-seeking intentions, combined across informal and formal sources. Finally, psychological distress was the single indicator used to represent the Psychological Distress latent variable.

The latent variables were modelled with formative indicators, except for HelpSeeking Intentions and Psychological Distress, which were modeled with reflective indicators. The structural model was specified to reflect hypotheses 1a through 1g, as elaborated below. As mentioned, PLS-PM adjusts the weighting of indicators with reference to the indicators making up the block (i.e. the measurement model), as well as the other latent variables in the model (i.e. the structural model). Adjustments made in reference to the structural model were done so using the path scheme, which takes into account the strength and direction of the structural model paths (Vinzi, Trinchera, \& Amato, 2010).

\section{Initial model.}

Measurement model. PLS-PM models are typically examined in a two-step process, wherein the measurement model is examined prior to the structural model (Chin, 2010). This ensures that the measurement model adequately represents the latent variables, before interpreting the relations among them. The correspondence between indicators and their latent variable can be described in terms of either the indicators' loadings or their weights. Indicator loadings represent the correlation between the 
indicator and its latent variable; the squared loading value reflects the amount of overlapping variance (Chin, 2010). In contrast, an indicator's weight is its regression coefficient in calculating its latent variable. For formative indicators, these represent multiple linear regression weights, but for reflective indicators they are simple linear regressions (Sanchez, 2013). Although indicator weights and loadings can both be used to interpret the measurement model, different approaches must be taken to assess the model's adequacy depending on whether formative or reflective indicators are used.

Reflective block. The Help-seeking Intentions latent variable was modelled with reflective indicators. Chin (2010) recommends that for reflective blocks, researchers examine the consistency and reliability among the indicators, to ensure they reflect a unidimensional construct. The square root of the average variance extracted (AVE) for Help-Seeking Intentions was .829 , which indicates that the latent variable accounted for 82.9\% of the variance in the indicators. This is well above the cut-off of AVE greater than .50 suggested by Chin (2010). The block showed strong internal consistency, with $\alpha$ of .90. Finally, the indicators' loadings ranged between .89 and .93 . As mentioned, the squared loading value indicates the amount of shared variance between an indicator and its latent variable. Thus, the indicators all had more than $75 \%$ overlapping variance with the Help-Seeking Intentions latent variable. Chin (2010) notes that when indicators within a block all have high loadings that are within a narrow range of each other, this provides support for the convergent validity of that block. Overall, the Help-Seeking Intentions latent variable appeared to be adequately represented by its indicators.

Formative blocks. Götz, Liehr-Gobbers, and Krafft (2010) suggest examining the weights formative indicators receive in making up their latent variables, to determine 
their relative contributions to the construct, rather than examining their loadings. The initial model appeared to represent the latent variables fairly well, but a few of the weights made the latent variables difficult to interpret. Specifically, in making up the Primary Stressors, the care-receiver's need for social approval stood out from the other indicators by having a modest negative weight. This was unusual, as the other primary stressors all had positive weights, suggesting that higher levels of the stressors contributed to higher scores on the latent variable. For the Secondary Stressors, gains and esteem both had relatively strong, positive weights, suggesting that positive experiences contributed to higher scores on the Secondary Stressors latent variable. As these weights in the initial model made the latent variables hard to interpret, the measurement model was modified before interpreting the structural model.

Modification. Given the aforementioned concern about multicollinearity between role captivity and esteem, role captivity was removed from the block of Secondary Stressors. This produced more interpretable weights within the block, as mastery and esteem received negative weights, whereas stressors such as schedule and family strain had positive weights. This pattern suggests that external strains contribute to higher levels of secondary stressors, but positive experiences or capacities, such as a higher sense of mastery, can lessen the impact of the secondary stressors. Additionally, the weight for care-receivers' need for social approval in making up the Primary Stressors became much smaller. When modelling formative blocks, it is recommended that indicators be eliminated only on the basis of concerns about multicollinearity (Götz et al., 2010). Moreover, it also is recommended that indicators not be removed on the basis of having a small relative weight, as the indicator may still hold theoretical importance in 
making up its latent variable (Götz et al., 2010). Thus, no other modifications were made to the measurement model.

Structural model and modification. Examination of the structural model, with the modified measurement model described above, revealed path coefficients that were generally in the hypothesized directions, as well as moderate explanatory power of the model. The non-parametric $\mathrm{R}^{2}$ value is interpreted as the percentage of variance that is explained in dependent latent variables by the latent variables specified to predict them. The model produced an $\mathrm{R}^{2}$ of .085 for the Primary Stressors, .566 for the Secondary Stressors, .062 for Help-Seeking Intentions, and .420 for Psychological Distress. In other words, the model accounted for $56.6 \%$ of the variance in the Secondary Stressors, and $42 \%$ in the caregivers' level of psychological distress, but much less in the other latent variables. Given the relatively low variance accounted for in the Primary Stressors, and because the variables that form the Caregiving History variable (stigma and problems with services) are considered to be background variables under the Stress Process Model, a path was added from Caregiving History to the Primary Stressors. This increased the amount of variance explained in the Primary Stressors by 33.9\%. No other paths were added.

\section{Final model.}

Measurement model. Refer to Figure 1 for a diagram of the final PLS-PM model. As no modifications were made to the Help-Seeking Intentions indicators, the AVE, Cronbach's $\alpha$, and loadings of the indicators remained the same as those reported for the initial model. Thus, the three types of support appeared to adequately represent respondents' help-seeking intentions. In forming the Background Variables, caregiver 


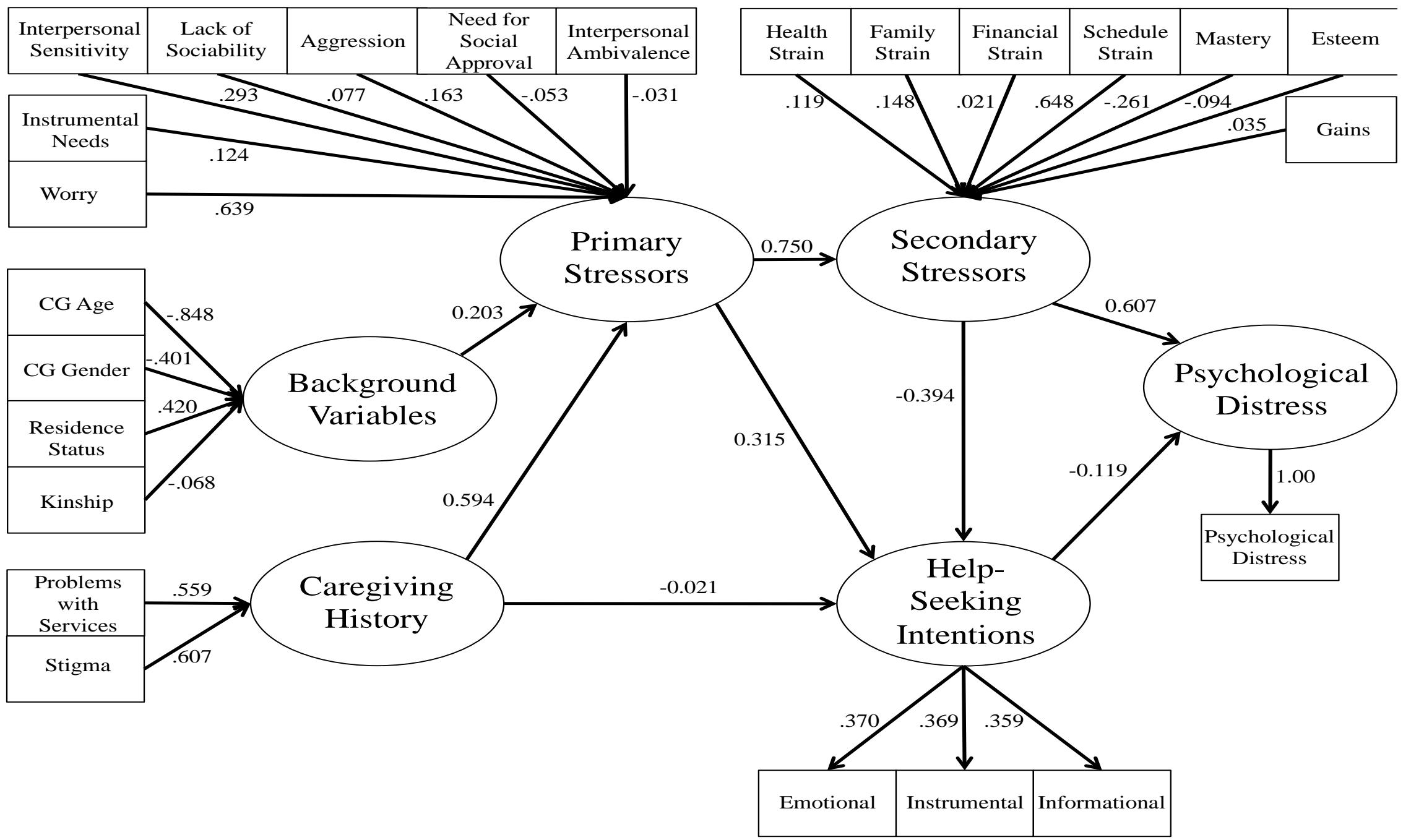

Figure 1. Diagram of Stress Process Model. Indicator weights, rather than loadings, are reported. 
age had the strongest (negative) weight, followed by residence status, which had a positive weight. Caregiver gender had a moderate negative weight, whereas kinship contributed little to the latent variable. Thus, caregivers who were older or female had lower scores on the latent variable, but those who resided with their loved ones had higher scores. Stigma and problems with services had approximately equal contributions to Caregiving History and both had positive weights. Out of the Primary Stressors, worry, the care-receivers' interpersonal sensitivity and aggression, and their instrumental needs all had positive weights. The care-receiver's lack of sociability, interpersonal ambivalence, and need for social approval contributed little weight to the Primary Stressors. Under the Secondary Stressors, schedule, family, and health strains had the strongest positive weights, and mastery and esteem had moderate negative weights. Gains and financial strains both had relatively low weights. Each of the latent variables had patterns of indicator weights that adhered to what would be expected under the Stress Process Model. That is, stressors with large weights contributed to higher scores on the Primary and Secondary Stressor latent variables, but positive experiences, such as esteem and mastery, contributed to lower scores on the Secondary Stressors. The paths between the latent variables (discussed below) generally behaved as expected by theory, further supporting the construct validity of the latent variables.

Structural model. It was hypothesized that (1a) residing with the care-receiver and being biologically related to them, as well as being female and older, would lead to higher levels of the primary stressors, and that (1b) higher levels of the primary stressors would lead to higher levels of the secondary stressors. It was also hypothesized that (1c) the higher levels of the secondary stressors would lead to more psychological distress, 
and that this path would account for the direct effect of the primary stressors on psychological distress. It was also expected that (1d) experiencing higher levels of stigma and more problems with services would lead to lower intentions to seek help. In contrast, it was hypothesized that higher levels of both the primary stressors (1e) and the secondary stressors (1f) would lead to higher help-seeking intentions. Finally, it was hypothesized that (1g) those with higher intentions to seek help would have lower levels of psychological distress.

Path coefficients. The path coefficients in PLS-PM are standardized beta coefficients; their value reflects the amount of change in the dependent variable that is expected per one standard deviation increase in the predictor variable (Götz et al., 2010). There was a positive, significant path from the Background Variables to the Primary Stressors, $\beta=0.203, t(104)=2.69, p=.008$. This partially supports hypothesis $1 \mathrm{a}$, as residing with the care-receiver contributed to higher scores on the latent variable, but female or older caregivers had lower scores. Although not previously specified as a hypothesis, there was also a significant path from Caregiving History to the Primary Stressors, $\beta=0.594, t(104)=7.89, p<.001$. There was a significant path from the Primary Stressors to the Secondary Stressors, $\beta=0.750, t(104)=11.50, p<.001$, as well as from the Secondary Stressors to Psychological Distress, $\beta=0.607, t(104)=7.89, p<$ .001 . These paths support hypothesis $1 \mathrm{~b}$ and partially support $1 \mathrm{c}$. The analyses to investigate whether hypothesis 1c was fully supported (by indicating mediation) are reported in the next section.

The path from Caregiving History to Help-Seeking Intentions was not significant, $\beta=-0.021, t(104)=-0.17, p=.870$. As such, hypothesis $1 \mathrm{~d}$ was not supported. There 
was a significant path from the Primary Stressors to Help-Seeking Intentions, $\beta=0.315, t$ $(104)=2.06, p=.042$. As higher Primary Stressors increased Help-Seeking Intentions, hypothesis 1e was supported. Higher Secondary Stressors significantly predicted lower Help-Seeking Intentions, $\beta=-0.394, t(104)=-2.65, p=.009$. However, it was hypothesized that higher levels of the secondary stressors would predict higher intentions to seek help, so hypothesis 1f was not supported. Finally, as the path from Help-Seeking Intentions to Psychological Distress was not significant, $\beta=-0.119, t(104)=-1.55, p=$ .125 , hypothesis $1 \mathrm{~g}$ was not supported.

Mediation by secondary stressors. To test whether the Secondary Stressors mediated the path between the Primary Stressors and Psychological Distress, a direct path from the Primary Stressors to Psychological Distress was added to the model as described above. The path was not significant, $\beta=-0.04, t(104)=-0.037, p=.97$, but the path from the Secondary Stressors to Psychological Distress remained significant, $\beta=0.609, t(104)$ $=5.04, p<.001$. As such, the direct path from the Secondary Stressors to Psychological Distress accounted for the relation between the Primary Stressors and Psychological Distress, fully supporting hypothesis 1c.

Determination coefficients. The Primary Stressors had an $\mathrm{R}^{2}$ value of .424 , meaning that $42.4 \%$ of the variance in the Primary Stressors was accounted for by the Background Variables and Caregiving History latent variables. 56.2\% of the variance in the Secondary Stressors was explained, but the model accounted for only $7.0 \%$ of the variance in Help-Seeking Intentions. Finally, the model accounted for $40.7 \%$ of the variance in Psychological Distress. Although there is no threshold for what constitutes an acceptable $\mathrm{R}^{2}$ value, these values are consistent with past applications of the Stress 
Process Model which, using hierarchical multiple regression analyses, have accounted for between 42\% (Haley et al., 2003) and 61\% (Provencher et al., 2003) of the variance in caregiver outcomes.

Change in determination coefficients. Another way to examine the influence a predictor latent variable has on the dependent latent variables in a model is to examine the change in determination coefficients $\left(\mathrm{R}^{2}\right)$ for the dependent variables when the predictor latent variable is removed from the model. To do so requires running the model first including the predictor latent variable in question, and then again excluding it. The $\mathrm{R}^{2}$ values for the dependent latent variables resulting from the analyses can be converted into an $f^{2}$ effect size, wherein values of $.02, .15$, and .35 correspond to weak, moderate, and substantial influence of the predictor latent variable on the dependent latent variable (Götz et al., 2010). Refer to Table 6 for the effect sizes associated with the predictor latent variables' influences on the following dependent latent variables: Primary Stressors, Secondary Stressors, Help-Seeking Intentions, and Psychological Distress. In general, predictor latent variables had the strongest influence on the dependent latent variables to which they had direct paths and little influence on the variables to which they had only indirect paths through other variables. The Background Variables had a weak influence on the Primary Stressors, but Caregiving History had substantial influence on the Primary Stressors. The Secondary Stressors had a weak influence on Help-Seeking Intentions, but a substantial influence on Psychological Distress. Finally, Help-Seeking Intentions had a weak influence on Psychological Distress. In general, the predictor latent variables had little influence on Help-seeking Intentions, which is consistent with the small $\mathrm{R}^{2}$ found for that latent variable in the overall model. The effect sizes are 
Table 6

Effect Sizes $\left(f^{2}\right)$ for Change in Determination Coefficients

\begin{tabular}{|c|c|c|c|c|}
\hline \multirow[b]{2}{*}{$\begin{array}{c}\text { Predictor Latent } \\
\text { Variables }\end{array}$} & \multicolumn{4}{|c|}{ Dependent Latent Variables } \\
\hline & $\begin{array}{l}\text { Primary } \\
\text { Stressors }\end{array}$ & $\begin{array}{l}\text { Secondary } \\
\text { Stressors }\end{array}$ & $\begin{array}{c}\text { Help-Seeking } \\
\text { Intentions }\end{array}$ & $\begin{array}{c}\text { Psychological } \\
\text { Distress }\end{array}$ \\
\hline $\begin{array}{l}\text { Background } \\
\text { Variables }\end{array}$ & .065 & .003 & -.001 & -.0001 \\
\hline $\begin{array}{l}\text { Caregiving } \\
\text { History }\end{array}$ & .589 & -.011 & .010 & -.022 \\
\hline Primary Stressors & - & - & -.084 & -.074 \\
\hline $\begin{array}{l}\text { Secondary } \\
\text { Stressors }\end{array}$ & - & - & .050 & .604 \\
\hline $\begin{array}{l}\text { Help-Seeking } \\
\text { Intentions }\end{array}$ & - & - & - & .034 \\
\hline
\end{tabular}

Note. Because the Primary Stressors is the only predictor variable for the Secondary Stressors, this procedure cannot be used determine the influence of the Primary Stressors on the Secondary Stressors.

generally consistent with the path coefficients already described.

External validation. As there are no significance tests for model fit under the PLS-PM framework, resampling techniques are used to determine model precision and external validity (Chin, 1998). Bootstrapping is a technique that builds an empirical distribution by repeatedly sampling with replacement from the dataset. The distribution is then used to calculate parameter estimates and associated $95 \%$ confidence intervals. Confidence intervals can be interpreted as significance tests; if the confidence interval does not include 0 , the estimate is statistically significant. Bootstrapping, with 1000 samples, was used to examine the external validity of the model described above. Refer to Table 7 for the original and bootstrap values of parameter estimates, as well as the 
Table 7

Parameter and Bootstrap Estimates

\begin{tabular}{|c|c|c|c|c|}
\hline \multirow[b]{2}{*}{ Estimate } & \multicolumn{4}{|c|}{ Indicator Weights } \\
\hline & Original & Bootstrap & $95 \%$ CI LL & $95 \%$ CI UL \\
\hline \multicolumn{5}{|l|}{ Background Variables } \\
\hline Kinship & -.068 & .131 & -.765 & .954 \\
\hline Residence Status & .420 & .126 & -.637 & .848 \\
\hline Caregiver Age & -.848 & .103 & -.991 & 1.08 \\
\hline Caregiver Gender & -.401 & .110 & -.823 & .963 \\
\hline \multicolumn{5}{|l|}{ Caregiving History } \\
\hline Problems with Services & .559 & .540 & .221 & .809 \\
\hline Stigma & .607 & .614 & .326 & .870 \\
\hline \multicolumn{5}{|l|}{ Primary Stressors } \\
\hline Instrumental Needs & .124 & .107 & -.238 & .395 \\
\hline Worry & .639 & .604 & .301 & .886 \\
\hline Interpersonal Sensitivity & .293 & .278 & -.078 & .651 \\
\hline Aggression & .163 & .181 & -.185 & .638 \\
\hline Need for Social Approval & -.053 & -.051 & -.268 & .177 \\
\hline Lack of Sociability & .077 & .082 & -.154 & .345 \\
\hline Interpersonal Ambivalence & -.031 & -.031 & -.336 & .255 \\
\hline \multicolumn{5}{|l|}{ Secondary Stressors } \\
\hline Schedule Strain & .648 & .611 & .329 & .871 \\
\hline Financial Strain & .021 & .0004 & -.240 & .232 \\
\hline Family Strain & .148 & .164 & -.019 & .374 \\
\hline Health Strain & .119 & .129 & -.126 & .388 \\
\hline Esteem & -.094 & -.084 & -.281 & .105 \\
\hline Gains & .035 & .007 & -.268 & .303 \\
\hline Mastery & -.261 & -.261 & -.434 & -.067 \\
\hline \multicolumn{5}{|l|}{ Help-Seeking Intentions } \\
\hline Emotional & .370 & .380 & .256 & .567 \\
\hline Instrumental & .369 & .366 & .239 & .503 \\
\hline \multirow[t]{2}{*}{ Informational } & .359 & .350 & .176 & .497 \\
\hline & \multicolumn{4}{|c|}{ Paths } \\
\hline Estimate & Original & Bootstrap & $95 \%$ CI LL & $95 \%$ CI UL \\
\hline $\mathrm{BV}$ to $\mathrm{PS}$ & .203 & .023 & -.351 & .376 \\
\hline $\mathrm{CH}$ to $\mathrm{PS}$ & .594 & .591 & .435 & .720 \\
\hline PS to SS & .750 & .751 & .614 & .846 \\
\hline SS to PD & .607 & .627 & .485 & .753 \\
\hline $\mathrm{CH}$ to $\mathrm{HS}$ & -.021 & .007 & -.242 & .235 \\
\hline PS to HS & .315 & .290 & -.034 & .627 \\
\hline $\mathrm{SS}$ to HS & -.394 & -.412 & -.754 & .062 \\
\hline HS to PD & -.119 & -.098 & -.240 & .040 \\
\hline
\end{tabular}




\begin{tabular}{lcccc}
\hline & \multicolumn{4}{c}{$\mathrm{R}^{2}$} \\
\cline { 2 - 5 } Estimate & Original & Bootstrap & $95 \%$ CI LL & $95 \%$ CI UL \\
\hline Primary Stressors & .424 & .459 & .302 & .599 \\
Secondary Stressors & .562 & .570 & .377 & .716 \\
Help-Seeking Intentions & .070 & .120 & .018 & .304 \\
Psychological Distress & .407 & .437 & .270 & .591 \\
\hline
\end{tabular}

Note . BV = Background Variables, $\mathrm{PS}=$ Primary Stressors, $\mathrm{CH}=$ Caregiving History, $\mathrm{SS}=$ Secondary Stressors, HS $=$ Help-Seeking Intentions, $\mathrm{PD}=$ Psychological Distress. 95\% CI LL $=95 \%$ Confidence Interval Lower Limit, 95\% CI UL = 95\% Confidence Interval Upper Limit.

95\% confidence interval for the bootstrap estimates. None of the indicators in the Background Variables block had significant weights. However, both problems with services and stigma had significant weights. Of the Primary Stressors, only worry had a significant weight, and schedule strain and mastery were the only significant indicators for the Secondary Stressors. All three help-seeking types had significant weights for the Help-Seeking Intentions. Only three of the paths were significant: those from Caregiving History to Primary Stressors, from Primary Stressors to Secondary Stressors, and from Primary Stressors to Psychological Distress. Finally, there were significant $R^{2}$ values for all of the dependent latent variables. Together, these results suggest that although parts of the model show external validity, many of the indicator weights may not replicate in another sample and the paths associated with caregivers' help-seeking intentions were not significant. However, the amount of variance explained in each of the dependent latent variables was significant, which supports the predictive ability of the model.

\section{Hypothesis 2 - Help-Seeking Intentions}

RANOVA. Analyses to examine hypothesis 2 were conducted in SPSS version 20. A 2 (Source: formal vs. informal) by 3 (Type: emotional vs. informational vs. instrumental) factorial RANOVA was conducted to examine differences in respondents' 
intentions to seek help. There was a significant interaction between help source and type, $F(2,210)=19.76, p<.001, \omega^{2}=.13, \mathrm{MSE}=.375$. There were also significant main effects of help type, $F(2,210)=7.12, p=.001, \omega^{2}=.04, \mathrm{MSE}=.693$, and help source, $F(1,105)=9.25, p=.003, \omega^{2}=.04, \mathrm{MSE}=1.91$. See Figure 2 for a graphical depiction of the interaction.

Planned Contrasts. The significant $F$-tests were followed up with the a priori contrasts previously outlined. It was hypothesized that caregivers would endorse higher intentions to seek out informal sources for informational and instrumental support, but have no preference for emotional support (2a). To test this hypothesis and further investigate the interaction effect, simple effect analyses using contrasts were conducted by comparing endorsements of formal and informal support sources separately within the emotional, informational, and instrumental support types. These revealed that, for informational help, caregivers reported significantly higher intentions to seek out formal support $(M=4.02, S D=1.45)$, rather than informal $(M=3.26, S D=1.10), F(1,105)=$ $39.75, p<.001, \omega^{2}=.15$. Additionally, there were no significant differences between caregivers' intentions to seek formal and informal sources for emotional, $F(1,105)=$ $0.181, p>.05, \omega^{2}=-.002$; or instrumental support, $F(1,105)=1.78, p>.05, \omega^{2}=.004$. Thus, hypothesis 2a was partially supported; no preference was found for emotional support, but the hypothesized difference within instrumental support was not found and caregivers preferred formal, rather than informal, sources of informational support.

It was also hypothesized that caregivers would have higher intentions to seek emotional and informational support, compared to instrumental support, regardless of whether the help came from formal or informal sources (2b). Contrasts revealed that, 


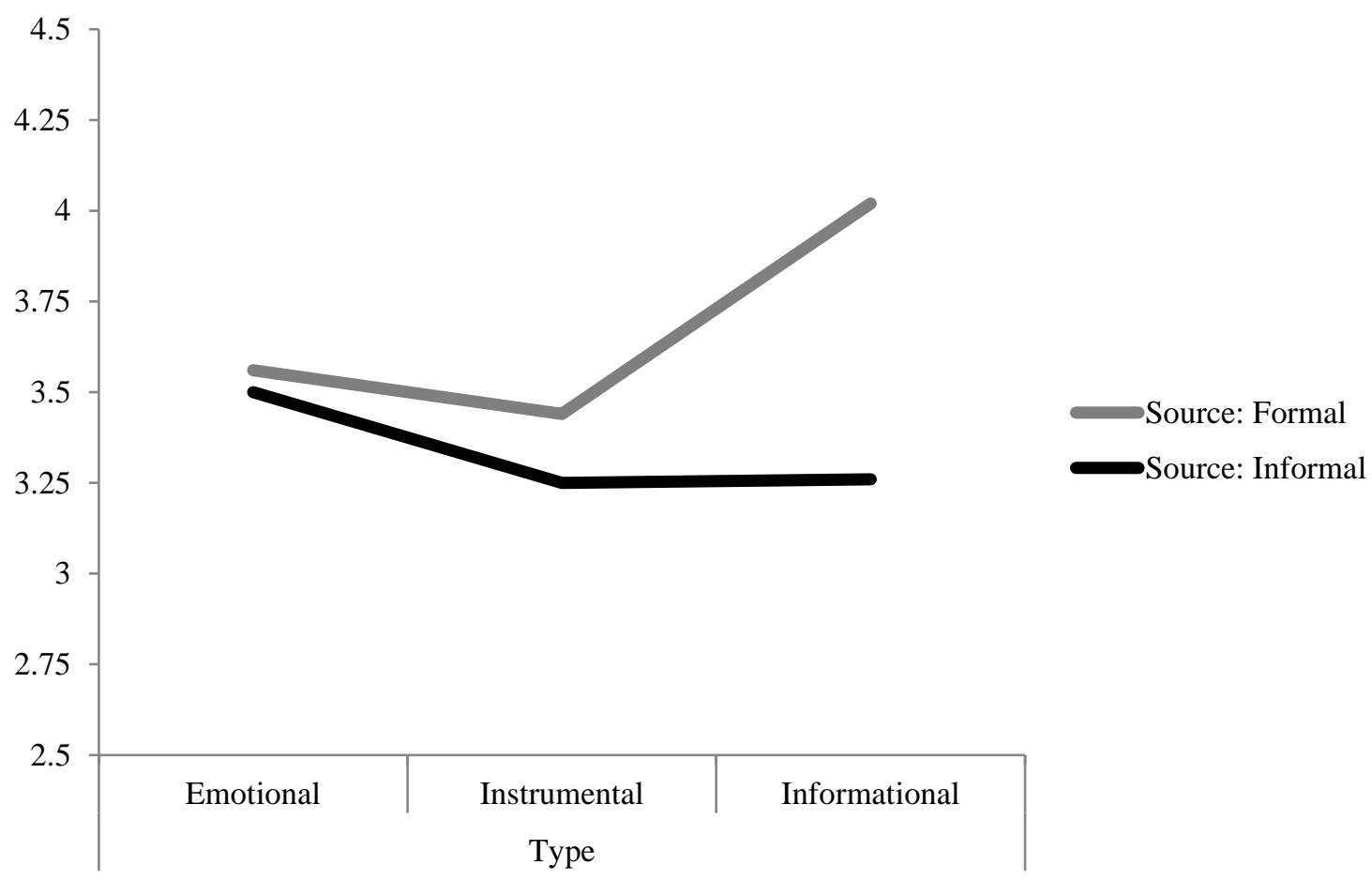

Figure 2. Interaction of intentions to seek help, by help source and help type.

with help sources combined, caregivers endorsed significantly higher intentions to seek emotional support $(M=3.53, S D=1.13)$, compared to instrumental support $(M=3.34$, $S D=1.22), F(1,105)=5.74, p<.05, \omega^{2}=.02$. Caregivers also had significantly higher intentions to seek out informational support $(M=3.64, S D=1.13)$, compared to instrumental support, $F(1,105)=11.45, p<.01, \omega^{2}=.05$. Thus, hypothesis $2 \mathrm{~b}$ was supported. 


\section{CHAPTER V}

\section{DISCUSSION}

\section{Major Findings}

Salient stressors. The current study applied the Stress Process Model (Pearlin et al., 1990) to the experiences of caregivers of people with personality disorders, in order to identify how the stressors in their lives interact to produce psychological distress. This investigation revealed that caregivers who were male, younger, or residing with their loved one were more likely to report high levels of worry and instrumental demands, as well as care-receiver interpersonal sensitivity and aggression (all considered to be primary stressors, which arise directly from the needs of the care-receiver). Caregivers who experienced more stigma and problems with services also had higher levels of these primary stressors. Caregivers who reported more worry, instrumental demands, and carereceiver interpersonal problems also had higher levels of secondary stressors, or areas of their lives outside the caregiving relationship that were affected by the caregiving role. Specifically, they lacked support from their families, had schedules that were more centred on caregiving, and experienced more physical health strain. Mastery and esteem related to caregiving appeared to reduce the impact of these stressors; yet, those with higher overall levels of the secondary stressors tended to have lower levels of mastery and esteem. Heightened levels of these stressors resulted in elevated levels of psychological distress. Caregivers with higher primary stressors had higher intentions to seek help, but those with higher secondary stressors reported being less likely to seek help. However, caregivers' help-seeking intentions did not affect their level of distress. 
Many of these findings are consistent with past research. Non-biologically related caregivers have endorsed higher levels of hostility (Scheirs \& Bok, 2007) and burden (Bailey \& Grenyer, 2015; Bauer et al., 2012), compared to biologically related carers. In the current study, those who resided with their loved ones had higher levels of primary stressors, but kinship contributed very little to the model. These findings may be due to overlap between kinship and residence status, such that many non-biologically related caregivers were spouses or partners, and thus more likely to live with their loved one and be exposed to primary stressors. The importance of stigma and problems with services in the current study coincides with past research documenting caregivers' experiences with stigma, as well as dissatisfaction, low involvement, and poor communication with services accessed on behalf of their loved ones (Bauer et al., 2012; Buteau et al., 2008; Dale et al., 2017; Dunne \& Rogers, 2013; Goodman et al., 2011).

The emergence of worry as the most salient primary stressor supports past findings of caregivers' high levels of emotional over-involvement, as well as the link between such anxious worry and heightened caregiver distress (Bailey \& Grenyer, 2015). Findings that the care-receivers' interpersonal problems are also important primary stressors further supports evidence that half of personality disorder subtypes are strongly associated with causing distress to others and the other half are linked to impaired social functioning (Miller et al., 2010). The relative importance of the care-receivers' interpersonal sensitivity and aggression, compared to other forms of interpersonal problems, is consistent with the personality disorder subtypes represented by the sample. Specifically, the vast majority of the caregivers supported someone with BPD, of which reactivity to interpersonal stressors and difficulty controlling anger are characteristic 
(APA, 2013). Finally, the literature suggests that those with personality disorders may need less day-to-day support than other groups (e.g., Bailey \& Grenyer, 2015; Skodol et al., 2002). However, $69 \%$ of current sample resided with their care-receiver and almost $70 \%$ reported receiving no assistance with caregiving, which appears to have led them to provide more instrumental support than expected. The care-receivers' day-to-day needs held a modest (but not trivial) weight in forming the primary stressors.

In terms of the secondary stressors, disruptions to the caregivers' schedule held the strongest weight. Schedule strain reflects a fairly broad impact to caregivers' lives, manifested through changes such as centering activities around caring, eliminating or stopping in the middle of other activities to provide care, and reducing the amount of time spent in leisure or with family. This, along with strains to family relationships and physical health, is similar to past research showing the widespread impact of supporting someone with a personality disorder (Bailey \& Grenyer, 2014; Bauer et al., 2012; Goodman et al., 2011). In contrast, caregivers' financial strains were not found to greatly impact their level of stress or psychological distress, despite the financial impact of caregiving being well documented by past research (Bauer et al., 2012; Buteau et al., 2008; Dunne \& Rogers, 2013; Goodman et al., 2011).

A unique feature of this research is its examination of the positive experiences that may arise from caregiving. This appears to be a fruitful addition, as mastery and esteem were found to lessen the impact of the other secondary stressors. However, the model also implies that those caregivers with higher levels of stressors and distress had lower levels of mastery and caregiving esteem. This interpretation is consistent with past research showing caregivers' high levels of disempowerment (Bailey \& Grenyer, 2013). 
Although it was removed from final model, role entrapment appears to overlap to a great extent with caregiving esteem - those who felt they had gained from caregiving did not feel trapped and had lower levels of the secondary stressors. Conversely, those caregivers who had higher levels of the secondary stressors had lower caregiving esteem and higher role captivity.

Relations among levels of Stress Process Model. Other major findings of this study concern the relations among the levels of the Stress Process Model and how they combine to produce psychological distress. Hypotheses 1a through 1c reflected a proposed trajectory through which certain background variables increase the likelihood of experiencing primary stressors, which, in turn, increase the likelihood of experiencing secondary stressors, which finally predict increased psychological distress. This trajectory was supported; the background variables outlined above (i.e. residing with the loved one, being male, and being younger, as well as experiencing stigma and problems with services) predicted more worry, care-receiver interpersonal sensitivity and aggression, and instrumental needs. The strongest path in the model indicated that higher levels of those primary stressors led to higher levels of schedule, health, and family strain, and lower mastery and caregiving esteem. Finally, higher levels of the salient secondary stressors led to more psychological distress. All in all, the trajectory provides support for the Stress Process Model as outlined by Pearlin and colleagues (1990).

It was also expected that the variables outlined by the Stress Process Model would affect caregivers' intentions to seek help. It was hypothesized that experiencing stigma and problems with services would decrease help-seeking intentions (1d), but that higher levels of primary stressors (1e) and secondary stressors (1f) would increase help-seeking 
intentions. The Stress Process Model outlines a role for social support and coping as buffers of the relations between stressors and outcomes like psychological distress (Pearlin et al., 1990). As such, it was also expected that higher help-seeking intentions would lead to lower psychological distress $(1 \mathrm{~g})$. However, the variables that were successful in delineating the Stress Process Model were less able to explain caregivers' help-seeking intentions. Caregivers' experience of stigma and problems with services had a negligible impact on their help-seeking intentions. Higher levels of the primary stressors predicted increased help-seeking intentions, which supports hypothesis 1e. However, those with higher levels of family, health, and schedule strain, as well as lower mastery and esteem, were less likely to seek help. This was counter to the hypothesis that higher levels of the secondary stressors would lead to higher help-seeking intentions (1f). Finally, caregivers' help-seeking intentions did not affect their level of psychological distress in the model, thus failing to support hypothesis $1 \mathrm{~g}$.

Help-seeking intentions. Further investigation looked more specifically at how caregivers' help-seeking intentions differed by help type and source. It was hypothesized that caregivers would report a higher likelihood of seeking out informal sources for instrumental and informational support, but have no preference for emotional support (2a). This hypothesis was partially supported, as there was no difference between caregivers' preferences for formal versus informal sources of emotional support. Yet, there also was no difference for instrumental support; further, caregivers reported a higher likelihood of seeking formal (rather than informal) sources for informational support. Across past studies, caregivers appear to have some ambivalence toward formal support, with high demand for psychoeducational support groups (Hoffman et al., 2005; 
Hoffman, Fruzzetti, et al., 2007; Pearce et al., 2017; Sanders \& Pearce, 2010), but also dissatisfaction with other support options (Bailey \& Grenyer, 2015) and significant barriers to and confusion about securing support (Dunne \& Rogers, 2013; Lawn \& McMahon, 2015). From this study, it appears that formal services are viewed as viable sources of informational support, but such mixed opinions may exist for emotional or instrumental support.

The literature suggests that caregivers may require all three forms of support. In terms of instrumental support, caregivers report high levels of burden (Bailey \& Grenyer, 2014), concern about their loved ones' symptoms (Bauer et al., 2012), and poor cooperation with care centers (Bauer et al., 2012; Lawn \& McMahon, 2015). However, there is greater evidence of caregivers' needs for informational support, as family members are often at a loss for information about BPD (Bauer et al., 2012; Buteau et al., 2008; Dunne \& Rogers, 2013) and many caregivers appear to receive insufficient explanations of the disorder from clinicians (Bailey \& Grenyer, 2014; Lawn \& McMahon, 2015). Additionally, the emotional costs of supporting someone with a personality disorder are well represented in the literature (Bailey \& Grenyer, 2014; Bauer et al., 2012; Goodman et al., 2011), as well as this study. Consistent with these past findings, it was found that, overall, caregivers had higher intentions to seek emotional and informational support, relative to instrumental help, supporting hypothesis $2 b$.

The Stress Process Model showed that higher levels of the primary stressors related to higher help-seeking intentions, whereas caregivers with higher secondary stressors had lower intentions to seek help. Moreover, the secondary stressors appear to be a 'double-edge sword', predicting both increased psychological distress and reduced 
intentions to seek help. One explanation for the opposite effects of the primary and secondary stressors on help-seeking is that more acute stressors may motivate or catalyze caregivers to seek help, whereas caregivers with more widespread impacts may be too overwhelmed to seek support. The secondary stressors reflect the organization of caregivers' lives around the caregiving role (Pearlin et al., 1990), and include specific strains that may impose practical constraints on caregivers' abilities to seek out support, such as those to finances and time. Additionally, the salience of reduced mastery may reflect a form of learned helplessness, wherein caregivers feel that they are unable to change their circumstances and thus do not intend to seek help. An early study found that caregivers who felt a loss of control in caregiving situations and tended to blame themselves for negative caregiving events were more likely to have elevated levels of depression (Pagel, Becker, \& Coppel, 1985). Conversely, Intrieri and Rapp (1994) found that caregivers who had higher levels of 'learned resourcefulness,' including systematic problem-solving and self-regulation of responses to stressors, reported lower caregiving burden. The dual links of the secondary stressors to psychological distress and helpseeking intentions highlight that the absence of help-seeking does not necessarily mean that support is not needed. Developing caregiver support organizations that parallel those such as the Nanny Angel Network, which provides free child-care to mothers with cancer, may help address the barriers that secondary stressors present between caregivers and help-seeking, as well as reduce caregivers' overall level of distress.

\section{Characteristics of Caregivers of People with Personality Disorders}

Past research has suggested that caregivers of people with personality disorders are most often female and middle aged (Bailey \& Grenyer, 2013; Lawn \& McMahon, 
2015), and typically the parents or spouses of the care-receiver (Bailey \& Grenyer, 2015;

Lawn \& McMahon, 2015). This was consistent with the current sample, which had an average age of nearly 47 years and was composed mostly (73\%) of females. A fairly even split between parents ( $46 \%$ of the sample) and partners (44\%) was also found. The current sample was quite highly educated, with more than $60 \%$ holding at least bachelor's degrees. Past research has highlighted the high levels of distress that carers of people with personality disorders experience (Bailey \& Grenyer, 2014; 2015; Scheirs \& Bok, 2007). The current sample had a mean score of just over 26 out of a possible 50 on psychological distress. Whereas at first glance this may seem relatively low, another study found that caregivers of people with schizophrenia had mean scores of nearly 18 on the same measure (Ong, Ibrahim, \& Wahab, 2016). Additionally, more than $40 \%$ of the current sample reported having been diagnosed with a psychological disorder, most commonly depression or an anxiety disorder. These findings support the notion that caregivers of people with personality disorders experience a high level of distress, even in relation to other caregiving groups.

In the current sample, the average length of caregiving was just over 13 years. Although Bailey and Grenyer (2015) showed that the duration of caregiving was not related to caregivers' distress, the long duration highlights that caring for a loved one with a personality disorder does appear to be a major commitment. Consistent with the intensity and commitment of the role, more than $25 \%$ of the caregivers' loved ones had been diagnosed with more than one personality disorder and more than $90 \%$ had an additional form of more acute psychopathology. In fact, only $4 \%$ of the care-receivers had a single, 'pure' personality disorder diagnosis. As such, the challenges faced by the 
caregivers in the current study may be linked to their loved ones' more acute symptoms, as well as to their personality disorders. However, there is evidence that personality disorders frequently co-occur with each other and acute psychopathology (e.g. Grant et al., 2008), so the care-receivers' complex diagnostic profiles in this study are likely representative of those experienced by caregivers of people with personality disorders.

\section{Inconsistencies with Past Research}

Past research has generally supported the notion that female caregivers experience higher levels of psychological distress than their male counterparts (Bauer et al., 2012; Hoffman, Fruzzetti, et al., 2007; Scheirs \& Bok, 2007). However, the current study found that male caregivers generally had higher levels of the primary stressors. Similarly, other research has shown that older caregiver age is predictive of higher levels of depressive symptoms (Scheirs \& Bok, 2007), but the opposite result was found in the current investigation. These results may be due to the higher representation of spouses of people with BPD found in the current study. Whereas previous studies have found that many caregivers are mothers supporting their adult daughters with BPD (Bailey \& Grenyer, 2013; Goodman et al., 2011), spouses and unmarried partners comprised nearly half of the current sample. Additionally, as residence status held a strong weight in predicting the level of stressors experienced, these results may indicate that young male caregivers may be more likely to reside with their loved one, and thus exposed to more stressors and a higher likelihood of developing psychological distress.

The impact of caregiving on financial stability had been frequently described in previous research (Bauer et al., 2012; Buteau et al., 2008; Dunne \& Rogers, 2013; Goodman et al., 2011). Although caregivers' mean level of financial strain was relatively 
high among the other external stressors, it did not emerge as particularly salient in the model. As such, financial strain may still impact caregivers' lives, but is less predictive of their level of psychological distress. Similarly, past research has generally suggested that caregivers are mistrustful of formal services, likely stemming from their seemingly negative experiences with services accessed on behalf of their loved ones. However, caregivers in the current study had a clear preference for formal informational support. It seems likely that they viewed trained professionals as more competent than friends, family, or neighbours in providing information about caregiving. Additionally, 52\% of caregivers in another survey reported that seeking education about BPD was helpful to them (Lawn \& McMahon, 2015), indicating that although the amount of information initially shared by practitioners may be insufficient for many caregivers, attempts to seek additional information from formal sources may be beneficial.

It is particularly surprising that caregivers' experiences of stigma and problems with services had such little impact on their help-seeking intentions. Past research has found that perceptions of the helpfulness and quality of past services are robust predictors of intentions to seek help in the future (Cusack et al., 2004; Wilson, Deane, Ciarrochi, \& Rickwood, 2005). Similarly, stigma has been identified as a barrier to individuals seeking help for mental health concerns, especially that which is internalized or specific to seeking treatment (Clement et al., 2015). However, in the current study, the experiences with stigma and problems with services surveyed were related to the loved one's condition and care. It is possible that the respondents were able to set these experiences aside when considering seeking help for their own needs and remain hopeful about the success of their own help-seeking ventures. The lack of relation between help- 
seeking intentions and psychological distress leaves open the possibility that whereas intentions to seek help appear to be insufficient for reducing psychological distress, actual help-seeking behaviours that successfully secure social support and fulfill coping functions may be a more potent buffer of psychological distress, as posited by Pearlin and colleagues (1990).

\section{Contribution to the Literature}

A primary contribution of this research is its synthesis of two lines of research. The first line demonstrates the widespread impact of the caregiving role on caregivers' lives. This includes research showing elevated burden (Bailey \& Grenyer, 2013), as well as impact to caregivers' marriages and family life, physical health, standard of living, social lives, career trajectories, and financial wellbeing (Bauer et al., 2012; Goodman et al., 2011). Moreover, such impact brings a number of other stressors, including feelings of helplessness, poor cooperation with care providers, and the experience of stigma and prejudice (Bauer et al., 2012). These impacts and stressors are represented in the variables chosen to represent each level of the Stress Process Model. The current study systematically combines the many ways caregiving can impact caregivers' lives with the second line of research, which demonstrates the elevated distress experienced by caregivers of people with personality disorders. Although the current study examined general psychological distress, caregivers have been shown to have heightened levels of anxiety and depression (Bailey \& Grenyer, 2013), grief and struggles with emotion regulation (Bailey \& Grenyer, 2014), as well as a host of other psychological symptoms (Scheirs \& Bok, 2007). The Stress Process Model (Pearlin et al., 1990) was used to merge these findings and organize the multitude of variables associated with caregiving, 
in order to determine which are the most associated with psychological distress. To that end, the study also provides support for the Stress Process Model as a successful way to understand the way that caregiving stressors can give rise to outcomes, such as distress.

Another contribution of this research is its preliminary findings regarding caregivers' help-seeking intentions. By looking at intentions in terms of both help types and sources, the current study showed caregivers' higher intentions to seek emotional and informational support, compared to instrumental support, as well as their preference for formal sources of informational support. Although the variables included under the Stress Process Model had limited success in explaining caregivers' help-seeking intentions, the model showed that caregivers with higher levels of the primary stressors had higher intentions to seek support. This coincides with research showing that caregiver helpseeking behaviours can be predicted by the needs of their care-receiver (Pickard et al., 2011) and burden related to behavioural problems (Roelands et al., 2008), as well as suggestions that caregivers who receive support may be more burdened than those who do not (Bauer et al., 2012). Conversely, caregivers with higher levels of more diffuse stressors, such as conflict with family and changes to their schedule, reported a lower likelihood of seeking help. Another study found that secondary stressors such as family conflict and financial strain were not robust predictors of whether caregivers accessed respite care or counselling (Del Santo et al., 2009). These findings present preliminary information regarding where and under which circumstances caregivers may be most likely to seek help. 


\section{Use of the Term Caregiver}

The current study defined its population of interest as caregivers of people with personality disorders, with caregiving defined as being involved in and supportive of a loved one's wellbeing through a personality disorder. As a result, this identity and its related activities are reflected by the sample recruited. However, the label of caregiver may not accurately represent all of those who are affected by someone else's personality disorder. The term caregiving seemed to adequately fit the role, identity, and experience of many loved ones of people with BPD. Accordingly, $85 \%$ of the current sample supported a loved one with BPD. However, throughout recruitment, several other groups of potential participants rejected the idea of being their loved ones' caregivers. For instance, in online communities devoted to supporting loved ones of people with NPD, several people questioned the placement of the flyer and whether anyone in the community would meet the criteria. Specifically, many saw themselves as victims of abuse at the hands of their diagnosed loved ones, rather than their supporters. This perception is supported by empirical findings, as narcissistic perfectionism is associated with a tendency to perceive failures in others' behaviour, leading to conflict and derogation of others (Nealis, Sherry, Sherry, Stewart, \& Macneil, 2015).

The site administrator of an online community for those with OCPD and their loved ones also questioned the appropriateness of the term caregiver, indicating that most of the loved ones on the site were thought of as supportive partners, rather than caregivers. Although the concept of a supportive partner fits within the definition of caregiving and eligibility criteria outlined for this study, it is possible that the loved ones of people with OCPD did not identify with the term caregiver, which was displayed 
prominently on the recruitment flyer, and thus did not participate. This is consistent with past research on the experiences of spouses of people with mental illness, who generally rejected the term carer, viewing themselves as a spouse or partner first (Lawn \& McMahon, 2014). As such, the use of the term caregiver to refer to the population of interest likely returned a specific subsample of those who are affected by another person's personality disorder. Caregivers of people with personality disorders do exist, and they are represented by the sample and findings of this study. However, throughout the recruitment process it became apparent that the term caregiver does not represent the entirety of those who interact with or support a loved one with a personality disorder.

Past research in this area has used terms such as carer or caregiver somewhat loosely in relation to recruitment procedures. For instance, Goodman and colleagues (2011, p. 62) asked potential participants to “share [their] family's unique experience with BPD." Although the term caregiving was not used on the recruitment materials, the authors used the term caretaker to refer to the sample (Goodman et al., 2011). However, as the sample focused exclusively on parents of daughters with BPD, referring to their sample as such may have been warranted. Bailey and Grenyer (2014, p. 789) promoted their study as seeking relatives or significant others of people with personality disorders, to help researchers "interested in the unique experience of caring for a person with a personality disorder." However, to gain access to the study, participants were only required to endorse having a relative with a personality disorder, thus de-emphasizing the caregiving role. Bailey and Grenyer (2014) referred to the sample with the term carer throughout their article. As such, these studies may appear to speak to the experiences of caregivers of people with personality disorders, without having fully confirmed or 
defined that role within their samples. Other research has been more explicit in defining the caregiving role before referring to the sample as caregivers. For instance, Bauer and colleagues (2012) recruited their sample by asking people with personality disorders to refer their closest care-providing contacts. Similarly, Lawn and McMahon (2015) refer to their sample as family carers, with their only inclusion criteria being that participants identified as providing informal care to a family member with BPD.

The varied reaction to the term caregiver highlights that caregiving is a role that someone must adopt and take on; it is an identity that some loved ones wear and others reject. The explicit focus on caregiving in the current study likely contributed to the smaller overall sample size than was expected. Studies referenced while planning this investigation, such as those by Goodman and colleagues (2011) and Bailey and Grenyer (2014), appear to have emphasized a family relation, rather than caregiving role, with the person with a personality disorder. This may have led to their larger sample sizes $(N \mathrm{~s}=$ 233 and 287, respectively) than what was recruited in this study. In future studies, researchers seeking to understand the experiences those who accept the caregiving role should be aware that using that term is likely to return a specific subset of individuals. However, to understand the broader social impact of personality disorders, a term such as (supportive) loved one may be more widely applicable, encompassing family and friends who do not identify strictly as caregivers, but still support the wellbeing of a loved one with a personality disorder. For instance, recruitment materials could ask, "Do you support someone with a personality disorder?" rather than, "Are you the caregiver of someone with a personality disorder?" This may return a larger and more representative sample of those affected by someone else's personality disorder. 


\section{Caregivers of People with BPD versus Other Subtypes}

Past research on caregivers or family members of people with personality disorders have largely reported on the experiences of those supporting someone with BPD. This was evident in a systematic review of past research on caregivers (Bailey \& Grenyer, 2013), as well as more recent research (e.g. Bailey \& Greyer, 2014; 2015; Lawn \& McMahon, 2015). Bailey and Grenyer (2014) sought to sample caregivers of people with each of the personality disorder subtypes, but found that over $80 \%$ of their sample supported someone with BPD. A concerted effort was made in the current study to present the study flyer to potential participants who support people with the less wellrepresented personality disorder subtypes, through online forums and social media sites. However, the current sample still splits heavily toward those supporting loved ones with BPD. This likely reflects the larger number of avenues that exist to reach loved ones of people with BPD, especially though formal support organizations. For instance, 10 out of 12 organizations that supported recruitment offered services specifically for loved ones of people with BPD, compared to a total of six recruitment pathways focusing on mental health, personality disorders in general, or non-BPD personality disorder subtypes. Bailey and Grenyer (2014) found that after BPD, NPD was the next most frequent personality disorder subtype in their study, representing $12 \%$ of the sample (Bailey \& Grenyer, 2014). The frequency of NPD "carers" appears to be at odds with the reception the current study received in NPD-related pathways, wherein the term caregiver was questioned and rejected. However, NPD was the third most represented personality disorder in the current study, which likely reflects the documented diagnostic overlap between NPD and BPD (Stinson et al., 2008). As mentioned, the large proportion of 
BPD caregivers also likely reflects the explicit emphasis on caregiving, rather than more general support, used in recruitment for the current study.

\section{Limitations}

Sample size. The sample size of the current study is smaller than was expected. As previously discussed, the explicit focus on caregiving likely excluded some potential participants who may have fulfilled the eligibility requirements, but did not identify with the role of caregiver. Issues related to conducting research within intact communities may have also limited the sample size, as several of the sites utilized for recruitment are tightly-knit communities where members may develop close relationships with their online counterparts. For instance, caregivers who use online forums often do so for emotional support, and active participation on online forums can buffer the effect of caregiving strain on well being (Tanis, Das, \& Fortgens-Sillmann, 2011). When recruiting on such sites, the response rate was typically higher if the administrators of the forum or agency endorsed the study, such as in the case of BPDFamily, wherein the flyer was given high visibility on the site and was endorsed by the site administrators. Similarly, the Personality Disorder Awareness Network promoted the study flyer on their organizational Facebook pages and such endorsement was generally well received.

In contrast, lower response rates were observed when the researcher entered a community to promote the research. For instance, to recruit participants on Facebook, an account was created with the name "UWindsor PDcaregiversurvey." The account did not display information about the researcher, aside from their email address and the University of Windsor logo. When the researcher joined groups and posted the study flyer from the account, the posts were generally ignored or flagged as "spam." The 
account was likely perceived as an unusual entity, without an identifiable human behind it, which had not previously contributed to the online community. The configuration of the study account was designed to meet the REB requirements for recruitment on Facebook, but also likely contributed to the posts' lukewarm reception in such groups. Similarly, forum posts without the endorsement of site moderators or administrators also resulted in fewer responses. On one such forum, the flyer post was viewed more than 1100 times, but no survey responses cited that forum as the recruitment pathway.

The relative success of these pathways is likely confounded with other factors; BPDFamily has promoted research advertisements in the past, the Personality Disorder Awareness Network has more than 500,000 page followers, and members of the less successful recruitment pathways may have not been eligible for or interested in the study. However, recruitment was generally better received when the study was promoted by the organization or forum, rather than just by the researcher. This is consistent with past research, which has suggested that unsolicited requests to participate in surveys may be perceived as violations of potential participants' physical privacy (that is, being free from unwanted intrusion or observation) within their online spaces (Cho \& LaRose, 1999).

Another limitation that likely contributed to the small sample size was that the direct link to the online survey was generally not provided with the study flyer. Rather, those interested in participating were required to email the researcher in order to receive the link. This protocol was chosen as a risk-management procedure in discussion with the REB. Yet, the few pathways in which the link was shared directly with potential participants generally had higher response rates than those in which only the study flyer was shared. It is possible that caregivers feared the effects that participating may have 
had on their relationship with their loved one, such that emailing the researcher could have created a "paper trail," per se. Trust appears to be a major concern for those with BPD, and by extension, their loved ones. Bauer and colleagues (2012) found that approximately one-third of caregivers reported worrying about their care-receiver's lack of trust and uncertainty in interactions with their loved one. In a comparison of self- and other-ratings, both people with BPD and their family members rated those with BPD as high on neuroticism and low on agreeableness, which subsumes trustfulness (Hoffman, Buteau, \& Fruzzetti, 2007). Moreover, Fruzzetti, Shenk, and Hoffman (2005) reported that those with BPD frequently have difficulty trusting others, often stemming from patterns of emotional invalidation from family members. As such, a sense of mistrust associated with BPD may have led potential participants to view the risks of emailing the researcher as too high to warrant participating.

Similarly, contacting the researcher involved participants disclosing their identity, through their names and email addresses. This may have been too large a step for some caregivers, despite assurances that there would be no way to connect their responses on the survey to their identity and that their confidentiality would be protected. Couper (2000) notes that nonresponse error reflects those in a population of interest who are not willing or able to participate in a study. He argues that such non-responses may be influenced by concerns about privacy, especially when the survey focuses on sensitive topics, such as in the current study. Similarly, another study found that students were more likely to participate in online message boards when they were anonymous, rather than identified (Roberts \& Rajah-Kanagasabai, 2013). The term information privacy refers to participants' control over the conditions in which personal data is released (Cho 
\& LaRose, 1999). As such, potential participants who were averse to emailing the researcher may have chosen to protect their information privacy, even if they were eligible for and interested in the study.

To contrast other research with this population, Bailey and Grenyer (2014) appear to have made the direct link to their survey available to all potential participants. Although they received more overall responses to their survey than the current investigation, providing the direct link may have affected the quality of those responses. Specifically, 474 people accessed their survey, but 167 responses were discarded because the respondent did not endorse supporting someone with a personality disorder or did not answer any questions (Bailey \& Grenyer, 2014). As such, the benefits of protecting the direct link for data quality and item security must be weighed against the additional privacy intrusion that may dissuade some potential participants.

Recruitment procedures. Although the participants of the current study may represent a unique subset of those affected by someone else's personality disorder, they may also represent a specific subgroup of caregivers of people with personality disorders. The caregivers were recruited primarily through help sources, such as organizations running support groups or online forums and social media sites. Thus, those who participated in this study were actively seeking support and information. There is some indication that caregivers who seek support may be more highly burdened than other caregivers; Bauer and colleagues (2012) suggested that those caregivers who received help appeared to have particularly difficult loved ones to support. However, it is also possible that some of the caregivers received gains from their participation in online communities. As mentioned, Tanis and colleagues (2011) found that active participation 
in an online forum buffered the impact of caregiving strain on carer wellbeing.

Additionally, online research biases toward educated, affluent, and Caucasian groups, who have easier access to computers and the Internet (Im, Chee, Tsai, Bender, \& Lim, 2007). This was borne out by the sample, which was predominantly composed of educated and Caucasian demographics. Despite such indications that online recruitment often returns only a subset of populations of interest, the demanding and unique situations of caregivers of people with personality disorders suggested that an online survey, which caregivers could complete when and wherever was most convenient for them, was the most appropriate format for this study. Moreover, the online procedure allowed worldwide recruitment of participants, rather than limiting the sample to those residing in the Windsor area.

The current study also used somewhat more stringent eligibility criteria than past studies, which may have excluded some potential participants and limited the sample size. For instance, a diagnosis of a personality disorder from a mental health professional was required, along with frequent contact with the loved one. The stricter inclusion criteria were chosen to counteract the researcher's inability to cross-validate participants' responses and confirm their identity, given the online procedure. Thus, additional stipulations were outlined, to attempt to recruit those who genuinely reflect the population of interest. Lawn and McMahon (2015) had relatively lax eligibility requirements, as their study was open to anyone who identified as providing informal care to a family member with BPD. Similarly, Bailey and Grenyer $(2014,2015)$ required only that participants endorse having a loved one with a personality disorder. Past studies have also employed screening measures related to the respondent's knowledge of 
personality disorders, to determine the validity of caregivers' status as such (Bailey \& Grenyer, 2014, 2015; Goodman et al., 2011). However, many family members have been found to lack information about BPD and have trouble finding resources to supplement their knowledge (Bailey \& Grenyer, 2014; Bauer et al., 2012; Buteau et al., 2008; Dunne \& Rogers, 2013; Lawn \& McMahon, 2015), so this procedure was not used in the current study.

\section{Future Research}

The current study looked only at the experiences of the caregiver. However, caregiving is an exchange that takes place between two people. As such, future research should consider the viewpoints of both the caregiver and care-receiver. For instance, the current study showed that the care-receiver's levels of interpersonal sensitivity and aggression are salient primary stressors for caregivers. To fully understand the impact of those interpersonal problems, research should examine whether and how they are borne out in the caregiving relationship, such as whether the caregiver is the target or arbitrator of such problems. Research should also more deeply examine the experiences of those supporting a loved one with a personality disorder subtype other than BPD. As discussed above, the term caregiver appeared to resonate with those supporting someone with BPD. However, though they may not identify as caregivers, it is likely that those who have close relationships to someone with a personality disorder subtype other than BPD are still affected by that diagnosis. To fully understand the varied and nuanced impact personality disorders can have, these populations should be studied in more depth.

The current study also provides preliminary information about caregivers' helpseeking intentions, but the variables included in the Stress Process Model were largely 
unable to explain caregivers' intentions to seek support. Although the study showed that those with higher levels of primary stressors are more likely to seek help and those with higher secondary stressors are less likely, the mechanisms behind these relations is not known. As such, future research should further elucidate the experiences and factors that predict caregivers' help-seeking intentions. Moreover, the route from help-seeking intentions to actual help-seeking behaviours is currently unknown. Past research has shown that there are many barriers between caregivers and securing support (Lawn \& McMahon, 2015). As such, the routes or barriers between help-seeking intentions, actual help-seeking behaviours, and securing and maintaining support require further research.

The results of the current study could be used to develop or modify support avenues, such as the practices of individual clinicians, curriculums of psychoeducational support groups, or caregivers' efforts to manage their own difficulties. As such, a logical next step from the current study is to examine whether interventions aimed at helping caregivers manage the stressors that emerged as salient in this study can help to reduce their level of distress. For instance, caregivers could be taught skills to manage the impact of their loved ones' interpersonal aggression and sensitivity, as well as their own levels of worry and over-involvement. Setting boundaries when it comes to scheduling activities, resolving conflict with other family members, and improving caregivers' sense of control over their lives are also targets identified in the current study as potential ways to reduce caregivers' distress. Additionally, although the current study focused on psychological distress as an outcome of caregiving, future studies should examine whether addressing such stressors can improve caregivers' quality of life or sense of life satisfaction. Recent theory in the study of positive psychology has indicated that the 
absence of mental illness or distress is not synonymous with flourishing or optimal functioning (Keyes, 2005). As such, research should not focus solely on reducing the negative outcomes of caregiving, but also increasing the number of positive experiences caregivers have.

In contrast to the researcher entering a community and seeking only to solicit data from its members, Participatory Action Research (PAR) recruits community members to be involved in the research effort to differing degrees (Turnbull, Friesen, \& Ramirez, 1998). For instance, community members or stakeholders can be involved as ongoing advisors to the research or co-investigators. PAR can bring several advantages to community research efforts, such as increasing the relevance of research to community members; increasing the feasibility and acceptability of the research design; reducing logistical problems, such as those associated with recruitment; and leading to higher utilization of research products (Turnbull et al., 1998). However, a PAR approach also brings unique challenges, such as a higher demand for time and resources, the need to navigate the differing experiences and expectations of researchers and family members, and institutional barriers on the researchers' end (Turnbull et al., 1998). In future research with loved ones of people with personality disorders, it would be beneficial to utilize aspects of a PAR approach, to ensure that the loved ones' perspectives and priorities are reflected throughout the research process. As mentioned, researchers should also consider ways care-receivers could be involved in the research effort, to reveal a more balanced perspective on the caregiving relationship. 


\section{Conclusion}

This study applied the Stress Process Model to the experiences of caregivers of people with personality disorders, to identify which factors in their lives are associated with psychological distress. A trajectory emerged in which caregivers who were male, younger, residing with their loved one, or had experienced stigma or problems with services, were more likely to have heightened worry and instrumental demands, as well as loved ones with interpersonal sensitivity and aggression. Elevated primary stressors predicted more diffuse impact of caregiving on respondents' schedules, physical health, family relationships, and self-concept. These changes predicted higher psychological distress. Although the variables outlined above were less successful in explaining caregivers' help-seeking intentions, preliminary findings showed that caregivers were more likely to seek out emotional and informational support than instrumental, and reported a preference for formal, rather than informal, informational support. The current study combines two lines of research, synthesizing findings regarding the widespread impact of caregiving on caregivers' lives with those demonstrating the emotional toll of caregiving. These findings can be used to better support caregivers of people with personality disorders, by showing which areas of their lives may be potent targets for intervention. Given the consistent findings that caregivers of people with personality disorders experience high levels of distress and generally perceive that they have little support, this study is a stepping-stone to better supporting these caregivers and reducing the dysfunction associated with personality disorders. 


\section{REFERENCES}

AlMakhamreh, S. S. (2017). Exploring experiences of informal carers of mental health: Developing community intervention in social work in Jordan. International Social Work, 1-12, doi: 10.1177/0020872817695391.

American Psychiatric Association (2013). Diagnostic and Statistical Manual of Mental Disorders Fifth Edition DSM-5. Washington DC: American Psychiatric Publishing.

Andrews, G., \& Slade, T. (2001). Interpreting scores on the Kessler psychological distress scale (K10). Australian and New Zealand Journal of Public Health, 25(6), 494-497. doi: 10.1111/j.1467-842X.2001.tb00310.x

Bailey, R. C., \& Grenyer, B. F. (2013). Burden and support needs of carers of persons with borderline personality disorder: A systematic review. Harvard Review of Psychiatry, 21(5), 248-258. doi: 10.1097/HRP.0b013e3182a75c2c

Bailey, R. C., \& Grenyer, B. F. S. (2014). Supporting a person with personality disorder: A study of carer burden and well-being. Journal of Personality Disorders, 28(6), 796-809. doi: 101521pedi201428136

Bailey, R. C., \& Grenyer, B. F. S. (2015). The relationship between expressed emotion and wellbeing for families and carers of a relative with borderline personality disorder. Personality and Mental Health, 9, 21-32. doi: 10.1002/pmh.1273

Barnicot, K., Katsakou, C., Marougka, S., \& Priebe, S. (2011). Treatment completion in psychotherapy for borderline personality disorder-a systematic review and metaanalysis. Acta Psychiatrica Scandinavica, 123(5), 327-338. doi: 10.1111/j.16000447.2010.01652.x 
Baronet, A. M. (1999). Factors associated with caregiver burden in mental illness: a critical review of the research literature. Clinical Psychology Review, 19(7), 819841. doi: 10.1016/S0272-7358(98)00076-2

Baronet, A. M. (2003) The impact of family relations on caregivers' positive and negative appraisal of their caretaking activities. Family Relations, 52(2), 137-142. doi: 10.1111/j.1741-3729.2003.00137.x

Bateman, A. W., \& Tyrer, P. (2004). Services for personality disorder: Organisation for inclusion. Advances in Psychiatric Treatment, 10(6), 425-433. doi: 10.1192/apt.10.6.425

Bauer, R., Döring, A., Schmidt, T., \& Spieß1, H. (2012). “Mad or bad?”: Burden on caregivers of patients with personality disorders. Journal of Personality Disorders, 26(6), 956-971. doi: 10.1521/pedi.2012.26.6.956

Bender, D. S., Dolan, R. T., Skodol, A. E., Sanislow, C. A., Dyck, I. R., McGlashan, T. H.,... \& Gunderson, J. G. (2001). Treatment utilization by patients with personality disorders. American Journal of Psychiatry, 158(2), 295-302. Retrieved from: http://ezproxy.uwindsor.ca/login?url=http://search.proquest. com/docview/220465566? accountid=14789

Bland, A. R., \& Rossen, E. K. (2005). Clinical supervision of nurses working with patients with borderline personality disorder. Issues in Mental Health Nursing, 26(5), 507-517. doi: 10.1080/01612840590931957

Bradford, D. \& Palmer, A. F. (2016). In strong hands: ehealth support for mental health carers. Poster session presented at the meeting of Computing and Mental Health, San Jose, CA 
Brown, J. W., Chen, S. L., Mitchell, C., \& Province, A. (2007). Help-seeking by older husbands caring for wives with dementia. Journal of Advanced Nursing, 59(4), 352-360. doi: 10.1111/j.1365-2648.2007.04290.x

Buteau, E., Dawkins, K., \& Hoffman, P. (2008). In their own words: improving services and hopefulness for families dealing with BPD. Social Work in Mental Health, 6(1-2), 203-214. doi: 10.1300/J200v06n01_16

Cairney, J., \& Krause, N. (2008). Negative life events and age-related decline in mastery: Are older adults more vulnerable to the control-eroding effect of stress? The Journals of Gerontology Series B: Psychological Sciences and Social Sciences, 63(3), S162-S170. Retrieved from: https://psychsocgerontology.oxfordjournals .org/content/63/3/S162.full

Cairney, J., Veldhuizen, S., Wade, T. J., Kurdyak, P., \& Streiner, D. L. (2007). Evaluation of 2 measures of psychological distress as screeners for depression in the general population. Canadian Journal of Psychiatry, 52(2), 111-120. Retrieved from: http://search.proquest.com/openview/45f88fe6129a13dbf112 cd360fe2e0a8/1?pq-origsite $=$ gscholar

Chen, F. P., \& Greenberg, J. S. (2004). A positive aspect of caregiving: The influence of social support on caregiving gains for family members of relatives with schizophrenia. Community Mental Health Journal, 40(5), 423-435. doi: 10.1023/B:СОМH.0000040656.89143.82

Chien, W. T., Thompson, D. R., \& Norman, I. (2008). Evaluation of a peer-led mutual support group for Chinese families of people with schizophrenia. American 
Journal of Community Psychology, 42(1-2), 122-134. doi: 10.1007/s10464-0089178-8

Chin, W. W. (1998). The partial least squares approach to structural equation modeling. In G. A. Marcoulides (Ed.). Modern methods for business research (pp. 295336). Mahwah, NJ: Lawrence Erlbaum Associates.

Chin, W. W. (2010). How to write up and report PLS analyses. In V. E. Vinzi, W. W. Chin, J. Hensler, \& H. Wang (Eds). In handbook of partial least squares: Concepts, methods and applications (pp. 655-690). New York, NY: Springer

Cho, H., \& LaRose, R. (1999). Privacy issues in Internet surveys. Social Science Computer Review, 17(4), 421-434. doi: 10.1177/089443939901700402

Ciarrochi, J. V., \& Deane, F. P. (2001). Emotional competence and willingness to seek help from professional and nonprofessional sources. British Journal of Guidance and Counselling, 29(2), 233-246. doi: 10.1080/03069880124843

Cleary, M., Siegfried, N., \& Walter, G. (2002). Experience, knowledge and attitudes of mental health staff regarding clients with a borderline personality disorder. International Journal of Mental Health Nursing, 11, 186-191. doi: 10.1046/j.1440-0979.2002.00246.x

Clement, S., Schauman, O., Graham, T., Maggioni, F., Evans-Lacko, S., Bezborodovs, N., ... \& Thornicroft, G. (2015). What is the impact of mental health-related stigma on help-seeking? A systematic review of quantitative and qualitative studies. Psychological Medicine, 45(1), 11-27. doi: 10.1017/S0033291714000129 
Clifton, A., Turkheimer, E., \& Oltmanns, T. F. (2005). Self-and peer perspectives on pathological personality traits and interpersonal problems. Psychological Assessment, 17(2), 123-131. doi: 10.1037/1040-3590.17.2.123

Cohen, J., Cohen, P., West, S. G., \& Aiken, L. S. (2003). Applied multiple regression/correlation analysis for the behavioral sciences: Third edition. New York, NY: Routledge.

Cotton, S. M., McCann, T. V., Gleeson, J. F., Crisp, K., Murphy, B. P., \& Lubman, D. I. (2013). Coping strategies in carers of young people with a first episode of psychosis. Schizophrenia Research, 146(1), 118-124. doi:

10.1016/j.schres.2013.02.008

Couper, M. P. (2000). Review: Web surveys: A review of issues and approaches. The Public Opinion Quarterly, 64(4), 464-494. Retrieved from: http://www.goetheuniversity-frankfurt.de/47929851/Couper_2000.pdf

Cramer, V., Torgersen, S., \& Kringlen, E. (2006). Personality disorders and quality of life. A population study. Comprehensive Psychiatry, 47(3), 178-184. doi: 10.1016/j.comppsych.2005.06.002

Crawford, M. J., Adedeji, T., Price, K., \& Rutter, D. (2010). Job satisfaction and burnout among staff working in community-based personality disorder services. International Journal of Social Psychiatry, 56(2), 196-206. doi: $10.1177 / 0020764009105702$

Cusack, J., Deane, F. P., Wilson, C. J., \& Ciarrochi, J. (2004). Who influence men to go to therapy? Reports from men attending psychological services. International 
Journal for the Advancement of Counselling, 26(3), 271-283. doi:

10.1023/B:ADCO.0000035530.44111.a8

Cummings, S. M. (1997). Spousal caregivers of early stage Alzheimer's patients: A psychoeducational support group model. Journal of Gerontological Social Work, 26(3-4), 83-98. doi: 10.1300/J083V26N03_07

Dale, O., Sethi, F., Stanton, C., Evans, S., Barnicot, K., Sedgwick, R., ... \& Urquia, N. (2017). Personality disorder services in England: findings from a national survey. BJPsych Bulletin, 1-7W. doi: 10.1192/pb.bp.116.055251

Deane, F. P., Wilson, C. J., \& Ciarrochi, J. (2001). Suicidal ideation and help-negation: Not just hopelessness or prior help. Journal of Clinical Psychology, 57(7), 901914. doi: 10.1002/jclp.1058

Dunne, E., \& Rogers, B. (2013). "It's us that have to deal with it seven days a week": carers and borderline personality disorder. Community Mental Health Journal, 49(6), 643-648. doi: 10.1007/s10597-012-9556-4

Fanaian, M., Lewis, K. L., \& Grenyer, B. F. (2013). Improving services for people with personality disorders: Views of experienced clinicians. International Journal of Mental Health Nursing, 22(5), 465-471. doi: 10.1111/inm.12009

Ferriter, M., \& Huband, N. (2003). Experiences of parents with a son or daughter suffering from schizophrenia. Journal of Psychiatric and Mental Health Nursing, 10(5), 552-560. doi: 10.1046/j.1365-2850.2003.00624.x

Few, L. R., Miller, J. D., Morse, J. Q., Yaggi, K. E., Reynolds, S. K., \& Pilkonis, P. A. (2010). Examining the reliability and validity of clinician ratings on the Five- 
Factor Model score sheet. Assessment, 50, 119-127. doi:

$10.1177 / 1073191110372210$

Fruzzetti, A. E., Shenk, C., \& Hoffman, P. D. (2005). Family interaction and the development of borderline personality disorder: A transactional model. Development and Psychopathology, 17(04), 1007-1030. doi:

10.10170S0954579405050479

Gelkopf, M., \& Roe, D. (2014). Evaluating outcome domains assessing caregivers of individuals with mental illness: A review. Family Process, 53(1), 150-174. doi: 10.1111/famp. 12056

Given, C. W., Given, B., Stommel, M., Collins, C., King, S., \& Franklin, S. (1992). The caregiver reaction assessment (CRA) for caregivers to persons with chronic physical and mental impairment. Research in Nursing and Health, 15, 271-283. doi: 10.1002/nur.4770150406

Goodman, M., Patil, U, Triebwasser, J. Hoffman, P., \& Weinstein, Z. A. (2011). Parental burden associated with borderline personality disorder in female offspring. Journal of Personality Disorders, 25(1), 59-74. doi: 10.1521/pedi.2011.25.1.59

Götz, O., Liehr-Gobbers, K., \& Krafft, M. (2010). Evaluation of structural equation models using the partial least squares (PLS) approach. In V. E. Vinzi, W. W. Chin, J. Hensler, \& H. Wang (Eds). In Handbook of partial least squares: Concepts, methods and applications (pp. 691-711). New York, NY: Springer

Grant, B. F., Chou, S. P., Goldstein, R. B., Huang, B., Stinson, F. S., Saha, T. D., ... \& Ruan, W. J. (2008). Prevalence, correlates, disability, and comorbidity of DSMIV borderline personality disorder: results from the Wave 2 National 
Epidemiologic Survey on Alcohol and Related Conditions. The Journal of Clinical Psychiatry, 69(4), 533. doi: 10.4088/JCP.v69n0404

Gunderson, J. G., Berkowitz, C., \& Ruiz-Sancho, A. (1997). Families of borderline patients: a psychoeducational approach. Bulletin of the Menninger Clinic, 61(4), 446 - 457. Retrieved from: http://search.proquest.com/openview/e0a66ec8b5161e23bba4958ddf433e81/1?pq -origsite $=$ gscholar $\&$ cbl $=1818298$

Haenlein, M., \& Kaplan, A. M. (2004). A beginner's guide to partial least squares analysis. Understanding Statistics, 3(4), 283-297. doi: 10.1207/s15328031us0304_4

Haley, W. E., LaMonde, L. A., Han, B., Burton, A. M., \& Schonwetter, R. (2003). Predictors of depression and life satisfaction among spousal caregivers in hospice: application of a stress process model. Journal of Palliative Medicine, 6(2), 215224. doi: $10.1089 / 109662103764978461$

Harvey, K., Burns, T., Fiander, M., Huxley, P., Manley, C., \& Fahy, T. (2002). The effect of intensive case management on the relatives of patients with severe mental illness. Psychiatric Services, 53(12), 1580-1585. Retrieved from: http://ps.psychiatryonline.org/doi/pdf/10.1176/appi.ps.53.12.1580

Herman, J. L., Perry, C., \& van der Kolk, B. A. (1989). Childhood trauma in borderline personality disorder. American Journal of Psychiatry, 146(4), 490-495. doi: 10.1176/ajp.146.4.490 
Hill, R. G., Shepherd, G., \& Hardy, P. (1998). In sickness and in health: The experiences of friends and relatives caring for people with manic depression. Journal of Mental Health, 7(6), 611-620. doi: 10.1080/09638239817761

Hill, R. W., Zrull, M. C., \& McIntire, K. (1998). Differences between self and peer ratings of interpersonal problems. Assessment, 5(1), 67-83. doi: $10.1177 / 107319119800500109$

Hoffman, P. D., Buteau, E., \& Fruzzetti, A. E. (2007). Borderline personality disorder: NEO-Personality Inventory ratings of patients and their family members. International Journal of Social Psychiatry, 53(3), 204-215. doi: $10.1177 / 0020764006074924$

Hoffman, P. D., Buteau, E., Hooley, J. M., Fruzzetti, A. E., \& Bruce, M. L. (2003). Family members' knowledge about borderline personality disorder: Correspondence with their levels of depression, burden, distress, and expressed emotion. Family Process, 42(4), 469-478. doi: 10.1111/j.1545-5300.2003.00469.x

Hoffman, P. D., Fruzzetti, A. E., \& Buteau, E. (2007). Understanding and engaging families: An education, skills and support program for relatives impacted by borderline personality disorder. Journal of Mental Health, 16(1), 69-82. doi: $10.1080 / 09638230601182052$

Hoffman, P. D., Fruzzetti, A. E., Buteau, E., Neiditch, E. R., Penney, D., Bruce, M. L., ... \& Struening, E. (2005). Family connections: a program for relatives of persons with borderline personality disorder. Family Process, 44(2), 217-225. doi: 10.1111/j.1545-5300.2005.00055.x 
Horowitz, L. M., Rosenberg, S. E., Baer, B. A., Ureño, G., \& Villaseñor, V. S. (1988). Inventory of interpersonal problems: Psychometric properties and clinical applications. Journal of Consulting and Clinical Psychology, 56(6), 885-892. doi: 10.1037/0022-006X.56.6.885

Im, E. O., Chee, W., Tsai, H. M., Bender, M., \& Lim, H. J. (2007). Internet communities for recruitment of cancer patients into an Internet survey: A discussion paper. International Journal of Nursing Studies, 44(7), 1261-1269. doi:

10.1016/j.ijnurstu.2006.07.003

Intrieri, R. C., \& Rapp, S. R. (1994). Self-control skillfulness and caregiver burden among help-seeking elders. Journal of Gerontology, 49(1), P19-P23. doi: 10.1093/geronj/49.1.P19

Jarrott, S. E., Zarit, S. H., Stephens, M. A. P., Townsend, A., \& Greene, R. (2005). Instrumental help and caregivers' distress: Effects of change in informal and formal help. American Journal of Alzheimer's Disease and Other Dementias, 20(3), 181-190. doi: 10.1177/153331750502000308

Joyce, J., Leese, M., \& Szmukler, G. (2000). The experience of caregiving inventory: Further evidence. Social Psychiatry and Psychiatric Epidemiology, 35(4), 185189. doi: $10.1007 / \mathrm{s} 001270050202$

Kessler, R. C., Andrews, G., Colpe, L. J., Hiripi, E., Mroczek, D. K., Normand, S. L., ... \& Zaslavsky, A. M. (2002). Short screening scales to monitor population prevalences and trends in non-specific psychological distress. Psychological Medicine, 32(06), 959-976. doi: 10.1017/S0033291702006074 
Keyes, C. L. (2005). Mental illness and/or mental health? Investigating axioms of the complete state model of health. Journal of Consulting and Clinical Psychology, 73(3), 539-548. doi: 10.1037/0022-006X.73.3.539

Kline, R. B. (2016). Principles and practice of structural equation modeling. New York, NY: Guilford Publications.

Koekkoek, B., van Meijel, B., \& Hutschemaekers, G. (2006). "Difficult patients" in mental health care: a review. Psychiatric Services, 57(6), 795-802. Retrieved from: http://ps.psychiatryonline.org/doi/abs/10.1176/ps.2006.57.6.795

Krawitz, R., Reeve, A., Hoffman, P., \& Fruzzetti, A. (2016). Family Connections ${ }^{\mathrm{TM}}$ in New Zealand and Australia: an evidence-based Intervention for family members of people with borderline personality disorder. Journal of the NZ College of Clinical Psychologists, (25)2, 20-25. Retrieved from: https://static1.squarespace.com/static/54262e6be4b001c7872a23d9/t/57ad0cd1d2 b8575c1ea7d12c/1470958808444/pdf-FC-JNZCCP-2016.pdf-stand-alone.pdf

Kutner, J., Kilbourn, K. M., Costenaro, A., Lee, C. A., Nowels, C., Vancura, J. L., ... \& Keech, T. E. (2009). Support needs of informal hospice caregivers: A qualitative study. Journal of Palliative Medicine, 12(12), 1101-1104. doi: 10.1089/jpm.2009.0178

Lawn, S., \& McMahon, J. (2014). The importance of relationship in understanding the experiences of spouse mental health carers. Qualitative Health Research, 24(2), 254-266. doi: 10.1177/1049732313520078 
Lawn, S., \& McMahon, J. (2015). Experiences of family carers of people diagnosed with borderline personality disorder. Journal of Psychiatric and Mental Health Nursing, 22(4), 234-243. doi: 10.1111/jpm.12193

Lazarus, R.S., \& Folkman, S. (1984). Stress, appraisal, and coping. New York, NY: Springer Publishing Company

Lenzenweger, M. F., Lane, M. C., Loranger, A. W., \& Kessler, R. C. (2007). DSM-IV personality disorders in the National Comorbidity Survey Replication. Biological Psychiatry, 62(6), 553-564. doi: 10.1016/j.biopsych.2006.09.019

MacDonald, P., Rhind, C., Hibbs, R., Goddard, E., Raenker, S., Todd, G., ... \& Treasure, J. (2014). Carers' assessment, skills and information sharing (CASIS) trial: A qualitative study of the experiential perspective of caregivers and patients. European Eating Disorders Review, 22(6), 430-438. doi: 10.1002/erv.2320

MacLeod, A., Skinner, M. W., \& Low, E. (2012). Supporting hospice volunteers and caregivers through community-based participatory research. Health \& Social Care in the Community, 20(2), 190-198. doi: 10.1111/j.1365-2524.2011.01030.x

McIntosh, C. N., Edwards, J. R., \& Antonakis, J. (2014). Reflections on partial least squares path modeling. Organizational Research Methods, 17(2), 210-251. doi: $10.1177 / 1094428114529165$

Miller, J. D., Campbell, W. K., \& Pilkonis, P. A. (2007). Narcissistic Personality Disorder: Relations with distress and functional impairment. Comprehensive Psychiatry, 48(2), 170-177. doi:10.1016/j.comppsych.2006.10.003

Miller, J. D., Maples, J., Few, L. R., Morse, J. Q., Yaggi, K. E., \& Pilkonis, P. A. (2010). Using clinician-rated five-factor model data to score the DSM-IV personality 
disorders. Journal of Personality Assessment, 92(4), 296-305. doi:

$10.1080 / 00223891.2010 .481984$

Montgomery, C., Lloyd, K., \& Holmes, J. (2000). The burden of personality disorder: A district-based survey. International Journal of Social Psychiatry, 46(3), 164-169. doi: $10.1177 / 002076400004600302$

Muralidharan, A., Lucksted, A., Medoff, D., Fang, L. J., \& Dixon, L. (2014). Stigma: a unique source of distress for family members of individuals with mental illness. The Journal of Behavioral Health Services \& Research, 1-10. doi: $10.1007 / \mathrm{s} 11414-014-9437-4$

Nealis, L. J., Sherry, S. B., Sherry, D. L., Stewart, S. H., \& Macneil, M. A. (2015). Toward a better understanding of narcissistic perfectionism: Evidence of factorial validity, incremental validity, and mediating mechanisms. Journal of Research in Personality, 57, 11-25. doi: 10.1016/j.jrp.2015.02.006

Nijboer, C., Triemstra, M., Tempelaar, R., Sanderman, R., \& van den Bos, G. A. (1999). Measuring both negative and positive reactions to giving care to cancer patients: psychometric qualities of the Caregiver Reaction Assessment (CRA). Social Science \& Medicine, 48(9), 1259-1269. doi: 10.1016/S0277-9536(98)00426-2

O'Connor, D. L. (2003). Toward empowerment: ReVisioning family support groups. Social Work with Groups, 25(4), 37-56. doi: 10.1300/J009v25n04_04

Ohaeri, J. U. (2003). The burden of caregiving in families with a mental illness: a review of 2002. Current Opinion in Psychiatry, 16(4), 457-465. doi: 0.1097/01.yco.0000079212.36371.c0 
Ong, H. C., Ibrahim, N., \& Wahab, S. (2016). Psychological distress, perceived stigma, and coping among caregivers of patients with schizophrenia. Psychology Research and Behavior Management, 9, 211-218. doi: 10.2147/PRBM.S112129

Pagel, M. D., Becker, J., \& Coppel, D. B. (1985). Loss of control, self-blame, and depression: An investigation of spouse caregivers of Alzheimer's disease patients. Journal of Abnormal Psychology, 94(2), 169-182. doi: 10.1037/0021843X.94.2.169

Pagan, J. L., Eaton, N. R., Turkheimer, E., \& Oltmanns, T. F. (2006). Peer-reported personality problems of research nonparticipants: Are our samples biased?. Personality and Individual Differences, 41(6), 1131-1142. doi:

10.1016/j.paid.2006.04.017

Pearce, J., Jovev, M., Hulbert, C., McKechnie, B., McCutcheon, L., Betts, J., \& Chanen, A. M. (2017). Evaluation of a psychoeducational group intervention for family and friends of youth with borderline personality disorder. Borderline Personality Disorder and Emotion Dysregulation, 4(1), 5. doi: 10.1186/s40479-017-0056-6

Pearlin, L. I., Mullan, J. T., Semple, S. J., \& Skaff, M. M. (1990). Caregiving and the stress process: An overview of concepts and their measures. The Gerontologist, 30(5), 583-594. doi: 10.1093/geront/30.5.583

Pearlin, L. I., \& Schooler, C. (1978). The structure of coping. Journal of Health and Social Behavior, 19, 2-21. Retrieved from: http://www.jstor.org/stable/2136319

Perseius, K. I., Kåver, A., Ekdahl, S., Åsberg, M., \& Samuelsson, M. (2007). Stress and burnout in psychiatric professionals when starting to use dialectical behavioural therapy in the work with young self-harming women showing borderline 
personality symptoms. Journal of Psychiatric and Mental Health Nursing, 14, 635-643. doi: 10.1111/j.1365-2850.2007.01146.x

Pickard, J. G., Inoue, M., Chadiha, L. A., \& Johnson, S. (2011). The relationship of social support to African American caregivers' help-seeking for emotional problems. Social Service Review, 85(2), 247-266. doi: 10.1086/660068

Pilkonis, P. A., Kim, Y., Proietti, J. M., \& Barkham, M. (1996). Scales for personality disorders developed from the Inventory of Interpersonal Problems. Journal of Personality Disorders, 10(4), 355-369. Retrieved from: http://search.proquest.com/openview/d742e765807cd4fc4c4cf6a4742df3f1/1?pqorigsite $=$ gscholar

Pituch, K. A. \& Stevens, J. P. (2016). Applied multivariate statistics for the social sciences. New York, NY: Routledge.

Provencher, H. L., Perreault, M., St. Onge, M., \& Rousseau, M. (2003). Predictors of psychological distress in family caregivers of persons with psychiatric disabilities. Journal of Psychiatric and Mental Health Nursing, 10(5), 592-607. doi: 10.1046/j.1365-2850.2003.00623.x

Razali, N. M., \& Wah, Y. B. (2011). Power comparisons of Shapiro-Wilk, KolmogorovSmirnov, Lilliefors and Anderson-Darling tests. Journal of Statistical Modeling and Analytics, 2(1), 21-33. Retrieved from: https://pdfs.semanticscholar.org/dcdc/0a0be7d65257c4e6a9117f69e246fb227423. pdf 
Reinhard, S. C. (1994). Perspectives on the family's caregiving experience in mental illness. Image: the Journal of Nursing Scholarship, 26(1), 70-74. doi: 10.1111/j.1547-5069.1994.tb00297.x

Roberts, L., \& Rajah-Kanagasabai, C. (2013). " I'd be so much more comfortable posting anonymously": Identified versus anonymous participation in student discussion boards. Australasian Journal of Educational Technology, 29(5), 612-625. Retrieved from: https://espace.curtin.edu.au/bitstream/handle/20.500.11937/32043/193580_97999 _Roberts_Rajah_2013_student_discussion_boards.pdf?sequence=2

Robinson, K. M. (1990). Predictors of burden among wife caregivers. Research and Theory for Nursing Practice, 4(3), 189-203. Retrieved from: http://ezproxy.uwindsor.ca/login?url=http://search.proquest.com/docview/207667 071 ?accountid=14789

Roelands, M., van Oost, P., \& Depoorter, A. (2008). Service use in family caregivers of persons with dementia in Belgium: psychological and social factors. Health and Social Care in the Community, 16(1), 42-53. doi: 10.1111/j.13652524.2007.00730.x

Sanchez, G. (2013). PLS path modeling with R. Berkeley: Trowchez Editions.

Sanders, S., \& Pearce, S. (2010). The Oxford Friends and Family Empowerment (OFAFE) service: support and education for those affected by friends or family with personality disorder. Mental Health Review Journal, 15(4), 58-62. doi: 10.5042/mhrj.2010.0741 
Scheirs, J. G. M., \& Bok, S. (2007). Psychological distress in caretakers or relatives of patients with borderline personality disorder. International Journal of Social Psychiatry, 53(3), 195-203. doi: 10.1177/0020764006074554

Sellin, N. (1995). Partial least square modeling in research on educational achievement. In W. Bos \& R. H. Lehmann (Eds.), Reflections on educational achievement (pp. 256-267). Münster, NY: Waxmann.

Skodol, A. E., Gunderson, J. G., McGlashan, T. H., Dyck, I. R., Stout, R. L., Bender, D. S., ... \& Sanislow, C. A. (2002). Functional impairment in patients with schizotypal, borderline, avoidant, or obsessive-compulsive personality disorder. American Journal of Psychiatry, 159, 276-283. Retrieved from: http://ajp.psychiatryonline.org/doi/pdf/10.1176/appi.ajp.159.2.276

Smyth, K. A., \& Milidonis, M. K. (1999). The relationship between normative beliefs about help seeking and the experience of caregiving in Alzheimer's disease. Journal of Applied Gerontology, 18(2), 222-238. doi:

$10.1177 / 073346489901800206$

Stern, B. L., Kim, Y., Trull, T. J., Scarpa, A., \& Pilkonis, P. (2000). Inventory of interpersonal problems personality disorder scales: Operating characteristics and confirmatory factor analysis in nonclinical samples. Journal of Personality Assessment, 74(3), 459-471.doi: 10.1207/S15327752JPA7403_9

St. Onge, M., \& Lavoie, F. (1997). The experience of caregiving among mothers of adults suffering from psychotic disorders: Factors associated with their psychological distress. American Journal of Community Psychology, 25(1), 7394. doi: 10.1023/A:1024697808899 
Stommel, M., Given, C. W., \& Given, B. (1990). Depression as an overriding variable explaining caregiver burdens. Journal of Aging and Health, 2(1), 81-102. doi: $10.1177 / 089826439000200106$

Szmukler, G. I., Burgess, P., Herrman, H., Benson, A., Colusa, S., \& Bloch, S. (1996). Caring for relatives with serious mental illness: the development of the Experience of Caregiving Inventory. Social Psychiatry and Psychiatric Epidemiology, 31, 137-148. doi: 10.1007/BF00785760

Tanis, M., Das, E., \& Fortgens-Sillmann, M. (2011). Finding care for the caregiver? Active participation in online health forums attenuates the negative effect of caregiver strain on wellbeing. Communications, 36(1), 51-66. doi:

10.1515/comm.2011.003

Torgersen, S., Lygren, S., Øien, P. A., Skre, I., Onstad, S., Edvardsen, J., ... \& Kringlen, E. (2000). A twin study of personality disorders. Comprehensive Psychiatry, 41(6), 416-425. doi: 10.1053/comp.2000.16560

Tracey, T. J., Rounds, J., \& Gurtman, M. (1996). Examination of the general factor with the interpersonal circumplex structure: Application to the Inventory of Interpersonal Problems. Multivariate Behavioral Research, 31(4), 441-466. doi: 10.1207/s15327906mbr3104_3

Treasure, J., Murphy, T., Szmukler, T., Todd, G., Gavan, K., \& Joyce, J. (2001). The experience of caregiving for severe mental illness: a comparison between anorexia nervosa and psychosis. Social Psychiatry and Psychiatric Epidemiology, 36(7), 343-347. doi: 10.1007/s001270170039 
Trull, T. J., Jahng, S., Tomko, R. L., Wood, P. K., \& Sher, K. J. (2010). Revised NESARC personality disorder diagnoses: gender, prevalence, and comorbidity with substance dependence disorders. Journal of Personality Disorders, 24(4), 412-426. doi: 10.1521/pedi.2010.24.4.412

Turnbull, A. P., Friesen, B. J., \& Ramirez, C. (1998). Participatory action research as a model for conducting family research. Journal of the Association for Persons with Severe Handicaps, 23(3), 178-188. doi: 10.2511/rpsd.23.3.178

Vinzi, V. E., Trinchera, L., \& Amato, S. (2010). PLS path modeling: From foundations to recent developments and open issues for model assessment and improvement. In V. E. Vinzi, W. W. Chin, J. Hensler, \& H. Wang (Eds). In Handbook of partial least squares: Concepts, methods and applications (pp. 47-82). New York, NY: Springer

Vittengl, J. R., Clark, L. A., \& Jarrett, R. B. (2003). Interpersonal problems, personality pathology, and social adjustment after cognitive therapy for depression. Psychological Assessment, 15(1), 29-40. doi: 10.1037/1040-3590.15.1.29

Weaver, T. L., \& Clum, G. A. (1993). Early family environments and traumatic experiences associated with borderline personality disorder. Journal of Consulting and Clinical Psychology, 61(6), 1068-1075. doi: 10.1037/0022-006X.61.6.1068

Weegmann, M., \& Head, A. (2016). Circles of care: Applied group analysis with family and friends. Group Analysis, 49(4), 431-451. doi: 10.1177/0533316416664155.

Whalen, K. J., \& Buchholz, S. W. (2009). The reliability, validity and feasibility of tools used to screen for caregiver burden: a systematic review. JBI Library of Systematic Reviews. Retrieved from: http://works.bepress.com/kimberly_ 
whalen/7/

Wilson, C. J., Deane, F. P., Ciarrochi, J., \& Rickwood, D. (2005). Measuring helpseeking intentions: Properties of the general help-seeking questionnaire.

Canadian Journal of Counselling, 39(1), 15-28. Retrieved from:

http://ezproxy.uwindsor.ca/login?url=http://search.proquest.com/docview/195809 895 ?accountid=14789

Wittenberg-Lyles, E., Washington, K., Demiris, G., Oliver, D. P., \& Shaunfield, S. (2014). Understanding social support burden among family caregivers. Health Communication, 29(9), 901-910. doi: 10.1080/10410236.2013.8

Wold, H. (1985). Partial least squares. Encyclopedia of Statistical Sciences. doi: 10.1002/0471667196.ess1914.pub2 


\section{APPENDICES}

\section{Appendix A: Recruitment Flyer}

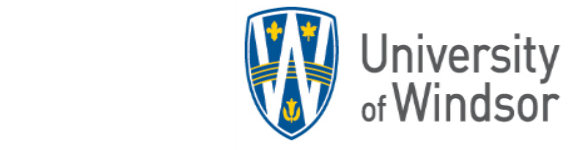

Are you the caregiver of a loved one with a personality disorder? Research opportunity

You are invited to participate in a 30-minute online survey

You are eligible for this study if:

$\checkmark$ You are actively involved in supporting your loved one's recovery and wellbeing.

$\checkmark$ Your loved one has been diagnosed with a personality disorder by a mental health care professional.

$\checkmark$ You have contact with your loved one at least once a week.

$\checkmark$ You have been caregiving for at least one year.

We are not looking for responses from:

$x$ Those diagnosed with a personality disorder.

x Those caring for a loved one with an undiagnosed or self-diagnosed personality disorder.

x Those caring for a loved one with a mental illness that is not a personality disorder.

$x$ Those who have contact with their loved one less than once a week.

$x$ Those who have been caregiving for less than a year.

Participating involves:
$\begin{gathered}\text { Completing online questionnaires about yourself } \\ \text { and your experiences with caregiving }\end{gathered}$
All responses will be kept confidential and secure
Complete the survey and enter to win
one of four \$50 CAD gift cards for Amazon.com

If interested, please contact Paige Lamborn for more information at: lamborn@uwindsor.ca

This study has received clearance from the University of Windsor Research Ethics Board. 


\section{Appendix B: Demographic Questionnaire}

Please answer the following questions about yourself.

1. How old are you (in years)? <text box>

2. What is your gender? <text box>

3. What is your ethnicity?
a. Aboriginal/First Nations
b. Arabic/Middle Eastern
c. Asian
d. Black/African
e. Caucasian or non-Hispanic White or European
f. Hispanic/Latino
g. Indian/South Asian
h. Other (please describe): <textbox>
i. Prefer not to answer

4. What is your highest completed level of education?
a. Did not finish high school
b. High school
c. College or trade program
d. Undergraduate university (Bachelor's) degree
e. Master's degree
f. Doctoral degree
g. Prefer not to answer

5. What is your employment status? 

a. Employed full-time
b. Employed part-time
c. Unemployed
d. Prefer not to answer

6. How did you hear about this study?
a. Online forum (please specify) $\langle$ text box $>$
b. Support group or organization (please specify) <text box>
c. Invited by another caregiver
d. Other (please specify) <text box $>$

Please answer the following questions about the loved one you care for:

1. How old are they (in years)? $<$ text box $>$

2. What is their gender? <text box>

3. What is their ethnicity?
a. Aboriginal/First Nations
b. Arabic/Middle Eastern
c. Asian
d. Black/African
e. Caucasian or non-Hispanic White or European
f. Hispanic/Latino
g. Indian/South Asian
h. Other (please describe): <textbox>
i. Prefer not to answer

4. What is their highest completed level of education? 

a. Did not finish high school
b. High school
c. College or trade program
d. Undergraduate university (Bachelor's) degree
e. Master's degree
f. Doctoral degree
g. Prefer not to say

5. What is their employment status?
a. Employed full-time
b. Employed part-time
c. Unemployed
d. Prefer not to say 


\section{Appendix C: Caregiving Relationship Questionnaire}

Please answer the following questions about your caregiving relationship.

1. How long have you been caring for your loved one (in years)? <text box>

2. What is your relationship to the person you care for? You are their...
a. Biological parent
b. Adoptive parent
c. Child
d. Sibling
e. Friend
f. Spouse
g. Unmarried Partner
h. Other (please specify):

3. Do you reside with your loved one?
a. Yes
b. No

4. Do you identify as your loved one's primary caregiver?
a. Yes
b. No

5. Do you receive assistance from anyone with caregiving?
a. Yes
b. No

6. How often do you have contact with your loved one?

a. Less than once a week 
b. More than once a week

7. Have you ever been diagnosed by a mental health care professional with any of the following disorders? (Select all that apply):
a. Major Depressive Disorder
b. Bipolar Disorder
c. Anxiety Disorder
d. Schizophrenia Spectrum Disorder
e. Post-Traumatic Stress Disorder
f. Obsessive Compulsive Disorder
g. Eating Disorder
h. Attention-Deficit/Hyperactivity Disorder
i. Oppositional Defiant Disorder
j. Conduct Disorder
k. Substance Use Disorder
1. Personality Disorder
m. Other (Please specify): <text box>

n. I have not been diagnosed with any of the above disorders.

8. What was the first personality disorder your loved one was diagnosed with by a mental health care professional?
a. Schizoid
b. Schizotypal
c. Paranoid
d. Borderline 

e. Narcissistic
f. Histrionic
g. Antisocial
h. Avoidant
i. Dependent
j. Obsessive-Compulsive
k. Not Otherwise Specified
1. Other (please explain): <textbox>

9. What year was your loved one first diagnosed with a personality disorder? < text box>

10. Has your loved one been diagnosed by a mental health care professional with any additional personality disorders? (Select all that apply)
a. Schizoid
b. Schizotypal
c. Paranoid
d. Borderline
e. Narcissistic
f. Histrionic
g. Antisocial
h. Avoidant
i. Dependent
j. Obsessive-Compulsive
k. Not Otherwise Specified 
1. Other (please explain): <textbox>

m. My loved one has not been diagnosed with any other personality disorders.

11. Has your loved one been diagnosed by a mental health care professional with any additional psychological disorders, besides a personality disorder? (Select all that apply):
a. Major Depressive Disorder
b. Bipolar Disorder
c. Anxiety Disorder
d. Schizophrenia Spectrum Disorder
e. Post-Traumatic Stress Disorder
f. Obsessive Compulsive Disorder
g. Eating Disorder
h. Attention-Deficit/Hyperactivity Disorder
i. Oppositional Defiant Disorder
j. Conduct Disorder
k. Substance Use Disorder
1. Other (Please specify): <text box>
m. My loved one has not been diagnosed with any of the above disorders.

12. How many times in the past year (12 months) has your loved one been hospitalized (that you are aware of)? <text box> 


\section{Appendix D: Experience of Caregiving Inventory}

Problems with Services subscale:

How often in the past month have you thought about...

1. How mental health professionals do not take you seriously

$\begin{array}{llll}\text { Never Rarely Sometimes Often } & \text { Nearly } \\ \text { Always }\end{array}$

2. Dealing with psychiatrists

0

12

3

4

3. How to deal with mental health professionals

4. How health professionals do not understand your 0

1

2 situation

5. How to make complaints about your loved one's care

0

1

2

3

6. Finding out how hospitals or mental health services work

7. Doctor's knowledge of services available

8. Difficulty getting information about your loved one's illness 
Stigma subscale:

How often in the past month have you thought about...

9. Covering up your

$$
\begin{array}{llll}
\text { Never Rarely } & \text { Sometimes } & \text { Often } & \text { Nearly } \\
\text { Always }
\end{array}
$$

loved one's illness

0

$$
1
$$

2

3

4

10. Feeling unable to tell anyone about your loved one's illness

0

1

2

3

4

11. Feeling unable to have visitors at home

0

1

2

3

4

12. The stigma of having a mentally ill loved one

0

1

2

3

4

13. How to explain your loved one's illness to others

0

1

2

3

4

\section{Difficult Behaviours subscale:}

How often in the past month have you thought about...

How often in the past month have you thought about...

$\begin{array}{lccccc}\text { 14. Your loved one } & \text { Never } & \text { Rarely } & \text { Sometimes } & \text { Often } & \begin{array}{c}\text { Nearly } \\ \text { Always } \\ \text { being moody }\end{array} \\ \begin{array}{l}\text { 15. Your loved one } \\ \text { being }\end{array} & 0 & 1 & 2 & 3 & 4 \\ \text { unpredictable } & 0 & 1 & 2 & 3 & 4 \\ \begin{array}{l}\text { 16. Your loved one } \\ \text { being irritable }\end{array} & 0 & 1 & 2 & 3 & 4 \\ \text { 17. Your loved one } & 0 & 1 & 2 & 3 & 4 \\ \text { being } \\ \text { inconsiderate }\end{array}$


18. Your loved one behaving in a reckless way

19. Your loved one being suspicious

0

1

2

3

4

20. Your loved one being embarrassing in 0 1 2 4 appearance

21. Your loved one behaving in a 0 1 2 3 4 strange way

Need to Back Up subscale:

How often in the past month have you thought about...

22. How your loved $\begin{array}{llll}\text { Never Rarely } & \text { Sometimes } & \text { Often } & \text { Nearly } \\ \text { Always }\end{array}$ one has difficulty looking after 0 1

2

3 money

23. Having to support your loved one

0

2

3

4

24. The effect on your finances

0 1 2 4

25. Backing up your loved one when they run out of money

0

1

2

3

4

26. Setting your loved one up in accommodation

0

1

2

3

4

27. Your loved one keeping bad

0

1

2

3

4 
company

Dependency subscale:

How often in the past month have you thought about...

$\begin{array}{llll}\text { Never Rarely Sometimes Often } & \text { Nearly } \\ \text { Always }\end{array}$

28. Being unable to do the things you want

0

12

3

4

29. Your loved one's dependence on you

0

1

2

4

30. Helping your loved one to fill in the day

0

1

2

4

31. How your loved one is always at the back of your mind

0

1

2

4

32. Feeling unable to leave your loved one alone

0

2

4

\section{Positive Personal Experiences subscale:}

How often in the past month have you thought...

$\begin{array}{lll}\text { Never Rarely Sometimes Often } & \begin{array}{l}\text { Nearly } \\ \text { Always }\end{array}\end{array}$

33. I have learnt more about myself

0

$$
1
$$

4

34. I have contributed to others' understanding of 0 1 2 the illness

35. I have become more confident 0

1
2

3 
36. I have become more understanding of others with

problems

37. I have become closer to some of my family

0

1

2

4

38. I have become closer to friends

2

40. I have met helpful people

41. I have discovered strengths in myself 


\section{Appendix E: IIP Personality Disorder Scales (Informant-Report)}

Consider each problem your loved one may have and rate how distressing that problem has been to them.

1. Your loved one is too

Not at all

A little
bit Moderately $\begin{gathered}\text { Quite a } \\ \text { bit }\end{gathered}$ Extremely sensitive to rejection

0

1

2

3

4

2. Your loved one is too sensitive to criticism

0

2

3

4

3. It is hard for your loved one to ignore criticism from other people

0

4. Your loved one feels too anxious when they are involved with another person

5. Your loved one feels attacked by other people too much

6. It is hard for your loved one to get over the feeling of loss after a relationship has ended

7. Your loved one is too envious and jealous of other people

0

2

4

8. It is hard for your loved one to trust other people

0

1

2

4

9. It is hard for your loved one to feel like a separate person when 0

1 2 they are in a relationship

10. Your loved one is too easily bothered by other 0 1 2 3 4 people making demands 
of them

11. Your loved one tells personal things to other people too much

0

1

2

3

4

12. It is hard for your loved one to take instructions from people who have authority over them

13. It is hard for your loved one to accept another person's authority over them

14. It is hard for your loved one to get along with people who have authority over them

15. It is hard for your loved one to be supportive of another person's goals in life

$\begin{array}{lllll}0 & 1 & 2 & 3 & 4\end{array}$

16. It is hard for your loved one to really care about other people's problems

0

12

3

4

17. It is hard for your loved one to feel good about another person's

0

1

2

3

4

happiness

18. It is hard for your loved one to put somebody else's needs before their 0 1 2 3 4 own

19. It is hard for your loved one to do what another person wants them to do

20. It is hard for your loved one to maintain a 
working relationship

with someone they don't

like

21. Your loved one feels competitive even when the situation does not call for it

22. Your loved one argues with other people too much

23. Your loved one loses their temper too easily

24. Your loved one fights with other people too much

25. Your loved one is too aggressive toward other people

26. Your loved one gets irritated or annoyed too easily

27. Your loved one criticizes other people too much

28. Your loved one wants to get revenge against people too much

29. Your loved one tries to please other people too much

30. Your loved one worries too much about disappointing other people

31. It is hard for your loved one to say "no" to other 
people

32. Your loved one is

influenced too much by another person's

0

1

2

3

4

thoughts and feelings

33. Your loved one worries

too much about other

people's reactions to

0

2

4

them

34. Your loved one is

affected by another

person's moods too

much

$\begin{array}{lllll}0 & 1 & 2 & 3 & 4\end{array}$

35. It is hard for your loved one to be assertive without worrying about hurting the other

0

person's feelings

36. It is hard for your loved one to make reasonable demands of other people

0

12

4

37. It is hard for your loved one to be assertive with another person

0

2

4

38. It is hard for your loved one to socialize with other people

0

2

4

39. It is hard for your loved one to feel comfortable around other people

0

12

4

40. It is hard for your loved one to join in on groups

0

12

4

41. It is hard for your loved one to be self-confident when they are with other 0 1 2

3 4 people 
42. It is hard for your loved one to introduce themselves to new people

43. It is hard for your loved one to ask people to get together socially with them

44. It is hard for your loved one to express their feelings to other people directly

45. Your loved one is too afraid of other people

46. Your loved one feels embarrassed in front of other people too much

47. It is hard for your loved one to set goals for themselves without other

12

3

4 


\section{Appendix F: Caregiver Reaction Assessment}

Please rate how much you agree or disagree with each statement.

Disrupted Schedule:

\begin{tabular}{|c|c|c|c|}
\hline $\begin{array}{l}\text { Strongly } \\
\text { disagree }\end{array}$ & Disagree & $\begin{array}{c}\text { Neither } \\
\text { agree nor } \\
\text { disagree }\end{array}$ & Agree \\
\hline
\end{tabular}

1. My activities are centered around care for my loved one

2. I have to stop in the middle of my work or activities to provide care

3. I have eliminated things from my schedule since caring for my

loved one

4. The constant interruptions make it difficult to find time for relaxation

5. I visit family and friends less since I have been caring for my loved one.

1

2

3

4

Financial Problems:

6. My financial resources are adequate*

1

2

3

5

7. It is difficult to pay for my loved one

1

2

3

4 
8. Caring for my loved one puts a financial strain on me

Lack of Family Support

9. My family works together at caring for my loved one*

10. Since caring for my loved one, I feel my family has abandoned

me

11. It is very difficult to get help from my family in taking care of my loved one.

12. Others have dumped caring for my loved one 1 2 onto me

13. My family (brothers, sisters, children) left me alone to care for my loved one

Health Problems:

14. I am healthy enough to care for my loved one*

15. It takes all my physical strength to care for my 
16. My health has gotten worse since I've been caring for my

loved one

17. Since caring for my loved one, it seems like I'm tired all of the time

\section{Esteem:}

18. Caring for my loved one is important to me

19. I enjoy caring for my loved one

20. Caring for my loved one makes me feel good

21. I feel privileged to care for my loved one

22. I resent having to care for my loved one*

23. I really want to care for my loved one

24. I will never be able to do enough caregiving to repay my loved one*

* Reverse coded 


\section{Appendix G: Mastery Scale}

How strongly do you agree or disagree with the following statements?

1. I have little control Strongly

Disagree

Agree

Strongly

disagree

agree

over the things that happen to me

1

2

3

4

2. There is really no way I can solve some of the

problems I have

3. There is little I can do to change many of the important

4. I often feel helpless in dealing with the problems of life

5. Sometimes I feel that I'm being pushed around in life

6. What happens to me in the future mostly depends on me*

7. I can do just about anything I really set my mind to do*

*reverse coded 


\section{Appendix H: Perceived Caregiver Burden Scale: Sense of Entrapment Subscale}

How strongly to you agree or disagree with the following statements?

1. I feel overwhelmed by

\begin{tabular}{|c|c|c|c|}
\hline $\begin{array}{l}\text { Strongly } \\
\text { Disagree }\end{array}$ & Disagree & $\begin{array}{l}\text { Neither } \\
\text { agree nor } \\
\text { disagree }\end{array}$ & Agree \\
\hline
\end{tabular}
the problems I have caring for my loved one

2. I resent having to take care of my loved one

1

2

3

4

5

3. I get very discouraged with caring for my loved one

2

3

4

5

4. Since caring for my loved one, I sometimes hate the way my life 1 2

3

4

5

has turned out

5. I feel I was forced into caring for my loved one

1

2

3

4

5

6. I feel trapped by my caregiving role

1

2

3

4

5

7. At this time in my life, I don't think I should be caring for my loved one

1

2

3

5

8. Caring for my loved one has made me miserable

1

2

3

4

5

9. Just when I thought times were going to be easier for me, I have to 1 2 3 be a caregiver. 


\section{Appendix I: General Help-Seeking Questionnaire}

1) If you were having problems dealing with your emotions related to caregiving, how likely is it that you would seek help from the following people?

Emergency
Extremely

unlikely
Extremely

likely

Services or

Hospital

Psychologist

1

2

3

2

3

3

4

4

group

Nurse

Friend

Family

Neighbour

Co-worker

Church

member

Peer-led

support group

Online source

I would not seek help from anyone
4

5

6

7

2

2

2

3

3

3

4

4

4

5

6

7

12

3

3

3

4

5

6

7

1

2

3

4

5

6

7 
2) If you were having problems dealing with day-to-day tasks related to caregiving, how likely is it that you would seek help from the following people?

\begin{tabular}{|c|c|c|c|c|c|c|c|}
\hline & $\begin{array}{c}\text { Extremely } \\
\text { unlikely }\end{array}$ & & & & & & $\begin{array}{l}\text { Extremely } \\
\text { likely }\end{array}$ \\
\hline $\begin{array}{l}\text { Emergency } \\
\text { Services or } \\
\text { Hospital }\end{array}$ & 1 & 2 & 3 & 4 & 5 & 6 & 7 \\
\hline Psychologist & 1 & 2 & 3 & 4 & 5 & 6 & 7 \\
\hline Psychiatrist & 1 & 2 & 3 & 4 & 5 & 6 & 7 \\
\hline Social worker & 1 & 2 & 3 & 4 & 5 & 6 & 7 \\
\hline Family doctor & 1 & 2 & 3 & 4 & 5 & 6 & 7 \\
\hline $\begin{array}{l}\text { Professional- } \\
\text { led support } \\
\text { group }\end{array}$ & 1 & 2 & 3 & 4 & 5 & 6 & 7 \\
\hline Nurse & 1 & 2 & 3 & 4 & 5 & 6 & 7 \\
\hline Friend & 1 & 2 & 3 & 4 & 5 & 6 & 7 \\
\hline Family & 1 & 2 & 3 & 4 & 5 & 6 & 7 \\
\hline Neighbour & 1 & 2 & 3 & 4 & 5 & 6 & 7 \\
\hline Co-worker & 1 & 2 & 3 & 4 & 5 & 6 & 7 \\
\hline $\begin{array}{l}\text { Church } \\
\text { member }\end{array}$ & 1 & 2 & 3 & 4 & 5 & 6 & 7 \\
\hline $\begin{array}{l}\text { Peer-led } \\
\text { support group }\end{array}$ & 1 & 2 & 3 & 4 & 5 & 6 & 7 \\
\hline Online source & 1 & 2 & 3 & 4 & 5 & 6 & 7 \\
\hline $\begin{array}{l}\text { I would not } \\
\text { seek help from } \\
\text { anyone }\end{array}$ & 1 & 2 & 3 & 4 & 5 & 6 & 7 \\
\hline
\end{tabular}


3) If you were having problems finding information related to caregiving, how likely is it that you would seek help from the following people?

Emergency

Services or

Extremely

Extremely

unlikely

likely

Hospital

Psychologist

12

3

3

4

5

7

Psychiatrist

2

3

4

5

7

Social worker

2

3

4

5

7

Family doctor

2

3

4

5

7

Professional-

led support

group

2

3

4

5

7

Nurse

Friend

Family

Neighbour

2

3

4

5

7

2

3

4

5

7

2

3

4

5

7

Co-worker

2

3

4

5

7

Church

member

Peer-led

support group

2

3

4

$5 \quad 6$

7

Online source

I would not seek help from

2

3

4

5

6

7 


\section{Appendix J: Kessler Psychological Distress Scale}

In the past 30 days, how often did you...

1. ...feel tired out

$\begin{array}{ccccc}\begin{array}{c}\text { None of the } \\ \text { time }\end{array} & \begin{array}{c}\text { A little of } \\ \text { the time }\end{array} & \begin{array}{c}\text { Some of } \\ \text { the time }\end{array} & \begin{array}{c}\text { Most of the } \\ \text { time }\end{array} & \begin{array}{c}\text { All of the } \\ \text { time }\end{array}\end{array}$

for no good reason?

1

3

4

5

2. ...feel nervous?

12

3

4

5

3. ... feel so nervous

that nothing could

calm you down?

1

2

3

5

4. ...feel hopeless?

1

2

3

5

5. ...feel restless or

fidgety?

1

2

3

5

6. ...feel so restless

that you could not

sit still?

1

2

3

5

7....feel depressed?

1

2

3

4

5

8. ... feel that

everything was an

effort?

1

2

3

4

5

9. ... feel so sad that

nothing could cheer

you up?

1

2

3

4

5

10. ... feel

worthless?

2

3

4

5 


\section{Appendix K: Research Ethics Board Clearance Certificate}

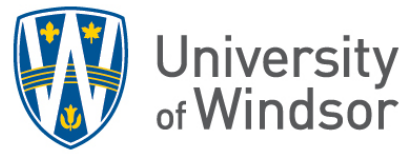

Today's Date: October 21, 2016

Principal Investigator: Ms. Paige Lamborn

REB Number: 33385

Research Project Title: REB\# 16-156: "Factors Associated with Distress in Caregivers of People with Personality Disorders"

Clearance Date: October 14, 2016

Project End Date: November 01, 2017

Milestones:

Renewal Due-2017/11/01(Pending)

Renewal Due-2017/09/01(Pending)

This is to inform you that the University of Windsor Research Ethics Board (REB), which is organized and operated according to the Tri-Council Policy Statement and the University of Windsor Guidelines for Research Involving Human Subjects, has granted approval to your research project on the date noted above. This approval is valid only until the Project End Date.

A Progress Report or Final Report is due by the date noted above. The REB may ask for monitoring information at some time during the project's approval period.

During the course of the research, no deviations from, or changes to, the protocol or consent form may be initiated without prior written approval from the REB. Minor change(s) in ongoing studies will be considered when submitted on the Request to Revise form.

Investigators must also report promptly to the REB:

a) changes increasing the risk to the participant(s) and/or affecting significantly the conduct of the study;

b) all adverse and unexpected experiences or events that are both serious and unexpected;

c) new information that may adversely affect the safety of the subjects or the conduct of the study. Forms for submissions, notifications, or changes are available on the REB website:

www.uwindsor.ca/reb. If your data is going to be used for another project, it is necessary to submit another application to the REB.

We wish you every success in your research.

Dr. Suzanne McMurphy, Ph.D.

Chair, Research Ethics Board

2146 Chrysler Hall North

University of Windsor

519-253-3000 ext. 3948

Email: ethics@uwindsor.ca 


\title{
Appendix L: Consent Form
}

\section{University of Windsor}

\section{CONSENT TO PARTICIPATE IN RESEARCH}

\author{
Title of Study: Experiences of Caregivers of People with Personality Disorders
}

You are asked to participate in a research study conducted by Paige Lamborn and Dr. Ken Cramer (Psychology Department) at the University of Windsor. The results of the study will be used for Paige Lamborn's master's thesis.

If you have any questions or concerns about the research, please contact Dr. Ken Cramer (Faculty Supervisor) at 1-519-253-3000 ext. 2239 or kcramer@uwindsor.ca, or Paige Lamborn (Student Investigator) at lamborn@uwindsor.ca

\section{PURPOSE OF THE STUDY}

The purpose of this study is to better understand the experiences of those caring for someone with a personality disorder. We wish to establish how caregivers feel about many different aspects of caregiving. We also wish to evaluate caregivers' likelihood of using different support sources for help with caregiving.

\section{PROCEDURES}

If you volunteer to participate in this study, you will be asked to participate in a one-time on-line survey. The survey will take approximately 30 minutes to complete. After completing the survey, you are invited to enter a draw for one of four \$50 CAD Amazon.com gift-cards, as compensation for your time.

Please complete the survey independently in a private, quiet location, on a personal computer, where you won't be interrupted. After you complete the survey (or if you withdraw before completing the survey), make sure you clear your Internet browser history.

\section{POTENTIAL RISKS AND DISCOMFORTS}

Those who participate in the study will be asked about psychological symptoms, such as anxiety and depression, as well as some negative aspects of caregiving, which some people may find uncomfortable.

The questions in this survey ask participants for their views on aspects of their relationship with the loved one they provide care for. As such, participation in this survey may identify or highlight strains or challenges within that relationship. This may also cause some participants to feel uncomfortable. Finally, some participants may find certain questions to be phrased in an insensitive or biased manner. However, this is not the intention of the researchers, as the questions have been selected from standardized measures.

However, given the nature of the survey, we anticipate any potential discomfort to be minimal. Further, participants are permitted to skip any questions that they do not wish to answer and may withdraw from the study at any time by exiting out of the browser and leaving the survey. Participants are encouraged to complete the survey independently. It is up to the participants whether to tell the loved one they care for about participating in the survey.

\section{POTENTIAL BENEFITS TO PARTICIPANTS AND/OR TO SOCIETY}

Those who participate in the study may benefit from increased self-knowledge through taking inventory of their own experiences with caregiving. Additionally, by participating, caregivers will provide valuable information regarding their experiences with caregiving. This information can be used in the future to 
develop ways to better support caregivers in similar situations. Participants may also gain a better understanding of how psychological research is conducted.

\section{COMPENSATION FOR PARTICIPATION}

After completing the survey, participants are invited enter a draw for one of four $\$ 50$ CAD gift cards to Amazon.com.

\section{CONFIDENTIALITY}

This study involves a confidential online survey. Because you had to contact the researchers in order to gain access to this survey, your identity is not anonymous to the researchers. However, your identity and participation in this research will be kept confidential by the researchers. There will be no way to link your identity to the responses you give. As such, it will not be possible to withdraw your responses once you have completed any part of the survey. Partial responses will be retained, even if you withdraw from the survey. Results from this study will only be reported publically as statistical summaries, so it will not be possible for others to identify you or your loved one.

It is up to you whether you tell the loved one you care for whether you have participated in this research. However, in order to protect the confidentiality of your answers, ensure you clear your Internet browser history after completing or withdrawing from this survey.

On-line survey responses will be housed on the secure FluidSurveys server, which is located in Canada. Downloaded data from the survey will be stored on the password-protected computers of the investigators and password-encrypted USB key.

As per standard practices, all original data sources will be stored/retained for approximately 5 years after the completion of the research project. At this time, any participant information in hard copy form will be shredded and any confidential and/or identifying participant information in electronic form will be deleted.

\section{PARTICIPATION AND WITHDRAWAL}

Participants may withdraw from the survey at any time by simply closing the web browser. There will be no consequences to the participants for withdrawing from the study. For participants who complete partial survey data, the data up to the point of exiting the survey will be retained for analysis.

The investigator may withdraw you from this research if circumstances arise which warrant doing so.

\section{FEEDBACK OF THE RESULTS OF THIS STUDY TO THE PARTICIPANTS}

If you are interested in receiving a summary of the research findings, you are welcome to contact the student investigator, Paige Lamborn at lamborn@uwindsor.ca. The results will also be made available on the University of Windsor Research Ethics Board website.

Web address: www.uwindsor.ca/reb

Date when results are available: $\quad$ November 1,2017

\section{SUBSEQUENT USE OF DATA}

These data will be used in Paige Lamborn's master's thesis. They may be used in subsequent studies, in publications, and in presentations.

\section{RIGHTS OF RESEARCH PARTICIPANTS}

If you have questions regarding your rights as a research participant, contact: Research Ethics Coordinator, University of Windsor, Windsor, Ontario, N9B 3P4; Telephone: 519-253-3000, ext. 3948; e-mail: ethics@uwindsor.ca

\section{SIGNATURE OF RESEARCH PARTICIPANT/LEGAL REPRESENTATIVE}


If you click the "I consent to participate." button below, you are agreeing with the following statement:

"I understand the information provided for the study "Experiences of Caregivers of People with Personality Disorders" as described herein. I agree to participate in this study."

Please print a copy of this form for your records.

$<$ consent to participate. $>$

$<$ do not consent to participate. $>$ 


\section{VITA AUCTORIS}

NAME:

PLACE OF BIRTH:

YEAR OF BIRTH:

EDUCATION:
Paige Lamborn

Saskatoon, SK

1993

Marion M. Graham Collegiate, Saskatoon, SK, 2011

University of Saskatchewan, B.A. (Hons), Saskatoon, SK, 2015

University of Windsor, M.A., Windsor, ON, 2017 